AUTARQUIA ASSOCIADA À UNIVERSIDADE DE SÃO PAULO

INVESTIGAÇÃO DO ÁCIDO ETANODIÓICO NA FORMAÇÃO DE FILMES SUPERFICIAIS SOBRE ZINCO E AVALIAÇÃO DO EFEITO DESTES FILMES NA RESISTÊNCIA À CORROSÃO

Marcelo de Oliveira

Dissertação apresentada como parte dos requisitos para obtenção do Grau de Mestre em Ciências na Área de Tecnologia Nuclear - Materiais

Orientadora:

Profa. Dra. Isolda Costa

$\#$

\#

São Paulo 
INSTITUTO DE PESQUISAS ENERGÉTICAS E NUCLEARES

Autarquia associada à Universidade de São Paulo

\title{
INVESTIGAÇÃO DO ÁCIDO ETANODIÓICO NA FORMAÇÃO DE FILMES SUPERFICIAIS SOBRE ZINCO E AVALIAÇÃO DO EFEITO DESTES FILMES NA RESISTÊNCIA À CORROSÃO
}

\author{
Marcelo de Oliveira
}

Dissertação apresentada como parte dos
requisitos para obtenção do Grau de
Mestre em Ciências na Área
de Tecnologia Nuclear - Materiais
Orientadora:

Profa. Dra. Isolda Costa

\#

Versão Corrigida

Versão Original disponível no IPEN

São Paulo

2018 
Eu agradeço a DEUS, de todo meu coração por me fazer sempre melhor e ficar mais velho a cada dia que se passa.

À minha esposa Kelly Pereira Cardoso Franco, pelo apoio, amor incondicional e paciência.

Aos meus pais, José Batista de Oliveira (in memoriam) e Antônia Alice, os quais se dedicaram a mim e me auxiliaram com sua sabedoria adquirida em uma vida dura.

À minha irmã, Priscila de Oliveira, aos meus irmãos, Mauricio, Marcio, e a todos os demais familiares pela motivação.

À Prof. Dra. Isolda Costa que de uma forma sábia e amiga, me ofereceu seu conhecimento. Orientou-me de forma sempre verdadeira, clara para cada passo dessa jornada.

Ao Professor e amigo Dr. Jesualdo Luiz Rossi, que me orientou e sempre esteve à disposição para me ajudar, incentivou e direcionou essa pesquisa.

Ao Dr. José Mario Ferreira Junior, o qual ajudou na escolha do tema, nas discussões e compreensão dos resultados de XPS.

Aos Doutores Luis Galego Martinez, Stephan Wolynec e José Oscar Willian Vega Bustillo pelas análises e sugestões. A Dra. Taeko Yonamin Fukuhara, pelas análises (FIB) e Cleber Rodrigues pelas análises de (RBS).

Ao Dr. Célia Regina Tomachuk, pelas contribuições e sugestões significativas para melhora desse trabalho. 
Aos amigos de laboratório e de longa data, os Doutores Wagner Izaltino dos Santos e Caio Palumbo de Abreu, sempre incentivando o desenvolvimento de novas idéias.

Aos amigos de trabalho: Mariana, Caruline, Fernanda, Aline, Olandir, Glauson, Nildemar, Giuseppe, Maurílio, Francisco, Kellie e outros, que aqui não foram citados, mas, que de alguma maneira contribuíram para este fim dessa dissertação.

Ao IPEN/CNEN-SP pela oportunidade de realizar este trabalho, utilizar laboratórios e dependências. E a todos que direta ou indiretamente me auxiliaram neste caminho, na realização deste trabalho e sonho.

Ao IPT - Instituto de Pesquisas Tecnológicas pelas analises de (FIB) focused ion beam 
"Se eu que sou eu, me acabo. E, no entanto, não fui feito para durar, imagina isto. "

Antônia Alice de Oliveira 


\section{INVESTIGAÇÃO DO ÁCIDO ETANODIÓICO NA FORMAÇÃO DE FILMES SUPERFICIAIS SOBRE ZINCO E AVALIAÇÃO DO EFEITO DESTES FILMES NA RESISTÊNCIA À CORROSÃO}

\section{MARCELO DE OLIVEIRA}

\section{RESUMO}

Um dos métodos mais utilizados para proteção contra a corrosão de aços comuns consiste na proteção catódica com revestimentos metálicos eletroquimicamente mais ativos, que estes. Os revestimentos de zinco são os mais usados para este tipo de proteção. De forma a protegerem o substrato, estes revestimentos devem atuar como anodos de sacrifício, sofrendo corrosão e transformando o substrato de aço em catodo. Todavia, não é de interesse, que o revestimento de zinco apresente altas taxas de corrosão de forma que a proteção contra a corrosão conferida ao aço seja duradoura. Uma das formas mais empregadas para reduzir a velocidade de corrosão do revestimento de zinco é por meio de tratamentos da superfície, por exemplo, por tratamentos de conversão. Os tratamentos de conversão mais eficientes são os que utilizam e geram rejeitos, que contêm íons de cromo hexavalente. Todavia, estes íons são carcinogênicos e tóxicos e, dessa forma, os processos que os utilizam em alguma etapa do tratamento, vêm sofrendo crescentes restrições, já sendo proibidos em países com leis ambientais mais rígidas. Esta é a razão para o crescente interesse e grande investimento em pesquisa tratamentos, que possam resultar em revestimentos com potencialidade para substituir, de forma eficiente e efetiva o uso do cromo hexavalente. Este foi o objetivo do presente trabalho. Neste estudo, foi investigado o efeito de tratamentos, que resultam em camadas de conversão na presença de ácido oxálico e na proteção contra a corrosão da superfície do zinco. Camadas de conversão foram obtidas por imersão de amostras de zinco em soluções de ácido oxálico (ácido etanodióico) com diferentes concentrações. Todas as soluções de tratamento apresentaram elevada acidez e resultaram em ataque da superfície de zinco com formação de revestimento de conversão com diferentes características. Ensaios 
preliminares de névoa salina foram então realizados para investigar a proteção conferida pelo sistema revestimento de conversão-verniz contra a corrosão do substrato de zinco. Estes ensaios foram decisivos para a escolha da faixa de concentração do banho de conversão com maior potencial para formação de revestimentos de conversão protetores. Os resultados deste ensaio e os de espectroscopia de impedância eletroquímica mostraram que tratamentos em soluções com composição superiores a $10^{-1} \mathrm{M}$ de ácido oxálico resultaram em camadas muito defeituosas, nas quais o ataque localizado do substrato metálico é favorecido, sendo obtidas impedâncias menores que a superfície do zinco sem qualquer tratamento. Os resultados de XPS mostraram, que os revestimentos de conversão formados em soluções de ácido oxálico na faixa de $10^{-3} \mathrm{M}$ a $10^{-1} \mathrm{M}$ são compostos de oxalato de zinco e produtos de corrosão do zinco, especificamente $\mathrm{ZnO}, \mathrm{Zn}(\mathrm{OH})_{2}$, e $\mathrm{ZnCO}_{3}$. Já a concentração de $10^{-1}$ $\mathrm{M}$ de ácido oxálico foi a, que produziu os resultados mais promissores com a formação de um revestimento, que conferiu proteção mais duradoura à superfície do zinco entre os obtidos. As espessuras médias das camadas de conversão de oxalato de zinco formadas em soluções com $10^{-1} \mathrm{M}$ e $1 \mathrm{M}$ de ácido oxálico, estimadas por FIB, foram respectivamente $600 \mathrm{~nm}$ e $300 \mathrm{~nm}$, o que mostra que a concentração de $1 \mathrm{M}$ de ácido causou intenso ataque corrosivo da superfície, enquanto a camada formada em meio com $10^{-1} \mathrm{M}$ permitiu a deposição de camada mais espessa e mais protetora contra a corrosão do substrato. Os resultados de XPS indicaram a degradação da camada de oxalato de zinco com o tempo de ensaio, porém o ataque desta ao longo do ensaio de corrosão, resulta na formação de simonkolleite, identificada por difração de raios $X$, para períodos mais longos do ensaio de corrosão, no caso do revestimento formado em solução com $10^{-1} \mathrm{M}$ em comparação a $1 \mathrm{M}$. A simonkolleiteatua por efeito barreira bloqueando os defeitos/porosidade da camada. O crescente acúmulo destes produtos de corrosão com a continuidade do processo corrosivo e a aderência destes ao substrato metálico foi indicada para superfície tratada em solução com $10^{-1} \mathrm{M}$ de ácido oxálico. Finalmente, foi proposto um modelo para interação entre o revestimento de conversão de oxalato de zinco e os produtos de corrosão em que a retenção 
dos produtos de corrosão na superfície faz com, que a camada na superfície se torne mais espessa e mais compacta com o tempo de exposição ao ensaio de corrosão. Estas observações explicam o aumento de impedância observado com o tempo de ensaio nesta condição. Os resultados obtidos permitiram concluir, que o revestimento de conversão de oxalato de zinco formado em solução com $10^{-1} \mathrm{M}$ de ácido oxálico resulta em proteção efetiva do substrato metálico além de apresentar boa aderência com camada de verniz. Estes resultados indicam potencialidade deste tratamento como preparação de superfícies de zinco, que serão recobertas com revestimentos orgânicos (tintas, vernizes ou lacas). 


\section{INVESTIGATION OF THE ETHANEDIOIC ACID ON THE FORMATION OF SURFACE FILMS ON ZINC AND EVALUATION OF THE EFFECT OF THESE FILMS FORMED ON THE CORROSION RESISTANCE}

\section{MARCELO DE OLIVEIRA}

\section{ABSTRACT}

One of the most used methods for protection of common steels is the cathodic protection by galvanic coupling with metallic coatings electrochemically more active than these. Zinc coatings are the most commonly used for this type of protection. In order to protect the metallic substrate, these coatings must act as sacrificial anodes, corroding themselves and converting the steel substrate into cathode. However, it is not appropriate that the zinc coating presents high corrosion rates, so that the corrosion protection conferred to the steel is longlasting. One of the most commonly employed methods of reducing the corrosion rate of zinc coatings is by surface treatments, such as, conversion treatments. The most efficient conversion treatments to date are those that use hexavalent chromium ions or generate residues containing these ions. However, hexavalent chromium is carcinogenic and toxic and, therefore, the processes that involve their use at some stage of the treatment, are under increasing restrictions, and have already been prohibited in developed countries. This is the reason for the growing interest and great investment in research studies in search for treatments that may result in coatings with the potential to efficiently and effectively replace the use of hexavalent chromium. This was the objective of the present study. In this study, the effect of treatments in oxalic acid solutions that resulted in conversion layers on the corrosion protection of zinc surface has been investigated. Conversion layers were obtained by immersion of zinc samples in solutions of oxalic acid (ethanedioic acid) with different concentrations. All the treatment solutions presented high acidity and resulted in attack of zinc surface and formation of conversion coatings of different characteristics. A layer of varnish was applied and preliminary salt spray tests were then carried out to investigate the corrosion protection provided by the 
system conversion coating -varnish to the zinc substrate. These tests were decisive for the choice of the conversion bath composition range with greater potentialities for the formation of protective conversion coatings. The results of the salt spray test and of electrochemical impedance spectroscopy (EIS) showed that treatments in solutions with compositions greater than $10^{-1} \mathrm{M}$ of oxalic acid resulted in very defective conversion layers in which the localized attack of the metallic substrate is favored, and lower impedances than the zinc surface without any treatment were obtained for surfaces treated in these solution. The XPS results showed that conversion coatings formed in oxalic acid solutions in the range of $10^{-3} \mathrm{M}$ to $10^{-1} \mathrm{M}$ are composed of zinc oxalate and zinc corrosion products, specifically $\mathrm{ZnO}, \mathrm{Zn}(\mathrm{OH})_{2}$, and $\mathrm{ZnCO}_{3}$. The concentration related to the most promising results was $10^{-1} \mathrm{M}$ and in this solution, the coating formed that promoted the longer lasting protection of the zinc surface among those obtained. The average thicknesses of the zinc oxalate conversion layers formed in solutions with $10^{-1} \mathrm{M}$ and $1 \mathrm{M}$ of oxalic acid, estimated by FIB, were respectively $600 \mathrm{~nm}$ and $300 \mathrm{~nm}$. This result showed that in $1 \mathrm{M}$ of oxalic acid an intense corrosive attack of the zinc surface occurred, while the layer formed in $10^{-1} \mathrm{M}$ was thicker and more protective against substrate corrosion. The XPS results indicated degradation of the zinc oxalate layer formed in $10^{-1} \mathrm{M}$ solution with time of exposure to the test solution, but for the protection of the coating lasted for longer periods, comparatively to that formed in $1 \mathrm{M}$ solution, once the attack of the first film resulted in formation ofsimonkolleite, which was identified by X-ray diffraction. Simonkolleite acts by barrier effect blocking defects I porosity in the conversion layer. The increasing accumulation of corrosion products with test time and their adhesion to the metallic substrate was indicated for surface treated in solution with $10^{-1} \mathrm{M}$ of oxalic acid. Finally, a model has been proposed for the interaction between the zinc oxalate conversion coating and the corrosion products in which the retention of these products on the surface is promoted by the conversion coating and the surface layer becomes thicker and more compact with time of exposure. These observations explain the increased impedance observed with the test time associated to this coating. The obtained results allowed concluding that the 
conversion coating of zinc oxalate formed in solution with $10^{-1} \mathrm{M}$ of oxalic acid results in effective protection of the metallic substrate besides promoting good adhesion with a layer of varnish. These results indicate the potential of this treatment as preparation of zinc surfaces that will be covered with organic coatings (paints, varnishes or lacquers). 

$1 . \quad$ INTRODUÇÃO-

2. OBJETIVO-- 7

3. REVISÃO DA LITERATURA- 8

3.1. Corrosão do zinco--- 8

3.2. Caracterização química do zinco e seus compostos por difração de Raios X (DRX) -------------------------------------------- 11

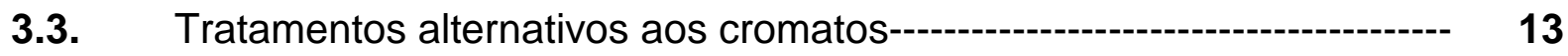

4. MATERIAIS E MÉTODOS -

4.1. Materiais---------------------------------------------------------- 19

4.2. Soluções de ácido oxálico para tratamentos da superfície de zinco----- 19

4.3. Métodos-------------------------------------------------------- 20

4.3.1. Limpeza do substrato-------- 20

4.3.2. Acondicionamento das amostras após preparo da superficial------------ 20

4.3.3. Caracterização da superfície e caracterização morfológica e química da superfície------------------------------------------------ 21

4.3.4. Caracterização química por difração de raios X - DRX 23

4.3.5. Caracterização química por espectroscopia fotoeletrônica de raios $X-$ XPS

4.3.6. Caracterização morfológica e de espessura-------------------------- 28

4.3.7. O Instrumento de feixe de íons focados (FIB) - -

4.3.8. Interação íons-sólido (Sputtering) -------------- 31

4.3.9. Gases FIB para deposição e gravação avançada---------------------- 32

4.3.10. Caracterização da resistência à corrosão por ensaio em câmara de névoa salina (ASTM B117)-----o 32

4.3.11. Caracterização eletroquímica da resistência à corrosão por espectroscopia de impedância eletroquímica (EIS) ------------------ 34

5. RESULTADOS E DISCUSSÃO-- 36

5.1. Ensaios preliminares de corrosão por exposição em câmara de névoa salina----or-- 36

5.2. Caracterização eletroquímica das superfícies de zinco como recebido e com tratamentos em solução com $10^{-1} \mathrm{M}$ e $1 \mathrm{M}$ de ácido oxálico

5.3. Caracterização da morfologia das superfícies tratadas e sem

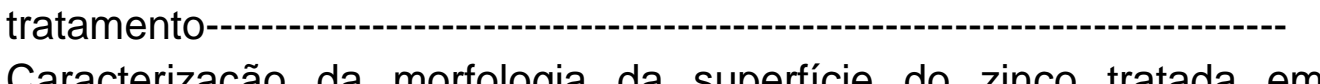
Caracterização da morfologia da superfície do zinco tratada em 5.4. solução com $10^{-1} \mathrm{M}$ de ácido oxálico e exposta a ensaio de corrosão--- 
5.5. Caracterização química da superfície de zinco após tratamento em solução com $10^{-1} \mathrm{M}$ de ácido oxálico por difração de raios $\mathrm{X}$

5.6. Caracterização química da superfície de zinco após tratamento em solução com $10^{-1} \mathrm{M}$ de ácido oxálico por difração de raios $X$ e após ensaio de corrosão

5.7. Caracterização química da superfície de zinco após tratamento em solução com $10^{-1} \mathrm{M}$ de ácido oxálico por XPS e após ensaio de corrosão

5.8. $\quad 5.8$ Caracterização morfológica e da espessura das camadas na superfície do zinco tratado em soluções com $10^{-1} \mathrm{M}$ e $1 \mathrm{M}$ de ácido oxálico em amostras preparadas pela técnica (FIB) antes do ensaio de corrosão-

5.9. Caracterização morfológicae da espessura das camadas na superfície do zinco tratado em soluções com $10^{-1} \mathrm{M}$ e $1 \mathrm{M}$ de ácido oxálico em amostras preparadas pela técnica FIB após ensaio de corrosão.

5.10. Proposta de mecanismo de proteção contra a corrosão para camada formada em solução com $10^{-1} \mathrm{M}$ de ácido oxálico

6. CONCLUSÃO

LISTA DE EQUAÇÕES

Equação 1. $\quad \mathrm{Zn}(\mathrm{OH})_{2(\mathrm{~s})}+4 \mathrm{Zn}^{+2}+4 \mathrm{OH}^{-}+2 \mathrm{CO}_{3}^{-2} \rightarrow \mathrm{Zn}_{5}\left(\mathrm{CO}_{3}\right)_{2}(\mathrm{OH})_{6}--------9$

Equação 2. R- $\mathrm{COOH}+\mathrm{M} \rightarrow \mathrm{R}-\mathrm{COM}+\mathrm{H}^{+}+1 \mathrm{e}^{-}-$

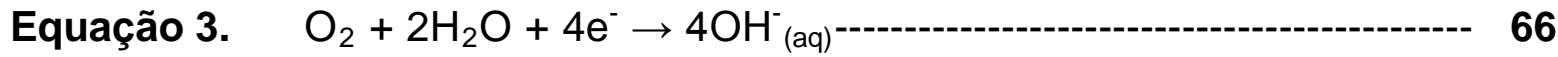

Equação $4 . \quad 4 \mathrm{Zn} \rightarrow \mathrm{Zn}^{2+}+2 \mathrm{e}^{-}$

Equação 5. $\quad \mathrm{Zn}^{2+}+2 \mathrm{OH}^{-} \rightarrow \mathrm{Zn}(\mathrm{OH})_{2}-\mathrm{O}^{-}$

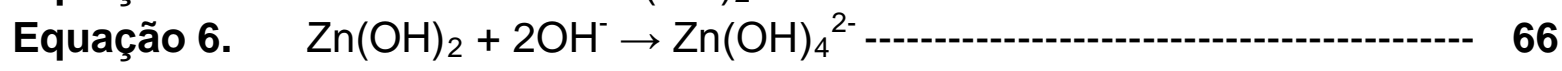

Equação 7. $\quad 5 \mathrm{Zn}(\mathrm{OH})_{2}+2 \mathrm{Cl}^{-}+\mathrm{H}_{2} \mathrm{O} \rightarrow 5 \mathrm{Zn}_{5}(\mathrm{OH})_{8} \mathrm{Cl}_{2}+2 \mathrm{OH}^{-}$

Equação 8. $\quad \mathrm{CO}_{2}+2 \mathrm{OH}^{-} \rightarrow \mathrm{CO}_{3}{ }^{2-}+\mathrm{H}_{2} \mathrm{O}$

Equação 9. $9 \mathrm{CO}_{3}{ }^{2-}+\mathrm{H}_{2} \mathrm{O} \rightarrow \mathrm{HCO}_{3}{ }^{-}+\mathrm{OH}^{-}$

Equação 10. $10 \mathrm{Na}^{+}+\mathrm{HCO}_{3}^{-} \rightarrow \mathrm{NaHCO}_{3}$ 
Equação 11. $\mathrm{Na}^{+}+\mathrm{NaHCO}_{3} \rightarrow \mathrm{Na}_{2} \mathrm{CO}_{3}$

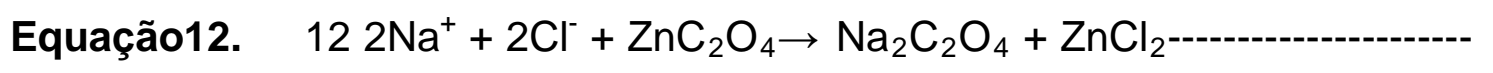

\section{LISTA DE TABELAS}

Tabela 1 Composição química (\% em massa) do zinco usado neste estudo. Resultados obtidos por espectrometria de emissão óptica com plasma - ICP-OES-------------- 19

Tabela 2 Concentração e pH das soluções de ácido oxálico utilizadas nos tratamentos adotados neste estudo-------------------------

Tabela 3 Energia de ligação dos picos obtidos por XPS, concentrações elementares para zinco não tratado, e zinco tratado em solução de ácido oxálico com várias concentrações--------------

Tabela 4 Energias de ligação de picos XPS e concentrações elementares observadas para amostra de zinco tratada em solução de ácido oxálico $\left(10^{-1} \mathrm{M}\right)$ após ensaio de corrosão em

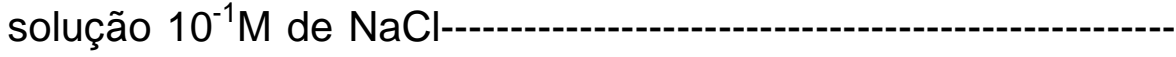

\section{LISTA DE FIGURAS}

Figura 1 Representação esquemática do processo de autorregeneração em defeito na superfície de aço eletrogalvanizado com camada de conversão de cromato (adaptado de Hughes, 2010) ------------

Figura 2 Estrutura de ZHC desenhada com jPOWD-Applet (JPX) v.1.1 Materiais Data Inc. adaptado de (Yoo, 2013; Chen, 2013).

Figura 3 Posições dos picos de difração de raios $X$ - DRX de referência para o zinco metálico (Padrão JCPDS01-087-0713).

Figura 4 Posições dos picos de difração de raios $X$ - DRX de referência do 
Figura 5 Posições dos picos de difração de raios $X$ - DRX de referência do $\mathrm{Zn}(\mathrm{OH})_{2}$ (Padrão JCPDS00-048-1066).

Figura 6 Representação da estrutura octaédrica do oxalato de zinco anidro.

Figura 7 Posições dos picos difração de raios $X$ - DRX de referência para $\mathrm{Zn}_{5}(\mathrm{OH})_{8} \mathrm{Cl}_{2} \cdot \mathrm{H}_{2} \mathrm{O}$ ou simonkolleite (ZHC) (Padrão JCPDS01072-1444).

Figura 8 Esquema a) de extremidade única e b) adsorção de duas extremidades das moléculas de ácido dicarboxílico em substratos metálicos (Taheri, 2011).-------------------------------------

Figura 9 Microscópio eletrônico de varredura (MEV) utilizado no presente trabalho. Fonte laboratório metalografia matériais e mertalurgica Poli-USP.

Figura 10 Espectroscópio fotoeletrônico de raios $X$ usado no presente trabalho. Fonte University of Surrey UK------------------------Série de espectros obtidos com intervalo de 30 s entre cada Figura 11 espectro. Nesta figura, o tempo aumenta do espectro inferior para o superior (adaptado de Ferreira Jr., 2017) ------------------

Figura 12 Espectro XPS Survey para amostra de oxalato de zinco em pó padrão (adaptado de Ferreira Jr., 2017).

Figura 13 Espectros XPS de alta resolução de carbono (a) C1s e oxigênio (b) O1s obtidos a partir de amostra de ácido oxálico em pó (padrão analítico), (adaptado de Ferreira Jr, 2017).

Figura 14 Gráfico de Wagnerde energias de ligação, energias cinéticas Auger e parâmetros Auger modificados para materiais que contêm Zn (linha fotoeletrônica principal: $2 p 3 / 2$; linha de elétron Auger principal: L3M45M45) (NIST, $X$. ray Photoelectron Spectroscopy Database, version

3.4https://srdata.nist.gov/xps/WagnerPlot.aspx)---

Figura 15 Equipamento FIB utilizado para o presente trabalho, com a descrição e disposição dos componentes. Fonte do Centro de Tecnologia em Metalurgia e Materiais do IPT-

Figura 16 A configuração típica da coluna de feixe duplo é uma coluna de elétrons vertical com uma coluna de íons inclinada. Neste caso, a amostra será inclinada para 52 graus para moagem normal para 
a superfície da amostra. Fonte Centro de Tecnologia em Metalurgia e Materiais do IPT. ---

Figura Sputtering ocorre como resultado de uma série de colisões 16a elásticas onde o momento é transferido dos íons incidentes para os átomos alvo dentro de uma região em cascata de colisão. -----

Figura $O$ desenho esquemático mostra o princípio da deposição / 16b remoção de material controlado. O processo de ataque avançado é mostrado. Se o gás adsorvido se decompõe a produtos não voláteis, a deposição ocorrerá --------------------------

Figura 17 Câmara de névoa salina usada neste estudo. Fonte laboratório de corrosão CCTM IPEN -------

Figura 18 Potenciostato e célula eletroquímica usados nos ensaios eletroquímicos deste estudo. Fonte Laboratório de Corrosao CCTM IPEN

Figura 19 Superfície das amostras de zinco, como recebida (Zn) ou tratadas em solução com $10^{-1} \mathrm{M}$ ou com $10 \mathrm{M}$ após diferentestempos de exposição (4h, 24h e 72 h) em câmara de névoa salina (ASTM B117)

Figura 20 Superfície das amostras de zinco, como recebida (Zn) ou tratadas em solução com $10^{-1} \mathrm{M}$ ou com $1 \mathrm{M}$ de ácido oxálico após diferentestempos de exposição (120 h e 172 h) em câmara de névoa salina (ASTM B117)

Figura 21 Superfície das amostras de zinco, como recebida (Zn) ou tratadas em solução com $10^{-1} \mathrm{M}$ ou com $1 \mathrm{M}$ de ácido oxálico e com verniz após vários tempos de exposição $(4 \mathrm{~h}, 24 \mathrm{~h}, 72 \mathrm{~h}$ e $120 \mathrm{~h}$ ) a ensaio de névoa salina (ASTM B117) e as amostra que tem risco na seção 23 e 24

Figura 22 Superfície das amostras de zinco, como recebida (Zn) ou tratadas em solução com $10^{-1} \mathrm{M}$ ou $1 \mathrm{M}$ de ácido oxálico e com verniz após $172 \mathrm{~h}$ de ensaio de névoa salina.

Figura 23 Figura 29: Resultados de EIS como (a) diagramas de Nyquist e (b) diagramas de Bode $|\mathrm{Z}|$ vs $f$ para amostras de zinco como recebido ou tratadas em soluções com $10^{-1} \mathrm{M}$ e $1 \mathrm{M}$ de ácido oxálico após 7 dias de imersão em solução com $10^{-1} \mathrm{M}$ de $\mathrm{NaCl}$. 
Figura 24 Superfície das amostras de zinco, como recebida (Zn) ou tratadas em solução com $10^{-1} \mathrm{M}$ ou com $1 \mathrm{M}$ de ácido oxálico, com verniz e com risco, após 172 h de exposição a ensaio de névoa salina (ASTM B117)

Figura 25 Diagramas de Nyquist para amostras de zinco como recebido ou tratadas em soluções com $10^{-1} \mathrm{M}$ e $1 \mathrm{M}$ de ácido oxálico e expostas à meio de ensaio com $10^{-1} \mathrm{M}$ de $\mathrm{NaCl}$ por $4 \mathrm{~h}$ e 1 dia. ----

Figura 26 Diagramas de Nyquist para amostras de zinco como recebido ou tratadas em soluções com $10^{-1} \mathrm{M}$ e $1 \mathrm{M}$ de ácido oxálico e expostas a meio de ensaio com $10^{-1} \mathrm{M}$ de $\mathrm{NaCl}$ por 3 dias e 5 dias

Figura 27 Diagramas de Nyquist para amostras de zinco como recebido ou tratadas em soluções com $10^{-1} \mathrm{M}$ e $1 \mathrm{M}$ de ácido oxálico e expostas a meio de ensaio com $10^{-1} \mathrm{M}$ de $\mathrm{NaCl}$ por 7 dias.

Figura 28 Micrografias obtidas por microscopia eletrônica de varredura da superfície de amostras zinco após tratamentos em soluções com (a) $10^{-1} \mathrm{M}$ e (b) $1 \mathrm{M}$ de ácido oxálico. Antes do ensaio de corrosão.

Figura 29 Resultados de EIS como (a) diagramas de Nyquist e (b) diagramas de Bode $|\mathrm{Z}|$ vs $f$ para amostras de zinco como recebido ou tratadas em soluções com $10^{-1} \mathrm{M}$ e $1 \mathrm{M}$ de ácido oxálico após 7 dias de ---

Figura 30 Micrografias de MEV das superfícies tratadas em solução com $10^{-1} \mathrm{M}$ de ácido oxálico e (a) antes de exposição ao meio corrosivo e após (b) $10 \mathrm{~min}$;; (c) $30 \mathrm{~min}$. e (d) $60 \mathrm{~min}$. de exposição a solução de cloreto de sódio $10^{-1} \mathrm{M}$ de $\mathrm{NaCl}$.

Figura 31 Micrografias das superfícies tratadas em solução com $10^{-1} \mathrm{M}$ de ácido oxálico após (a) 4h, (b) 3 dias; (c) 5 dias e (d) 7 dias em solução $10^{-1} \mathrm{M}$ de $\mathrm{NaCl}$.

Micrografias das superfícies tratadas em soluções com $10^{-1} \mathrm{M}$, $3 \times 10^{-1} \mathrm{M}, 6 \times 10^{-1} \mathrm{M}, 9 \times 10^{-1} \mathrm{M}$ e $1 \mathrm{M}$ de ácido oxálico antes de

Figura 32 exposição ao meio corrosivo. Todas a micrografias $20000 \times$ de $5 \mu \mathrm{m}--------------------------------$

Figura 33 MEV da superfície de zinco (a) não tratada, e após tratamento por 5 min. em soluções de ácido oxálico com concentrações, (b) $10^{-3} \mathrm{M}$; (c) $10^{-2} \mathrm{M}$; e (d) $10^{-1} \mathrm{M}$. --.

Figura 34 Figura 34: (a) Micrografias por microscopia eletrônica de varredura da superfície de zinco após tratamento de imersão em solução de ácido oxálico 100 mM durante 5 min e com remoção parcial da camada por risco para expor o substrato metálico. Mapas elementares (EDS) sobre a área arranhada e regiões 
circunvizinhas, (b) carbono; (c) zinco e (d) oxigênio.

Figura 35 Figura 35:(a) Micrografia obtida por microscopia eletrônica de varredura da superfície de zinco e (b) resultados da análise por EDS para amostra preparada por imersão em solução de ácido oxálico $10^{-1} \mathrm{M}$ durante 5 min.

Figura 36 Figura 36: Micrografias obtidas por MEV da superfície de zinco após tratamento por imersão em solução de ácido oxálico $10^{-1} \mathrm{M}$ seguida por imersão em solução de $\mathrm{NaCl} 10^{-1} \mathrm{Mpor}$ (a) 10 min., (b) 30 min. e (c) 60 min.

Figura 37 Figura 37: Micrografias obtidas por MEV da superfície de zinco após tratamento em solução com ácido oxálico $10^{-1} \mathrm{M}$ e exposição a solução de ensaio $\left(10^{-1} \mathrm{M}\right.$ de $\left.\mathrm{NaCl}\right)$ por (a) $10 \mathrm{~min}$.; (B) 30 min. e (c) 60 min.

Figura 38 Difratogramas de raios $X$ obtidos de amostras de zinco (a) como recebido e (b) com tratamento em solução com $10^{-1} \mathrm{M}$ de ácido oxálico por 5 min

Figura 39 Figura 39: Difratogramas da superfície de zinco (a) como recebido e exposto por 7 dias a solução $10^{-1} \mathrm{M}$ de $\mathrm{NaCl}$; e com tratamento em solução com $10^{-1} \mathrm{M}$ de ácido oxálico após exposição a solução $10^{-1} \mathrm{M}$ de $\mathrm{NaCl}$ por (b) 5 dias e (c) 7 dias. ----

Figura 40 Figura 40: Espectros Survey (XPS) para: (a) zinco sem tratamento; ou zinco com tratamento por imersão em soluções de ácido oxálico concentrações: (b) $10^{-3} \mathrm{M}$; (c) $10^{-2} \mathrm{M}$; (d) $10^{-1} \mathrm{M}$. -----

Figura 41 Sobreposição dos espectros de XPS de alta resolução para: (a) Carbono (C1s); (b) Oxigênio (O1s); (c) Zinco (Zn2p3/2) e (d) Zinco Auger (Zn L3M45N45).

Figura 42 Sobreposição de espectros de XPS de alta resolução para vários tempos de exposição à solução de ensaio $\left(10^{-1} \mathrm{M}\right.$ de $\left.\mathrm{NaCl}\right)$. (a) carbono (C1s); (b) oxigênio (O1s); (c) zinco (Zn2p3/2), (d) zinco Auger (Zn L3M45N45) e (e) sódio (Na1s) ---

Figuras Perfil de profundidade obtido por XPS para a camada de oxalato

43

Figuras

44

Figura 45 de zinco (a) e (b) antes do ensaio de corrosão

Perfil de profundidade obtido por XPS para a camada de oxalato de zinco (a) antes do ensaio de corrosão, e após ensaio de corrosão por; (a) 30 min.; (b) 60 min.; (c) 5 dias e (d) 7 dias. -----Preparação de amostra por desbaste por feixe de íons de argônio. (b) Micrografias das seção da amostra preparada pela técnica FIB para observação da camada de oxalato formada a partir detratamentos em solução $\operatorname{com} 10^{-1} \mathrm{M}$ de ácido oxálico. ------ 
Figura 46 Micrografias das seções de amostras preparadas pela técnica FIB para observação da camada de oxalato formada a partir detratamentos em solução com $10^{-1} \mathrm{M}$ de ácido oxálico (a) antes e após exposição a solução $10^{-1} \mathrm{M}$ de $\mathrm{NaCl}$ por (b) 30 min. e (c) 3 dias.

Figura 47 Micrografias das seções transversais de amostras preparadas pela técnica FIB para observação da camada de oxalato formada a partir de tratamentos em solução com $10^{-1} \mathrm{M}$ de ácido oxálico após exposição a solução $10^{-1} \mathrm{M}$ de $\mathrm{NaCl}$ (a) por 5 dias (b) 7 dias e (c) amostras como recebidasapós 7 dias de ensaio de corrosão.

Figura 48 Micrografias das seçõesde amostras obtidas por (FIB) de amostra com camada de oxalato (a) antes do ensaio de corrosão e após imersão em solução $10^{-1} \mathrm{M}$ de $\mathrm{NaCl}$ por(b) 30 min.; (c) 3 dias; (d) 5 dias e (e) 7 dias; e (f) amostra como recebida após 7 dias de exposição a solução de ensaio $\left(10^{-1} \mathrm{M}\right.$ de $\left.\mathrm{NaCl}\right)$.

Figura 49 Processo esquemático de corrosão para a camada de oxalato de zinco em diferentes tempos de exposição ao cloreto de sódio (a) primeiras horas (b) das primeiras horas até 1 dia, (c) de 3 a 5 dias e (d) entre 5 e 7 dias. -----.- 


\section{INTRODUÇÃO}

A justificativa para uso do zinco puro é a busca por compreensão sobre as interações entre o ácido oxálico (ácido dicarboxílico) e o zinco, na formação de camada na superfície do zinco

O desenvolvimento e a utilização de materiais metálicos em larga escala podem ser utilizados como parâmetros para medir o avanço tecnológico de uma sociedade. Dentre os diferentes tipos de metais, os aços, galvanizados e o zinco encontram a mais variada gama de aplicaçõessendo os mais produzidos.

Os aços comuns e os de baixa liga são os materiais metálicos de mais usado pelo ser humano e, portanto, os de maior produção. Estes estão sujeitos à ação do meio ambiente ao qual ficam expostos e tendem a sofrer corrosão com perda de suas propriedades físicas, químicas e mecânicas.

Um dos métodos mais utilizados para proteção de aços consiste na proteção catódica por acoplamento com metais mais ativos, que o aço. Uma das formas de se realizar este acoplamento é pelo uso de revestimentos metálicos eletroquimicamente mais ativos (anódicos), que os aços. A corrosão do aço é significativamente reduzida pelo uso de revestimentos anódicos em relação ao aço promovendo proteção sacrificial (Newman, 1994). Ozinco é o metal mais usado como revestimento para proteção de substratos de aço.

Vários métodos podem ser usados para aplicar revestimentos eletroquimicamente mais ativos que o aço, a imersão em banho fundido de zinco (também conhecido como imersão a quente), a eletrodeposição de zinco ou de suas ligas, os revestimentos orgânicos com grande concentração de partículas de zinco, entre outros. A eletrodeposição produz revestimentos de melhor aspecto decorativo devido ao zinco depositado ser mais puro e apresentar boa aderência e ductilidade. Os revestimentos de zinco obtidos por eletrodeposição, ou eletrozincados, atuam por proteção galvânica do aço (Pereira, 2006; Schlesinger, 2011). Os revestimentos de zinco obtidos pelo processo de eletrodeposição são considerados mais econômicos e eficazes na proteção contra a corrosão de aços carbono (Kalantary, 1998). 
Aços com revestimentos de zincosão amplamente utilizados na indústria da construção civilemgrandes estruturas, tais como torres de transmissão, tubulações de coleta e transporte de gás, de água e combustíveis, além do crescente consumo na indústria automotiva com o aumento do uso de aços galvanizados. A literatura reporta que as tubulações de sistemas de coleta e distribuição de água consomem quantidades maciças de aço galvanizado (Van Genderen, 2016; Mudd, 2017).

O mercado mundial de zinco e aço galvanizado apresentou crescimento na última década, principalmente nos países emergentes e nos Estados Unidos da América - EUA, sendo previsto para o período de 2016 a 2020 um crescimento de 5,18\% (Mudd, 2017). A criação de novas redes de distribuição de energia e atualização das antigas redes além dos novos mercados de produção de automóveis tem impulsionado este setor (Mudd, 2017). A China e os EUA, são apontados como os mercados de maior crescimento de uso do aço galvanizado. Tem sido previsto que estes dois países passem a representar 68\% da receita global destes mercados em 2020. O principal motivo para o crescimento é a alta demanda por produtos laminados planos de aço galvanizado para a produção de carrocerias automotivas e para uso na construção civil (Mudd, 2017, Sastri, 2015).

O emprego de quantidades cada vez maiores de metais é um indicador de desenvolvimento, mas também uma preocupação, uma vez que os processos de deterioração a que estão sujeitos, com perda de propriedades físicas também resultamem rejeitos que interferem com o meio ambiente, e afetam a de vida dos seres vivos (Mansfeld, 1986; Shaw, 2006; Cole, 2012). Vale ressaltar aqui que a corrosão do zinco, seja para a utilização como revestimento sobre aço ou para uso como anodos de sacrifício conectado, é uma necessidade para a proteção do aço, todavia, não é de interesse que o zinco corroa. As altas taxas, de forma que sua atuação seja duradoura e, portanto, a proteção contra a corrosão do aço seja mantida por longos períodos.

Embora não tenha sido estabelecido um método definitivo para determinar os custos da corrosão, estudos realizados em vários países 
desenvolvidos, incluindo Japão, Reino Unido e EUA, indicaram perdas estimadas de até 5\% do PIB - Produto Interno Bruto devido à corrosão (Sastri, 2015). Esta estimativa leva em conta apenas custos diretos e não incluem custos indiretos, como danos ambientais, desperdício de recursos naturais, perda de produção por redução ou paradas ocasionais ou mesmo danos pessoais com até perdas de vidas humanas resultantes da corrosão. Os principais aspectos

que tornam os custos relativos à corrosão muito elevados é a baixa conscientização sobre o impacto econômico da corrosão e a seleção inadequada de medidas de proteção (Yunovich, 2003; Biezma, 2005).

A susceptibilidade à corrosão dos aços eletrozincados está diretamente relacionada com as características de agressividade do meio corrosivo aos quais são expostos. É importante ressaltar que para ocorrer a proteção galvânica do aço substrato, o revestimento de zinco ou anodo de zinco deve atuar como anodo de sacrifício e, portanto, deve ser corroído. Todavia, para, que se mantenha a proteção do aço por longos períodos é importante, que o revestimento de zinco seja corroído de forma lenta podendo persistir por tempos prolongados na superfície do aço.

Uma das formas mais empregadas para reduzir a velocidade de corrosão do revestimento de zinco é por meio de tratamentos da sua superfície, entre os quais, encontram-se os revestimentos de conversão. Os tratamentos de conversão mais eficientes são os, que utilizam e geram rejeitos que contêm cromo hexavalente. Este tratamento consiste na imersão de peças em ácido crômico com formação de camadas de conversão de cromato com cromo hexavalente.

As principais características, que tornaram estes revestimentos populares foram seu baixo gasto energético; a resistência à corrosão; a boa aderência a tintas; a aparência decorativa; e principalmente, devido ao seu mecanismo de autorregeneração (self-healing) (Zhang, 2005). A alta eficiência e a grande utilização dos tratamentos de conversão que resultam em resíduos contendo cromo hexavalente se deve, principalmente, à capacidade de autorregeneração das camadas formadas na superfície dos metais tratados, 
propriedade também muito conhecida como self-healing (Hagans, 1994; Zhang, 2005; Eppensteiner, 2007). A Fig. 1 mostra de forma esquemática o processo de autorregeneração (self-healing) em três etapas que ocorre em superfícies de aço eletrogalvanizado com camadas de cromato (adaptado de Hughes, 2010).

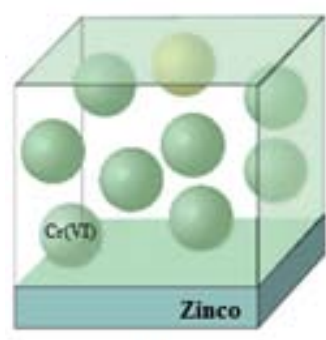

(A)

Camada de conversào de cromatos CCCs (Sem secagem)

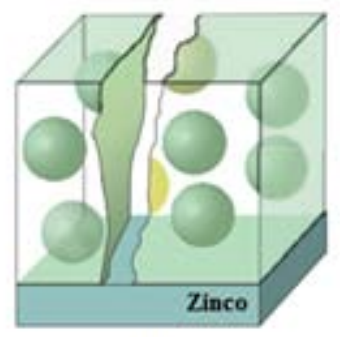

(B)

Camada de conversão de cromatos CCCs Seca

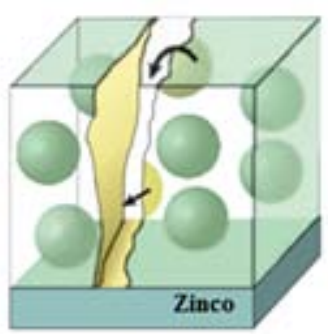

(C)

Migraçào das espécies $\mathrm{Cr}$ (VI) para regiào de defeito "setf-healing"

Figura 1: Representação esquemática do processo de autorregeneração em defeito na superfície de aço eletrogalvanizado com camada de conversão de cromato (adaptado deHughes, 2010).

As camadas de cromato têm como características principais apresentar boa aderência a filmes poliméricos (tintas) e resistência à oxidação atmosférica. No entanto, o cromo hexavalente é carcinogênico e tóxico e, portanto, os resíduos gerados nestes processos causam problemas ambientais e aos seres vivos (Lamb, 2013). Dessa forma, o uso de processos/tratamentos que utilizem cromo hexavalente $\left(\mathrm{Cr}^{6+}\right)$ vem sofrendo crescentes restrições e sendo proibidos em vários países. Tem sido proibida também a importação por esses países de produtos, que utilizem cromo hexavalente em seus processos de fabricação. A indenização, caso a proibição seja descumprida, tem custo muito elevado e os valores a serem pagos pelas indústrias tem desincentivado o uso desses tratamentos. É de vital importância a substituição desses processos que são potencialmente prejudiciais ao meio ambiente e à vida. Consequentemente, abusca por novos tratamentos que não envolvam ou que resultem em substâncias prejudiciais ao meio ambiente, seja pelo setor industrial ou tecnológico/científico tem se intensificando nos últimos anos (Zuckerman, 2004; Baral, 2006).

Uma das grandes dificuldades na substituição dos tratamentos de 
conversão que utilizam o cromo hexavalente é a obtenção de revestimentos/camadas com propriedades de autorregeneração. Além disso, outras propriedades são requeridas aos processos alternativos, tais como, eficiência de proteção equivalente às das camadas de conversão obtidas de tratamentos com cromo hexavalente, atoxicidade, e custo não muito elevado (Almeida, 1998).

Os países da União Europeia e os EUA são os países com o maior número de leis e diretrizes regulatóriasde restrição ao uso de cromo hexavalente já efetivadas e a tendência é que, muito em breve, o uso de cromo hexavalente nos processos industriais seja completamente banido. Esta é a razão para o crescente interesse e grande investimento feito por esses países em pesquisa e desenvolvimento tecnológico de processos/tratamentos que substituam de forma eficiente e efetiva o uso do cromo hexavalente (Baral, 2002; Baral 2006).

Diversas pesquisas têm mostrado a potencialidade do uso dos ácidos dicarboxílicos na proteção contra a corrosão de vários substratos metálicos, sejam em associação ou não a outros compostos. Estes têm sido propostos para a formulação de banhos de tratamentos de conversão e/ou como inibidores de corrosão (Sazou, 2001; Beck, 1994; Sagoe-Crentsil,1993; Hussein, 2016; El-kemary, 2016; Mert, 2016; Ates, 2016; Seifzadeh, 2016; Fayyad, 2017).

A crescente demanda pelo uso de aços galvanizadose a necessidade de substituição de tratamentos de proteção contra a corrosão de metais e/ou ligas que utilizam processos associados a rejeitos tóxicos e cancerígenos são argumentos que justificam as pesquisas desenvolvidas no sentido de se encontrar tratamentos alternativos amigáveis ao meio ambiente e aos seres vivos.

Uma das vias que têm sido propostas para aproteção contra a corrosão de superfícies metálicas é o uso de ácidos dicarboxílicos devido à tendência da interação de grupos carboxílicos destes com as superfícies metálicas. A forma de interação destes grupos funcionais com as superfícies metálicas, todavia, depende das propriedades das soluções utilizadas, tais como pH, concentração 
do ácido, tipo de ácido, tempo e temperatura de interação, entre outros.

$\mathrm{Na}$ área de corrosão, tem sido investigada a interação dos grupos funcionais carboxílicos do ácido com a superfície de óxidos e metais, porém com a intenção de formação de um reticulado, que apresenta uma característica de revestimento orgânico, o que não acontece no caso deste estudo, devido a acidez elevada dos meios. Para tanto, a interação do ácido oxálico com a superfície do zinco metálico e os filmes resultantes desta interação foram investigados por várias técnicas. Informações sobre interação entre ácido oxálico e zinco são escassas na literatura e, portanto, estas não são ainda totalmente compreendidas.

Os mecânismo de formação de interação de filmes orgânicos de cadeias logas, ligações metálicas, ligações não metálicas e carbônicas atuam com efeito de barreira para meios corrosivos, por se tratar de um filme de camadas nanometricas irregulares e porosa, porém com aderência efetivamente elevada para aplicações de tintas e lacas de elevada densidade.

E notável que essa aplicação de tintas, e algum outro revestimento orgânico utilizado sobre esses filmes sempre causara um beneficio de acordo com aos ensaios apresentado adiante nas próximas paginas nesse trabalho.

Outro custo-beneficio, que viabiliza para a indústria automotiva e metalúrgica suas caraterísticas ambientalmente amigáveis e com muito baixo rejeito de precipitados resultante de soluções de $\mathrm{pH}$, neutro, após uso com com metais, dessa formação de conversão.

O tempo e temeratura em faixas pequenas e a secagem do filme rápida que confere a esse tratamento uma premissa e extraordinária defessa ante corrosiva. No entanto, os aspectos negativos estão associados em duas etapas; Reagentes de alta pureza, limpeza e agitação mecânica. 


\section{OBJETIVO}

O objetivo geral do presente trabalho é a investigação da interação do ácido oxálico com a superfície do zinco metálico e da potencialidade dos filmes formados quanto á proteção contra a corrosão da superfície do zinco.

Os objetivos específicos deste trabalho são o de estudar o efeito da concentração de ácido oxálico (ácido etanodióico) na formação de filmes que confiram proteção ao zinco e caracterizar morfologicamente, quimicamente e eletroquimicamente a superfície do zinco após tratamento na solução com concentração que mostre maior potencial de proteção contra a corrosão do zinco. Além disso, outro objetivo específico do presente trabalho é o de investigar a interação da superfície tratada e com maior potencial de proteção contra a corrosão com um verniz, avaliando a aderência entre a superfície tratada e o verniz e a resistência à corrosão do sistema superfície tratadaverniz. Finalmente, propor um mecanismo para a proteção contra a corrosão conferida pelo tratamento selecionado. 


\section{REVISÃO DA LITERATURA}

Nas seções seguintes são apresentados aspectos referentes à corrosão do zinco, sua caracterização química e os tratamentos alternativos aos cromatos.

\subsection{Corrosão do zinco.}

O fornecimento global de zinco estimado pelo US Geological Surveyé de 1.800.000 toneladas por ano (U.S. Geological Survey, 2014). A estimativa feita em 2005 do estoque de zinco em uso países ricos foi de aproximadamente 200 kg per capita (Beers, 2005).

O zinco é um metal mais eletronegativo que o ferro e, portanto, apresenta capacidade de fornecer proteção galvânica ao aço (Roebuck, 1984; Karakasch, 2001). Rapidamente após exposição do zinco metálico ao ambiente uma fina camada superficial de óxido de zinco é formada.

Vários autores relatam que a composição química da superfície do zinco quando exposto ao intemperismo apresenta formas diferentes, tais como óxidos e hidróxidos $\left(\mathrm{ZnO}, \mathrm{Zn}(\mathrm{OH})_{2}\right)$, carbonatos $\left(\mathrm{Zn}_{5}(\mathrm{OH})_{6}\left(\mathrm{CO}_{3}\right)_{2}\right)$, cloretos $\left(\mathrm{Zn}_{5}(\mathrm{OH})_{8} \mathrm{Cl}_{2} \cdot \mathrm{H}_{2} \mathrm{O}\right)$, sulfatos $\left(\mathrm{ZnSO}_{4} \cdot \mathrm{nH}_{2} \mathrm{O}\right.$ e $\left.\mathrm{Zn}_{4} \mathrm{SO}_{4}(\mathrm{OH})_{6} \cdot \mathrm{nH}_{2} \mathrm{O}\right)$, clorossulfatos $\left(\mathrm{NaZn}_{4} \mathrm{Cl}(\mathrm{OH})_{6} \mathrm{SO}_{4} .6 \mathrm{H}_{2} \mathrm{O}\right)$ e $\mathrm{Zn}_{4} \mathrm{Cl}_{2}(\mathrm{OH})_{4} \mathrm{SO}_{4} .5 \mathrm{H}_{2} \mathrm{O}$ ) (Keddam, 1992; Zhu, 2000; Lindström, 2000; Pérez, 2000; Almeida, 2000; Yadav, 2004; Jagadish, 2011;Nishikata, 2016).

A corrosão do zinco em meios aquososocorre por um mecanismo em etapas sucessivaso qual tem início com a solubilização do zinco metálico, seguida pela migração de íons de zinco para a solução. Caso a umidade sobre a superfície de zinco perdure por períodos prolongados de tempo, ocorre aumento na quantidade de água superficial adsorvida, aumento na mobilidade iônica, e, assim, uma película fina de $\mathrm{Zn}(\mathrm{OH})_{2}$ se forma (Keddam, 1992). A exposição a meios úmidos e subsequente secagem das superfícies, possibilita a aeração do hidróxido de zinco e ocorre reação com o dióxido de carbono, 
dissolvido na água ou proveniente da atmosfera (Neufeld, 2002; Tsuru, 2004; Chen, 2005). Esta reação, indicada na Eq. 1, ocasiona a formação de uma camada de carbonato básico compacta e aderente na superfície do zinco que consiste emZn ${ }_{5}\left(\mathrm{CO}_{3}\right)_{2}(\mathrm{OH})_{6}$, este filme, conhecido como hidrozincato, atua como uma barreira entre substrato de zinco e omeio corrosivo e, assim, promove proteção contra a corrosão (Cole, 2009; Zhang, 2013; Leygraf, 2016).

$$
\mathrm{Zn}(\mathrm{OH})_{2(\mathrm{~s})}+4 \mathrm{Zn}^{+2}+4 \mathrm{OH}^{-}+2 \mathrm{CO}_{3}^{-2} \rightarrow \mathrm{Zn}_{5}\left(\mathrm{CO}_{3}\right)_{2}(\mathrm{OH})_{6}
$$

Dependendo das condições e das espécies presentes nos meios de exposição das superfícies de zinco há formação de diversos outros produtos de corrosão. Um dos produtos de corrosão que se desenvolvem na superfície do zinco empresença de cloretos no ambiente é o hidroxicloreto de zinco (ZHC), $\left(\mathrm{Zn}_{5}(\mathrm{OH})_{8} \mathrm{Cl}_{2} \cdot \mathrm{H}_{2} \mathrm{O}\right)$ ou simonkolleite. Este é o principal produto formado por exposição do zinco a este tipo de meio. Estes produtos podemaparecer em estágios intermediários entre produtos iniciais e finais, e seu aparecimento depende da sua solubilidade no meio. $O$ hidroxicloreto de zincoatua como barreira entre o substrato de zinco e o meio corrosivo atuando como proteção contra a corrosão de zinco. Alguns autores consideram que o desenvolvimento desses produtos de corrosão protetores corresponderia a um processodeselfhealingou de autorregeneraçãoda proteção do zinco (Zhang, 2013).

A partir da solubilização de zinco metálico e formação de $\mathrm{ZnO}$, a disponibilidade de íons hidróxidos e cloretos, geralmente provenientes do meio/atmosfera marinhos, propiciam condições para formação de hidroxicloreto de zinco (Ortiz, 2009; Volovitch, 2011; Azevedo, 2015). Altas concentrações de íons zincoecloretos são fundamentais para a formação do ZHC, como produto de corrosão do zinco. A precipitação do ZHC, altamente insolúvel, é desfavorável à difusão de oxigênio e, consequentemente, o processo de corrosão do zinco é dificultado (Qu, 2002).

A baixa solubilidade e a capacidade de proteção apresentadas pelasimonkolleite $\left(\mathrm{Zn}_{5}(\mathrm{OH})_{8} \mathrm{Cl}_{2} \cdot \mathrm{H}_{2} \mathrm{O}\right)$, podem ser explicadas por sua estrutura, vide Fig. 2. Esta apresenta empacotamento de camadas tipo A-B-C, que 
implica em descontinuidade entre as cadeias de ânionse cátions alternados. A transferência de prótons de uma camada para outra é difícil, o que implica em um elevado grau de isolamento e, consequentemente, efeito barreira acentuado ou marcante (Yoo, 2013).
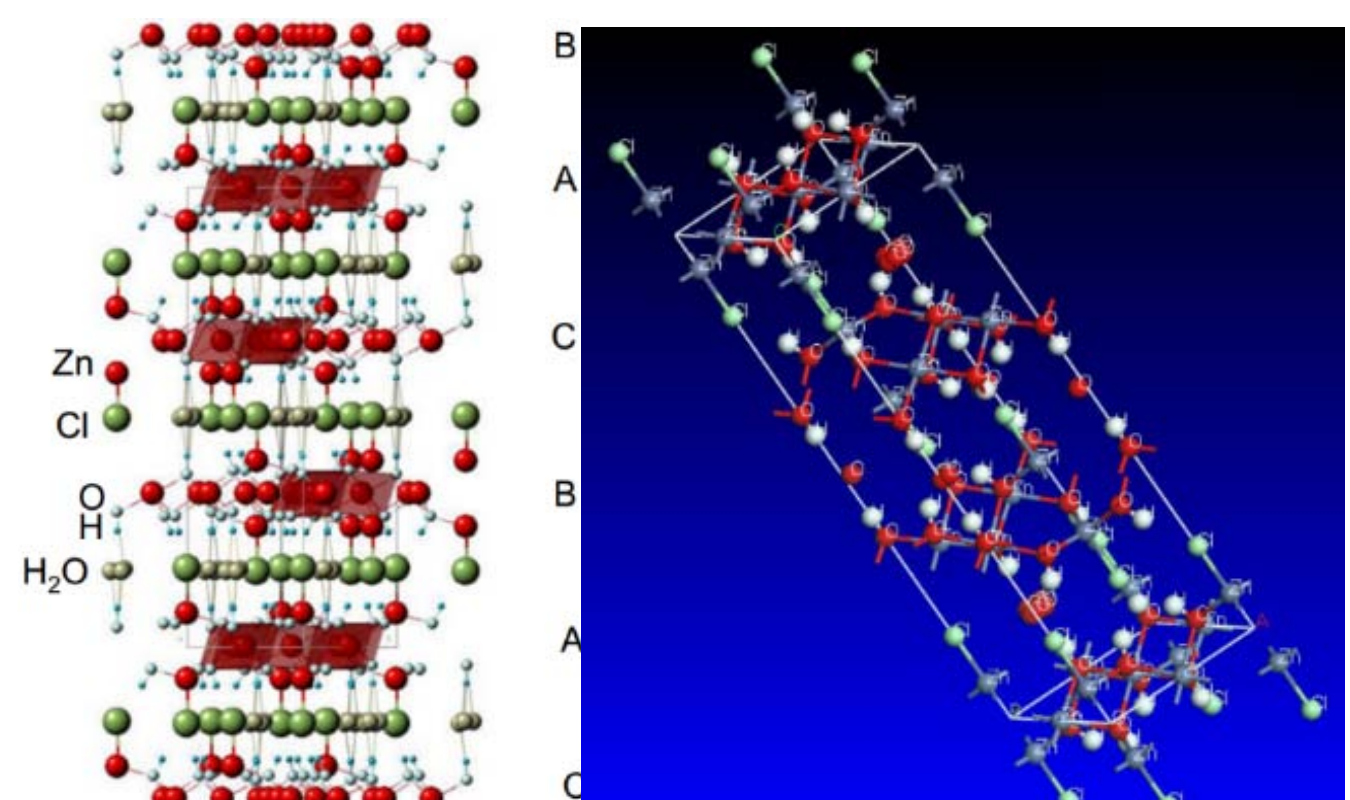

Figura 2: Estrutura de ZHC desenhada com jPOWD-Applet (JPX) v.1.1 Materiais Data Inc. adaptado de (Yoo, 2013; Chen, 2013).

Várias explicações têm sido propostas para a inibição da corrosão do zinco pela presença da "simonkolleite" $\left(\mathrm{Zn}_{5}(\mathrm{OH})_{8} \mathrm{Cl}_{2} \cdot \mathrm{H}_{2} \mathrm{O}\right)$. Considerando que quanto maior a quantidade desta nos produtos de corrosão, maior o efeito barreira à difusão de oxigênio, maior será a resistência à corrosão da superfície. O processo de difusão afetao mecanismo de corrosão, seja este na fase líquida (meio corrosivo), como através da camada de produtos de corrosão depositados sobre a superfície metálica (Keddam, 1992; Amadeh, 2002; Zhang, 2005; Volovitch, 2010; Chavan, 2013). Portanto, o efeito barreira causado pela presença de produtos precipitados, como é o caso da simonkolleite $\left(\mathrm{Zn}_{5}(\mathrm{OH})_{8} \mathrm{Cl}_{2} \cdot \mathrm{H}_{2} \mathrm{O}\right)$, tem efeito significativo no processo corrosivo do zinco. 
3.2. Caracterização química do zinco - difração de raios $X(D R X)$.

A presença de zinco na forma metálica é indicada por picos apresentados na Fig. 3, segundo ficha cristalográfica (Padrão 01-087-0713), isto é, os picos DRX de referência do Zn.

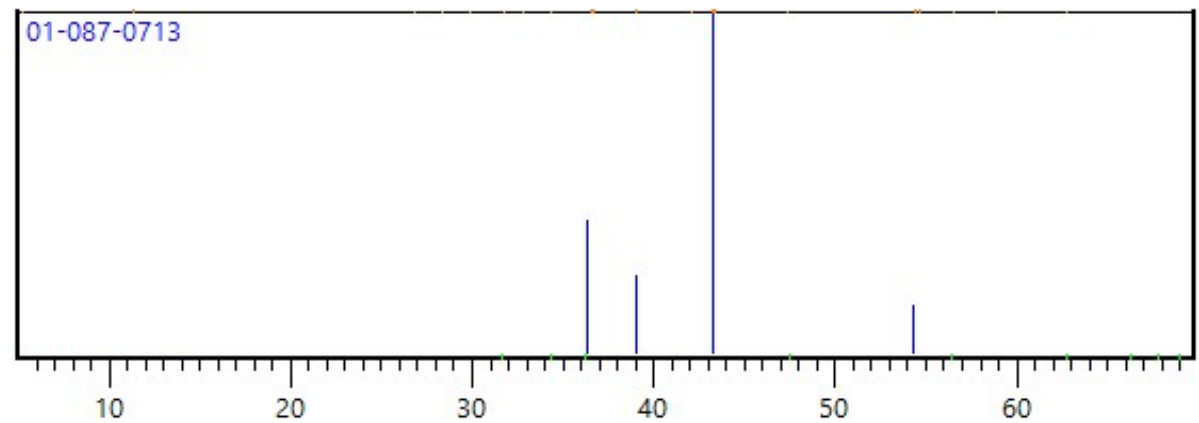

Figura 3: Posições dos picos de difração de raios $X$ - DRX de referência para o zinco metálico (Padrão JCPDS01-087-0713).

O óxido de zinco é uma forma típica de compostos de zinco de estrutura zincita, que se decompõe-se em altas temperaturas. Classificado como semicondutor extrínseco do tipo $\mathrm{n}$, de forma cristalina hexagonal, apresenta em sua estrutura, o átomo de zinco no centro de um tetraedro distorcido coordenado a quatro oxigênios. Seus valores de parâmetro de rede são a = 3,2539 e c $=5,2098 \AA$ (Padrão JCPDS 01-079-0207). A presença do óxido de zinco na superfície é indicada por picosmostrados na Fig. 4, segundo ficha cristalográfica (Padrão JCPDS 01-079-0207), isto é, os picos DRX de referência do ZnO.

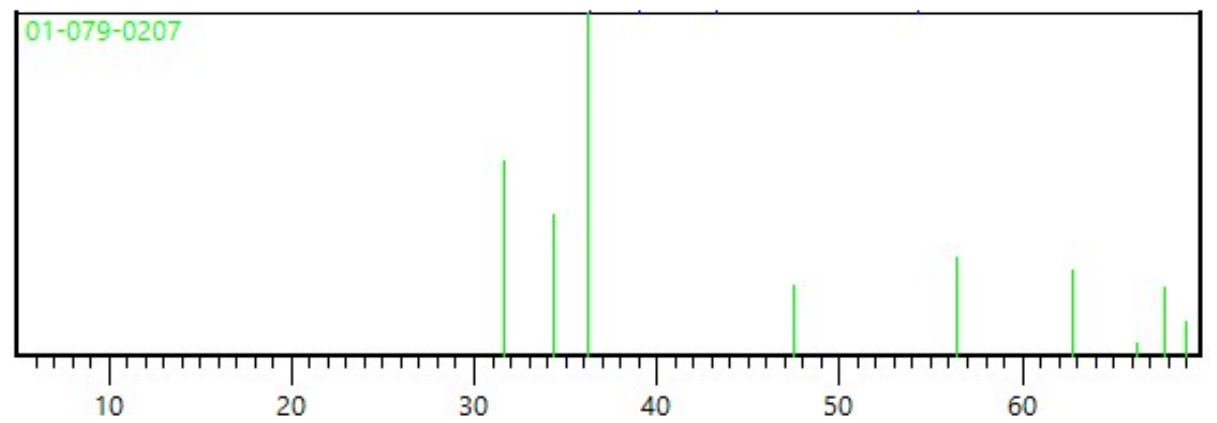

Figura 4: Posições dos picos de difração de raios $X$ - DRX de referência do ZnO (Padrão JCPDS01-079-0207). 
O hidróxido de zinco tem uma estrutura ortorrômbica, onde tetraedros de $\mathrm{ZnO}_{4}$ estão dispostos em rede tridimensional, para a fase mais estável $\mathrm{Zn}(\mathrm{OH})_{2}$. Fases de menor estabilidade tipo $\alpha, \beta$ e z̃ospouco conhecidas, sendo que a fase cristalina tipo a apresenta coç̃̃dentratraédrica e octaédrica. O hidróxido de zinco é indicado pelos picos de DRX de referência (Padrão JCPDS 00-048-1066) do $\mathrm{Zn}(\mathrm{OH})_{2}$, vide Fig. 5.

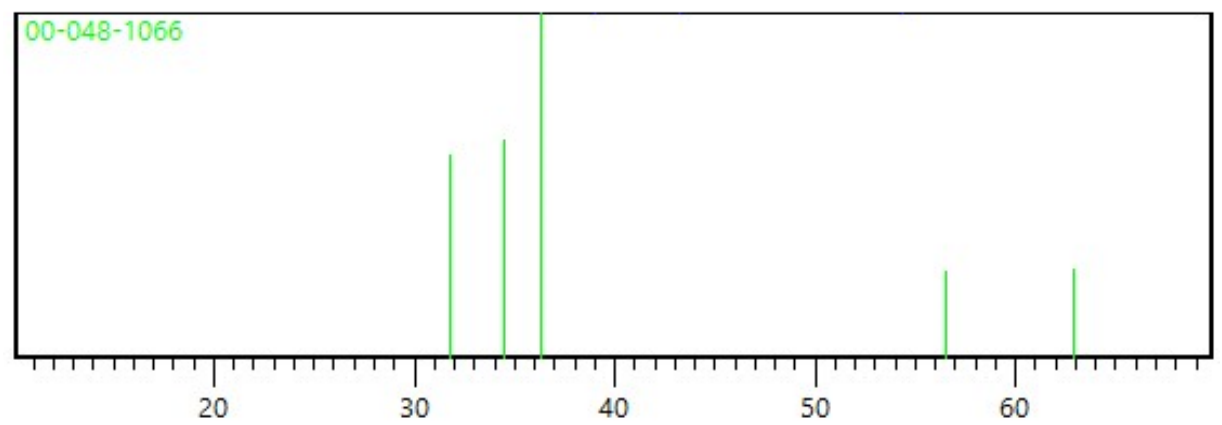

Figura 5: Posições dos picos de difração de raios $X$ - DRX de referência do $\mathrm{Zn}(\mathrm{OH})_{2}$ (Padrão JCPDS00-048-1066).

O zinco na forma de oxalato é polimórfico com estruturas cristalográficas pertence ao espaço Grupo P21. A coordenação do elemento zinco nesta estrutura é octaédrica. Nesta, os átomos de oxigênio estão conectados com 0 zinco por diferentes números de ligações, com comprimentos de ligações C-O no ânion oxalato desordenado para oxalato de zinco. Seis átomos de oxigênio são dispostos ao redor de um átomo de zinco e os octaedros distorcidos são conectados entre si, pelas extremidades e, por isso, aparecem distorcidos. A estrutura octaédrica do oxalato de zinco é mostrada na Fig. 6.

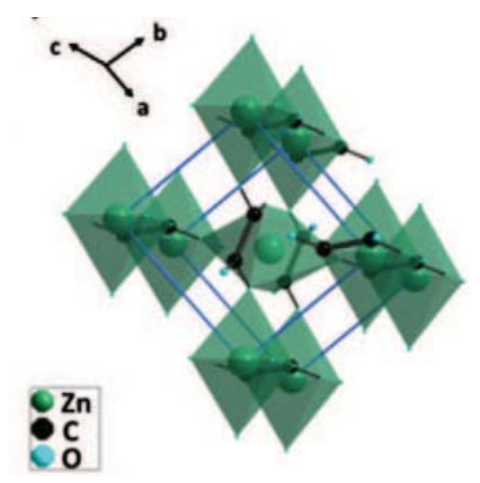


Figura 6: Representação da estrutura octaédrica do oxalato de zinco anidro.

Os picos de DRX referentes Materials Studiosao $\mathrm{Zn}_{5}(\mathrm{OH})_{8} \mathrm{Cl}_{2} \cdot \mathrm{H}_{2} \mathrm{O}$, também conhecido como simonkolleite (ZHC) são mostrados naFig.7.

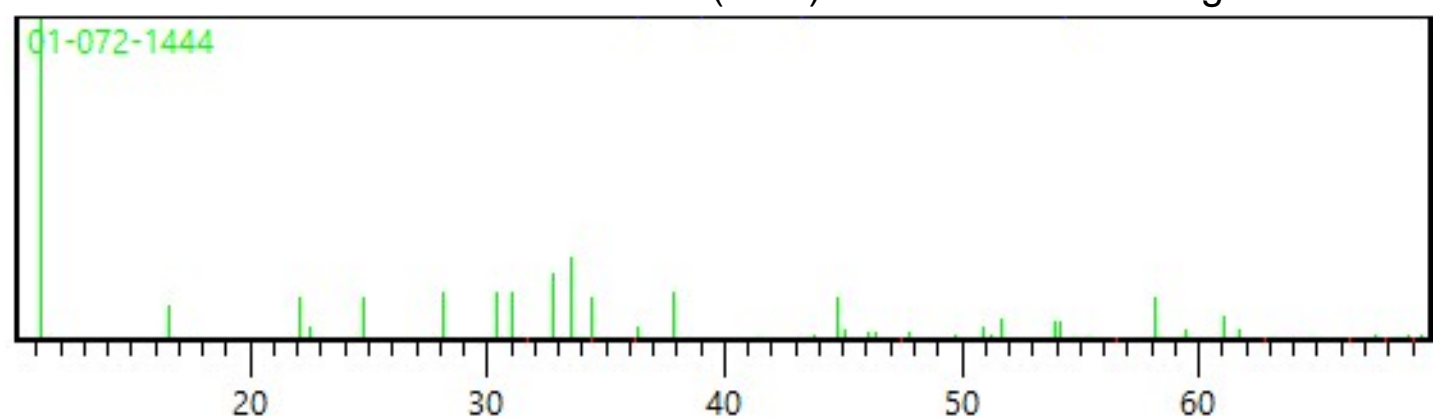

Figura 7: Posições dos picos difração de raios $X$ - DRX de referência para $\mathrm{Zn}_{5}(\mathrm{OH})_{8} \mathrm{Cl}_{2} \cdot \mathrm{H}_{2} \mathrm{O}$ ou simonkolleite (ZHC) (Padrão JCPDS01-072-1444).

\subsection{Tratamentos alternativos aos cromatos}

Os tratamentos alternativos aos tratamentos de conversão com cromatos tiveram início com a investigação de banhos de conversão contendo os elementos molibdênio e tungstênio. Estes elementos apresentam características semelhantes às do cromo pois pertencem à mesma família química. As investigações se estenderam em seguida às famílias químicas vizinhas do cromo na tabela periódica, tais como vanádio e manganês (Stankiewicz, 2013; Hinton, 1992; Zhang, 2005). Estes elementos são empregados na forma de sais dos seus compostos e, em alguns casos, como o dos molibdatos, foram mais estudados por serem atóxicos. Mesmo com estas características favoráveis, os resultados destes estudos mostraram camadas com desempenho anticorrosivo inferior ao das camadas de cromato (Aramaki, 2001).

Outros estudos que buscaram alternativas aos revestimentos de conversão obtidos de banhos com cromo hexavalente envolveram o uso de elementos de terras raras, nanomateriais, organosilanos, sais de nióbio, sais de zircônia, ou mesmo a associação de diferentes compostos e de diversas formas de tratamento, em alguns casos com resultados promissores (Montemor, 2002; ARAMAKI). No entanto, até o presente momento, nenhuma das alternativasinvestigadas foi completamente satisfatória para a substituição das camadas de cromato, seja devido apropriedades ainda 
insatisfatórias, tais como aderência, toxicidade, razão custo/benefício desta forma as opções estudadas são consideradas como sendo parcialmente viáveis, são necessárias e pesquisas adicionaispara tratamentos viáveis (Peng, 2009).

De maneira a compreender o assunto, recorreu-se à literatura, a fim de entender as interações químicas, que ocorrem durante a conversão do ácido oxálico.

Taheri (2012) investigou os mecanismos de adsorção de ácido succínico, ácido mirístico e moléculas de anidrido succínico, como as ligações interfaciais representativas, em amostras de zinco tratadas de forma diferente por meio, onde foi verificada a formação das bandas de vibração simétrica, e assimétrica que mostrou a desprotonação das moléculas e a formação de carboxilatos. Os ácidos succínico e mirístico, bem como o anidrido succínico, apresentam as funcionalidades de vários revestimentos poliméricos, tais como a poliolefina copolimerizada e polímeros enxertados com anidrido maleico (Oberg, 2001). Uma compreensão mecanística fundamental da interação desses grupos com as superfícies é um fator importante para entender as propriedades de ligação dos revestimentos de polímeros. A oxidação de moléculas adsorvidas em substratos metálicos leva à formação espontânea de estruturas interfaciais. Conforme a literatura, essas monocamadas foram amplamente caracterizadas (Chen, 2007; Plank, 2007). Contudo, os aspectos mecanicistas que determinam sua dessorção não foram completamente compreendidos.

A compreensão de fatores, que governam a estrutura e as propriedades das monocamadas são essenciais para utilizações nos estudos dos processos interfaciais. A formação das monocamadas pode ocorrer tanto em condições de circuito aberto, isto é, por imersão do substrato numa solução do monômero, ou sob controle potenciostático, ou seja, aplicando um potencial externo ao substrato metálico numa solução incluindo o monômero. Alguns estudos mostraram uma variação nas propriedades de ligação interfacial através da aplicação de um potencial externo (Jackowska, 1996; Griveau, 2001). Os grupos funcionais carboxílicos interagem com superfícies de óxido 
ao consumir hidroxilas de superfície durante as montagens (Brand, 2004; Willis, 2005). As cadeias de ácido carboxílico longo, tais como o ácido mirístico, $\mathrm{CH}_{3}\left(\mathrm{CH}_{2}\right)_{12} \mathrm{COOH}$, reagem com a fração de hidroxila através da funcionalidade - $\mathrm{COOH}$. No entanto, ácidos dicarboxílicos curtos tais como, o ácido succínico, $\left(\mathrm{CH}_{2}\right)_{2}(\mathrm{COOH})_{2}$, possuem grupos $-\mathrm{COOH}$ bifuncionais que podem estar envolvidos no procedimento de adsorção. As moléculas de ácido dicarboxílico de tipo anidrido são mostradas para abrir na proximidade das superfícies metálicas devido à interação com a fração de hidroxila (Taheri, 2011). Posteriormente, os grupos de ácido dicarboxílico tornam-se desprotonados, para formar uma espécie de carboxilato de ligação coordenada com o metal. A Fig. 8 mostra a adsorção de uma extremidade e duas extremidades das moléculas de ácido dicarboxílico dependendo da estrutura molecular e dos parâmetros experimentais (Taheri, 2011).

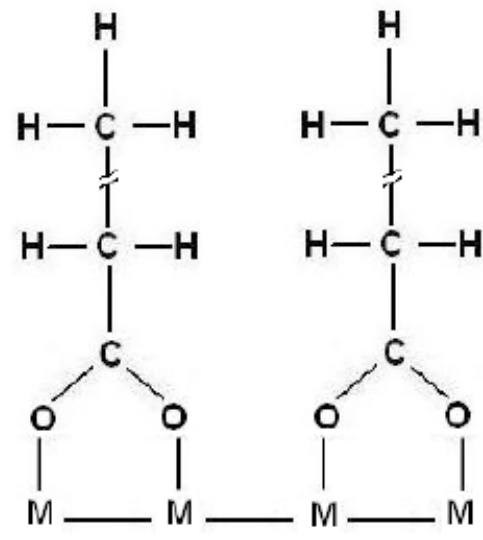

(a)

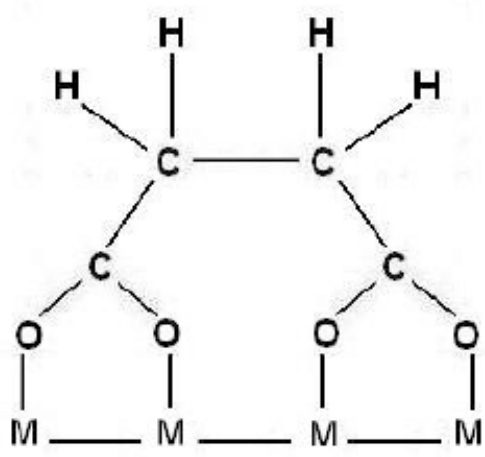

(b)

Figura 8: Esquema a) de extremidade única e b) adsorção de duas extremidades das moléculas de ácido dicarboxílico em substratos metálicos (Taheri, 2011).

As adsorções de ácidos dicarboxílicos de uma extremidade podem ser explicadas pela reação, Eq. 2:

$$
\mathrm{R}-\mathrm{COOH}+\mathrm{M} \rightarrow \mathrm{R}-\mathrm{COM}+\mathrm{H}^{+}+1 \mathrm{e}^{-}
$$

Os resultados obtidos por Taheri (2012) mostraram, que o anel de anidrido abre na proximidade das hidroxilas de zinco e carbonatos para formar ligações de carboxilato na superfície metálica. Os resultados também 
mostraram que o potencial positivo aplicado resultou em uma ordenação dos adsorventes e uma ligeira alteração na quantidade dos carboxilato formados. Os gráficos de tempo potencial da adsorção molecular no substrato de zinco mostraram que a injeção das moléculas resultou em uma clara resposta de potencial, que implicava algumas interações entre as moléculas e o substrato de zinco. Uma quantidade aumentada de carboxilato formados por adsorção de moléculas de ácido mirístico foi detectada por uma mudança potencial significativa. Além disso, a mudança de potencial durante a adsorção de anidrido succínico mostrou a importância da composição da superfície metálica no procedimento de abertura do anel. As medidas de cronoamperometria mostraram que a adsorção de ácidos succínico e mirístico está associada a uma reação de oxidação eletroquímica, enquanto que a adsorção de anidrido succínico está associada a um conjunto de redução de oxidação eletroquímica. Além disso, uma diminuição gradual na resposta atual durante o processo de adsorção foi correlacionada ao bloqueio dos defeitos inibindo a transferência de elétrons.

Os voltamogramas cíclicos dos eletrodos de zinco revelaram que as moléculas adsorvidas não formam uma barreira efetiva à transferência heterogênea de elétrons (Taheri, 2012). No entanto, as amostras com moléculas de ácido mirístico adsorvido apresentaram uma monocamada menos permeável àquelas formadas pelo ácido succínico adsorvido. Uma diminuição considerável nos valores da capacitância da dupla camada $\left(C_{d l}\right)$ após a adsorção de moléculas de anidrido succínico implicou em alteração nos valores de ponto de carga zero (point of zero charge) PZC, enquanto a diminuição dos valores de $\mathrm{C}_{\mathrm{dl}}$ devido à adsorção de ácidos succínico $\mathrm{e}$ mirístico em amostras tratadas de forma diferente foi correlacionada com a formação de uma monocamada menos permeável. Por outro foi obtido lagura, um valor da largura a meia altura FWHM (do inglês full width at half maximum) maior para as moléculas de ácido succínico e anidrido succínico adsorvido do que para o ácido mirístico, indicando um mecanismo de dessorção mais complicado devido às configurações de adsorção de uma e duas extremidades. Assim, as diferentes configurações de adsorventes levam a uma 
permeabilidade iônica diferente e ao potencial ao quais os dicarboxilatos são reduzidos. Além disso, a mudança negativa de $\mathrm{E}_{\mathrm{pc}}$ (potencial de pico catódico) nas segundas varreduras mostrou, que as moléculas fracamente unidas foram removidas das superfícies após a primeira varredura. Os transientes cronoamperométricos (CA) são caracterizados pela presença de picos de corrente, cuja altura e tempo dependem da característica de transferência de elétrons (Calvente, 1996; Mulder, 2001).

Ainda recorrendo à literatura, como não foram encontrados outros relatos de aplicações de tratamentos de ácido oxálico para conversão em substrato de zinco puro 99,9\%, buscou-se a compreensão da aplicação de ácido oxálico com outros metais. Gorantla et al. (2005) utilizaram ácido oxálico como agente complexante em suspensões de CMP (do inglês chemical mechanical planarization) de cobre e em formulações de limpeza pós de CMP. Ao pH natural do sistema ( 1,5), a taxa de dissolução foi de $30 \mathrm{~nm} / \mathrm{min}$., enquanto a taxa de polimento era de $1500 \mathrm{~nm} / \mathrm{min}$. A superfície de cobre após experimentos de dissolução revelou a presença de um filme azulado. A taxa de dissolução do cobre aumentou com o pH até o pH 3,0, acima desde valor a taxa diminuiu. A superfície do cupom de cobre foi brilhante sem qualquer sinal de filme azulado observado a pH 1,5. As experiências de polarização potenciométrica mostraram a formação de um filme de passivação forte na superfície do cobre para pH 1,5, enquanto que não foi formada tal película nos outros valores de $\mathrm{pH}$. As medidas de potencial de circuito aberto (OCP do inglês open circuitpotential) durante o polimento a $\mathrm{pH}$ 1,5 indicaram um aumento gradual do potencial quando o polimento foi interrompido. Esse comportamento foi atribuído a um crescimento gradual de um filme de superfície modificado sobre cobre. Quando o polimento foi retomado, o valor OCP estabilizou de volta ao seu valor anterior, mais baixo antes da parada do polimento. Foi deduzido que o $\mathrm{pH}$ desempenhava um papel muito importante na determinação das interações químicas entre o ácido oxálico e a superfície de cobre. A forte capacidade complexante do ácido oxálico torna desejável a utilização no eletrólito para polimento mecânico eletroquímico ECMP (do inglês electrochemicalmechanical polishing). O eletrólito à base de ácido oxálico 
também requer o uso de um inibidor de corrosão para controlar a taxa de dissolução estática. 


\section{MATERIAIS E MÉTODOS}

Nesta seção são apresentados os materiais usados neste trabalho, as soluções de ácido oxálico usadas para tratamentos da superfície de zinco e os métodos experimentais utilizados.

Após ser realizada a pesquisa bibliográfica em, que se buscou os trabalhos publicados em que o ácido oxálico se apresenta como alternativa potencial para substituição de tratamentos de conversão com ácido crômico em várias indústrias, pode-se dizer que, apesar do fato que não se pode afirmar a ausência de algum trabalho sobre esse tema, não foram encontradas publicações pela revisão realizada.

No presente estudo foram utilizados tratamentos de superfície com ácido oxálico na faixa de $\mathrm{pH}$, entre $0,89(1 \mathrm{M})$ e 2,89 $\left(10^{-3} \mathrm{M}\right)$ de ácido oxálico, e o verniz poliuretano alto brilho 7100 , para fazer teste de corrosão em câmera de nevoa salina e ensaio de aderência Tais parâmetros de tratamento de superfícies mostraram que este é um estudo promissor e economicamente viável para a indústria, podendo ser utilizado como tratamento superficial livre de agentes poluidores ao meio ambiente.

As superfícies de aço galvanizado compõem vários elementos como Zn, $\mathrm{Fe}, \mathrm{Al}$ e $\mathrm{Mg}$ entre outros, de acordo com o grau do aço, a composição do banho e os subsequentes tratamentos térmicos (Marder, 2000; Wienströer, 2003). A complexidade do sistema não permite um estudo interfacial mecanístico. Em razão disso, Zn puro foi selecionado neste estudo como substrato modelo para o conhecimento fundamental e compreensão dos mecanismos interfaciais, e como base para novas pesquisas baseadas em abordagens aplicadas.

Devido à importância interfacial das monocamadas orgânicas, a última década viu a aplicação das transformadas de Fourier (FTIR) e a espectroscopia de fotoelétrons excitados por raios X (XPS), o que ajudou na formulação de modelos detalhados de nível molecular e o, que se busca a compreensão neste trabalho. 


\subsection{Materiais.}

O zinco puro (99,9\%), cuja composição química (\% em massa) obtida por ICP-OES é dada na Tab. 1. O material analisado foi fornecido na forma de chapas finas, retirados corpos de prova nas dimensões $2 \times 2 \times 0,01 \mathrm{~cm}$ cortados antes do tratamento de imersão, foi utilizada como substrato para os tratamentos com ácido oxálico. As superfícies de zinco foram limpas em acetona e etanol PA, lavadas em água deionizada e secadas sob corrente de ar quente durante $5 \mathrm{~s}$. Após secagem, as amostras foram expostas ao ar durante 2 min para esfriamento e, depois, imersas nas soluções de tratamento que corresponderam as soluções aquosas de ácido oxálico. Não foram feitos ativação da superfície do corpo de prova e também não foram feitas comparação com o cromo hexavalente.

Tabela 1: Composição química (\% em massa) do zinco usado neste estudo. Resultados obtidos por espectrometria de emissão óptica com plasma - ICPOES.

\begin{tabular}{cccccccccccc} 
OES. & \multicolumn{10}{c}{19} & \multicolumn{10}{c}{} & \\
\hline $\begin{array}{c}\mathrm{Ag} \\
(\mathrm{ppm})\end{array}$ & $\begin{array}{c}\mathrm{Al} \\
(\mathrm{ppm})\end{array}$ & $\begin{array}{c}\mathrm{Ba} \\
(\mathrm{ppm})\end{array}$ & $\begin{array}{c}\mathrm{Be} \\
(\mathrm{ppm})\end{array}$ & $\begin{array}{c}\mathrm{Bi} \\
(\mathrm{ppm})\end{array}$ & $\begin{array}{c}\mathrm{Ca} \\
(\mathrm{ppm})\end{array}$ & $\begin{array}{c}\mathrm{Cd} \\
(\mathrm{ppm})\end{array}$ & $\begin{array}{c}\mathrm{Co} \\
(\mathrm{ppm})\end{array}$ & $\begin{array}{c}\mathrm{Cr} \\
(\mathrm{ppm})\end{array}$ & $\begin{array}{c}\mathrm{Cu} \\
(\mathrm{ppm})\end{array}$ & $\begin{array}{c}\mathrm{Fe} \\
(\mathrm{ppm})\end{array}$ & $\begin{array}{c}\mathrm{Mg} \\
(\mathrm{ppm})\end{array}$ \\
$<0,020$ & 0,487 & 0,02 & $<0,020$ & $<0,010$ & $<0,020$ & $<0,015$ & $<0,010$ & $<0,020$ & $<0,020$ & 0,810 & $<0,500$ \\
$\mathrm{Y}$ & $\mathrm{Mn}$ & $\mathrm{Na}$ & $\mathrm{Ni}$ & $\mathrm{V}$ & $\mathrm{Pb}$ & $\mathrm{Sb}$ & $\mathrm{Se}$ & $\mathrm{Si}$ & $\mathrm{Sn}$ & $\mathrm{Ti}$ & $\mathrm{Zn}$ \\
$(\mathrm{ppm})$ & $(\mathrm{ppm})$ & $(\mathrm{ppm})$ & $(\mathrm{ppm})$ & $(\mathrm{ppm})$ & $(\mathrm{ppm})$ & $(\mathrm{ppm})$ & $(\mathrm{ppm})$ & $(\mathrm{ppm})$ & $(\mathrm{ppm})$ & $(\mathrm{ppm})$ & $(\%)$ \\
$<0,020$ & $<0,020$ & 0.70 & $<0,010$ & $<0,020$ & 0,077 & $<0,020$ & $<0,020<0,020$ & $<0,100<0,100$ & $99,99 \%$ \\
\hline
\end{tabular}

Este material foi escolhido como base para o tratamento com o objetivo de se investigar a interação de zinco com o ácido oxálico (AO) e avaliar a proteção à corrosão ocasionada pela camada formada durante esta interação, sem a interferência de outros elementos de liga ou de impurezas em teores que pudessem interferir na avaliação desta interação.

\subsection{Soluções de ácido oxálico para tratamentos da superfície de zinco.}

As soluções de tratamento foram preparadas pela adição de ácido oxálico a água deionizada para a obtenção de soluções em uma ampla faixa de concentrações, a saber: $10^{-3} \mathrm{M}, 10^{-2} \mathrm{M}, 10^{-1} \mathrm{M}, 3 \times 10^{-1} \mathrm{M}, 6 \times 10^{-1} \mathrm{M}, 9 \times 10^{-1} \mathrm{M}$ e 1 
M. O pH das soluções utilizadas é apresentado na Tabela 2.

Tabela 2: Concentração e pH das soluções de ácido oxálico utilizadas nos tratamentos adotados neste estudo.

\begin{tabular}{cccccccc}
\hline$\left[\mathrm{H}_{2} \mathrm{C}_{2} \mathrm{O}_{4}\right] \mathrm{M}$ & $10^{-3}$ & $10^{-2}$ & $10^{-1}$ & $3 \times 10^{-1}$ & $6 \times 10^{-1}$ & $9 \times 10^{-1}$ & 1.00 \\
\hline $\mathrm{pH}$ & 2,89 & 2,40 & 1,33 & 1,13 & 1,01 & 0,94 & 0,89 \\
\hline
\end{tabular}

Como um dos objetivos principais deste trabalho foi o de se avaliar o efeito da concentração de ácido oxálico. Este foi o motivo da escolha da faixa das concentrações a serem testadas (entre $10^{-3} \mathrm{M}$ e $1 \mathrm{M}$ ).

Objetivos da aplicação do verniz, sobre o substrato preparado com o tratamento é aplicável à avaliação de aderência sobre substratos metálicos de uma ou mais camadas de tintas e verniz de sistemas de pintura. O verniz poliuretano, alto brilho 7100, foi aplicado por imerção em lenta por 5 s, e retirado lentamente da imerção, secagem em entufa $60^{\circ} \mathrm{C}$. Aparelhagem, para o métodoA, corte em $X$, dispositivo de corte uma lâmina de aço, com aproximadamente $17 \mathrm{~mm}$ de largura e ângulo de corte de $19^{\circ} \pm 2^{\circ}$.

(NORMA BRASILEIRA ABNT NBR 11003 Tintas. Determinação da aderência)

\subsection{Métodos.}

4.3.1. Limpeza do substrato.

As superfícies das placas de zinco foram limpas em ultrassom por 5 min de imersão sequencialmente nos seguintes solventes, acetona PA, etanol PA e água deionizada. Sequencialmente, o excesso de água foi removido por agitação mecânica e as amostras foram secas em estufa a $90{ }^{\circ} \mathrm{C}$ por 15 min. Após serem secas as amostras foram resfriadas ao ar (15 min.) e imediatamente após a limpeza foram imersas nasolução de ácido oxálico por 5 $\min$.

4.3.2. Acondicionamento das amostras após preparo da superfície. 
Depois de imersas nas soluções de conversão de ácido oxálico, com diferentes concentrações $\left(10^{-3} \mathrm{M}, 10^{-2} \mathrm{M}, 10^{-1} \mathrm{mM}, 3 \times 10^{-1} \mathrm{M}, 6 \times 10^{-1} \mathrm{M}, 9 \times 10^{-1} \mathrm{M} \mathrm{e}\right.$ 1M) por 5 min., as amostras foram secadas em estufa por $10 \mathrm{~min}$. a $80{ }^{\circ} \mathrm{C}$ e, sequencialmente, acondicionadas em dessecador para posteriores análises.

Entende-se que a exposição das amostras ao ambiente torna-as susceptíveis à contaminação por carbonatos $\left(\mathrm{CO}_{2}\right.$ atmosférico) e umidade, alterando sua composição superficial (aproximadamente $5 \mathrm{~nm}$ ). É previsto que esta contaminação não é suficiente para comprometer a morfologia e mesmo as propriedades de proteção à corrosão. Apenas para efeito de estudo e compreensão comparativa de composição química da camada formada, todas as amostras foram analisadas após tempo comum de preparo em iguais condições de armazenamento.

4.3.3. Caracterização da superfície e caracterização morfológica e química da superfície.

Após os tratamentos por imersão nas soluções de ácido oxálico, a morfologia das superfícies das amostras e a composição química (semiquantitativa) foram analisadas por microscopia eletrônica de varredura (MEV) e por espectroscopia de dispersão de energia (EDS). Nestas análises foi utilizado microscópio eletrônico de varredura com resolução espacial máxima de $1,2 \mathrm{~nm}$ em $30 \mathrm{kV}$ equipado com um sistema de análise tripla e um espectrômetro por comprimento de ondaWDS (do inglês wave dispersive spectrometer) de feixe paralelo, vide Fig. 9. Foi utilizada nesta análise uma pistola de emissão de campo Schottky, operada a uma tensão incidente de 5 keV com ampliação variando de 500 X a 30000 X. O detector utilizado era equipado com um sistema de microanálise de raios $X$ para registrodos mapas químicos elementares. As imagens foram obtidas em mesmas ampliações para comparação da morfologia entre as amostras preparadas em diferentes concentrações.

Embora os níveis de carbono observados tenham sido relativamente altos, e apesar de a emissão dos primeiros dez elementos (hidrogênio ao neônio) serem representada por bandas na região de baixa energia, o 
recobrimento das amostras com material condutor não foi necessário indicando que as superfícies analisadas apresentavam condutividade suficiente para análise sem recobrimento.

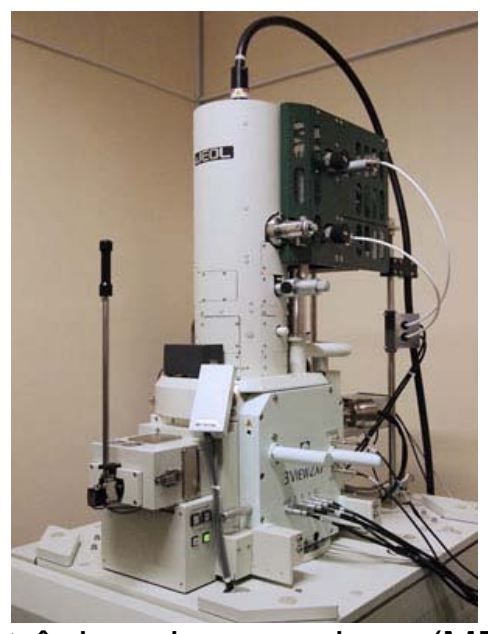

Figura 9: Microscópio eletrônico de varredura (MEV) utilizado no presente trabalho. Fonte laboratório metalografia matériais e mertalurgica Poli-USP.

Como a resolução das imagens (FEG/MEV) depende da tensão de aceleração dos elétrons; corrente da sonda e a distância de trabalho, uma menor distância de trabalho implica em melhor resolução. No entanto, maiores distâncias de trabalho proporcionam maiores profundidades de campo. A resolução que se pode obter com o microscópio eletrônico de varredura depende do tamanho da zona de onde vem o sinal utilizado para formar a imagem. A resolução será determinada pelo diâmetro a partir do qual o sinal será emitido, seja de elétrons secundários (SE), elétrons retroespalhados (BSE) ou raios $X$ utilizados para formar a imagem, não sendo possível observar detalhes de tamanho inferior a este diâmetro.

Segundo as relações entre distância de trabalho e resolução, o modo automático do equipamento foi acionado para todos os resultados apresentados neste trabalho, assim a distância de trabalho foi mantida constante $(10 \mathrm{~mm})$ e as energias de aquisição das imagens variaram entre 5 kV e $15 \mathrm{kV}$, para a ampliaçãorequerida. Como o número máximo de fótons em uma dada energia é produzido por tensão de aceleração 2,5 vezes superior à energia dos fótons, as tensões utilizadas são capazes de gerar fótons de $2 \mathrm{keV}$ a $6 \mathrm{keV}$. Vale ressaltar a importância de tensão de aceleração utilizada sendo 
esta capaz de abranger elementos de interesse carbono, oxigênio, zinco e para as amostras após corrosão: carbono, oxigênio, zinco, cloro e sódio.

4.3.4. Caracterização química por difração de raios $X-D R X$.

A análise da superfície por difração de raios $X(D R X)$ foi realizada comvariação de ângulo de difração $\theta$ (20 $\left(20^{\circ}\right.$ a $\left.60^{\circ}\right)$, com fonte de raḑã̃o $\operatorname{CuK}_{a}(\lambda=1,5405 \AA)$ e $1^{\circ}$ de ângulo de incidência. Os resultados de DRX permitiram identificar os compostos presentes na superfície servindo como análise complementarà análise por EDS e XPS, para amostras antes e depois de corrosão.

4.3.5. Caracterização química por espectroscopia fotoeletrônica de raios $X-$ XPS.

As medidas de XPS foram realizadas utilizando o espectrofotômetro mostrado na Fig.10. O equipamento é equipado com duas câmaras (ânodo e monocromador). Os espectros XPS foram adquiridos utilizando fonte de raios $X$ AlK $_{\alpha}$ monocromada ( $\mathrm{hv}=1486,6 \mathrm{eV}$ ) e resolழ̧ão e spacial de $400 \mu \mathrm{m}$ de raio. Via de regra, todos os espectros foramreferenciados ao pico C1s em $285 \mathrm{eV}$, para correção da aquisição. As análises químicas são quantificadas após remoção da linha de base (Background / Shirley). O software Advantage com fatores de correção foi utilizado (Ferreira Jr., 2017). 


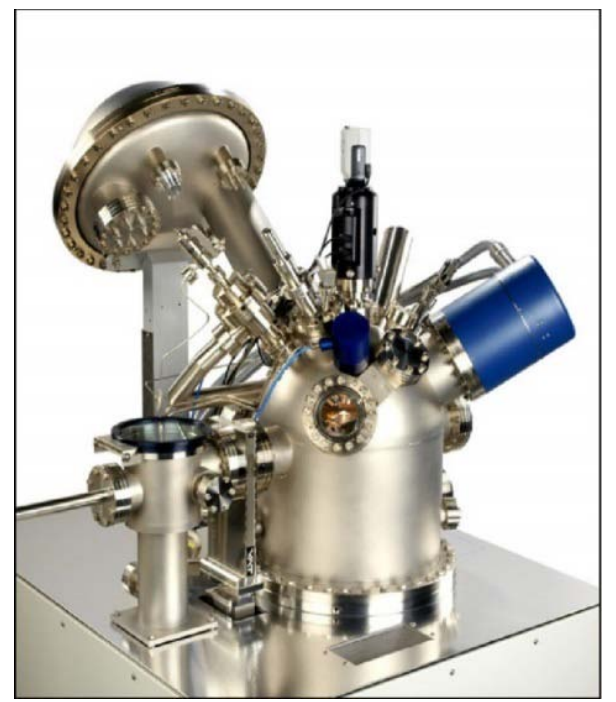

Figura 10: Espectroscópio fotoeletrônico de raios $\mathrm{X}$ usado no presente trabalho. Fonte University of Surrey UK.

Geralmente a aquisição de dados de XPS tem início com a obtenção de um espectro (snapshot) para carbono (C1s), de baixa intensidade energética e de rápida interação, em algum caso menor que um segundo. Este espectro possibilita avaliar se a superfície é isolante ou condutora proporcionalizando a adoção de parâmetros adequados para análises mais eficientes. É muito comum manter a aquisição contínua de espectro para C1s e, assim, fazer ajustes nos parâmetros de aquisição, até que picos estreitos, com maior número possível de contagens e com o centro mais próximo de 285 eV, sejam obtidos para o elemento carbono. Estes ajustes podem ser feitos usando software Flood Gun e ajuste de outros tantos parâmetros destecanhão de íons. A série de espectros, Fig. 11, com intervalo de 30 s entre cada espectro ilustra como o uso do Flood Gun e ajustes de parâmetros possibilitam a obtenção de espectros de maior qualidade. Os resultados mostrados na Fig. 11são ilustrativos e foram obtidos para pó de ácido oxálico padrão. 


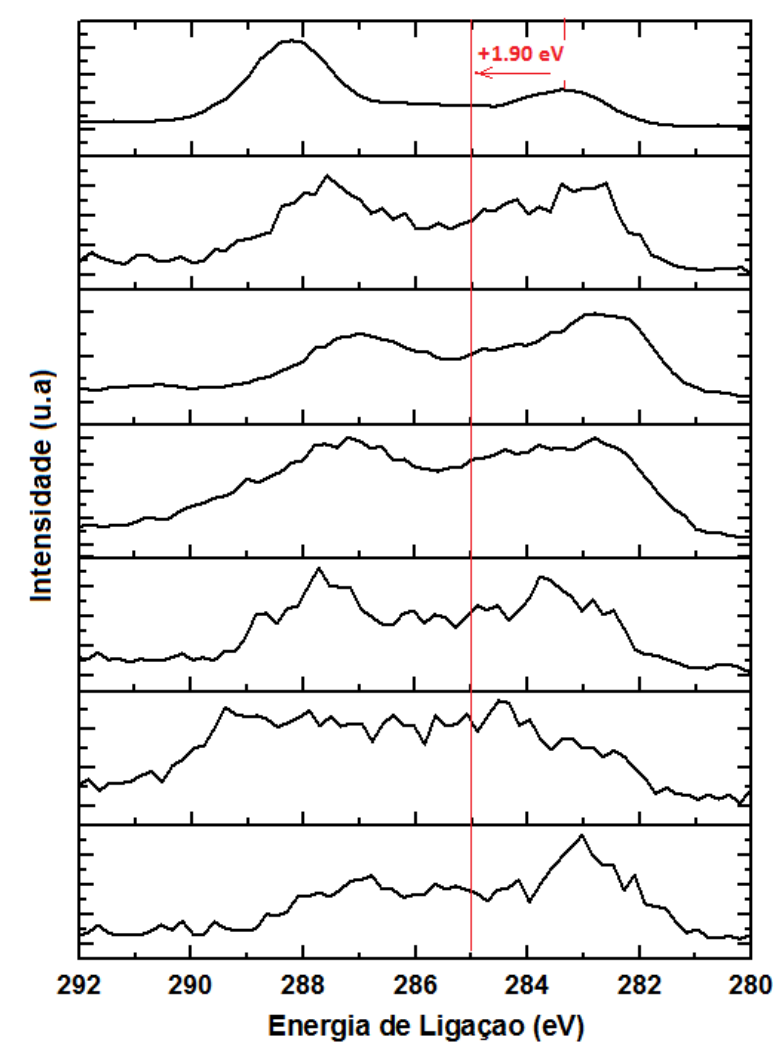

Figura 11: Série de espectros obtidos com intervalo de 30s entre cada espectro. Nesta figura, o tempo aumenta do espectro inferior para o superior (adaptado de Ferreira Jr., 2017).

A linha em vermelho, vide Fig. 11, mostra a posição do pico (285 eV) ajustada para o carbono e demais espécies presentes, pela adição de 1,90 eV. Os ajustes possibilitam a aquisição de espectros XPS com boa resolução. O passo experimental seguinte é a aquisição de espectro Survey e, em seguida, podem ser obtidos os espectros de alta resolução para as espécies de interesse encontradas. Na Fig.12é possível observar o espectro Survey para amostra de oxalato de zinco em pó padrão.

A Fig. 13 mostra um espectro do oxalato de zinco utilizado como padrão de comparação com os resultados obtidos das superfícies analisadas. Este espectro e os demais espectros Survey deste trabalho foram obtidos a partir de 3espectros experimentais com passo de energia de $300 \mathrm{eV}$, área de análise de $400 \mu \mathrm{m}$, tamanho dos passos de energia de $0,400 \mathrm{eV}$ e número total de passos de 3401. Após a obtenção dos espectros Survey os experimentos seguintes consistiram na obtenção de espectros de alta resolução para os elementos de interesse, neste caso, O1s e C1s. Figura 13(a) e 13(b) mostram, 
respectivamente, os espectros de alta resolução C1s e 01s para amostra de ácido oxálico padrão em pó.

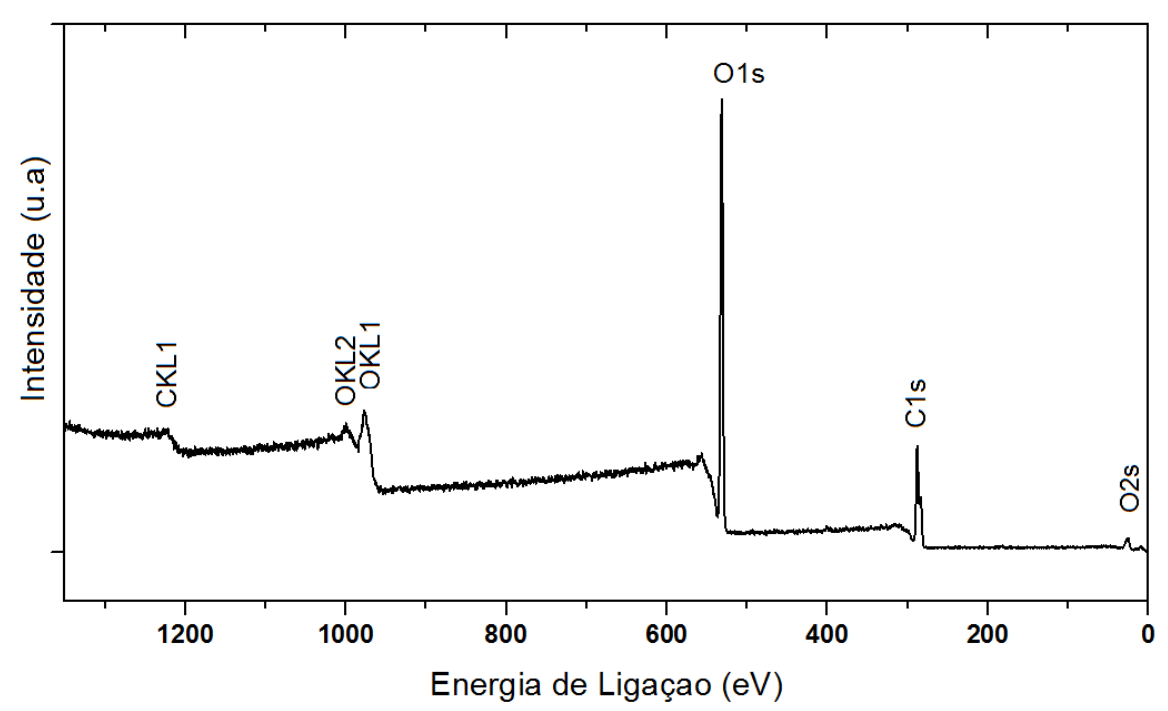

Figura 12: Espectro XPS Survey para amostra de oxalato de zinco em pó padrão (adaptado de Ferreira Jr., 2017).

É comum observar o pico oxigênio O1s centrado na energia de ligação $532 \mathrm{eV}$ em caso de amostras isolantes. Assim sendo, o posicionamento do pico de carbono C1s em 285 eV e a do oxigênio em 532 eV são indicativos de, que os parâmetros usados para aquisição e ajustes dos resultados foi correta (Ferreira Jr., 2017).
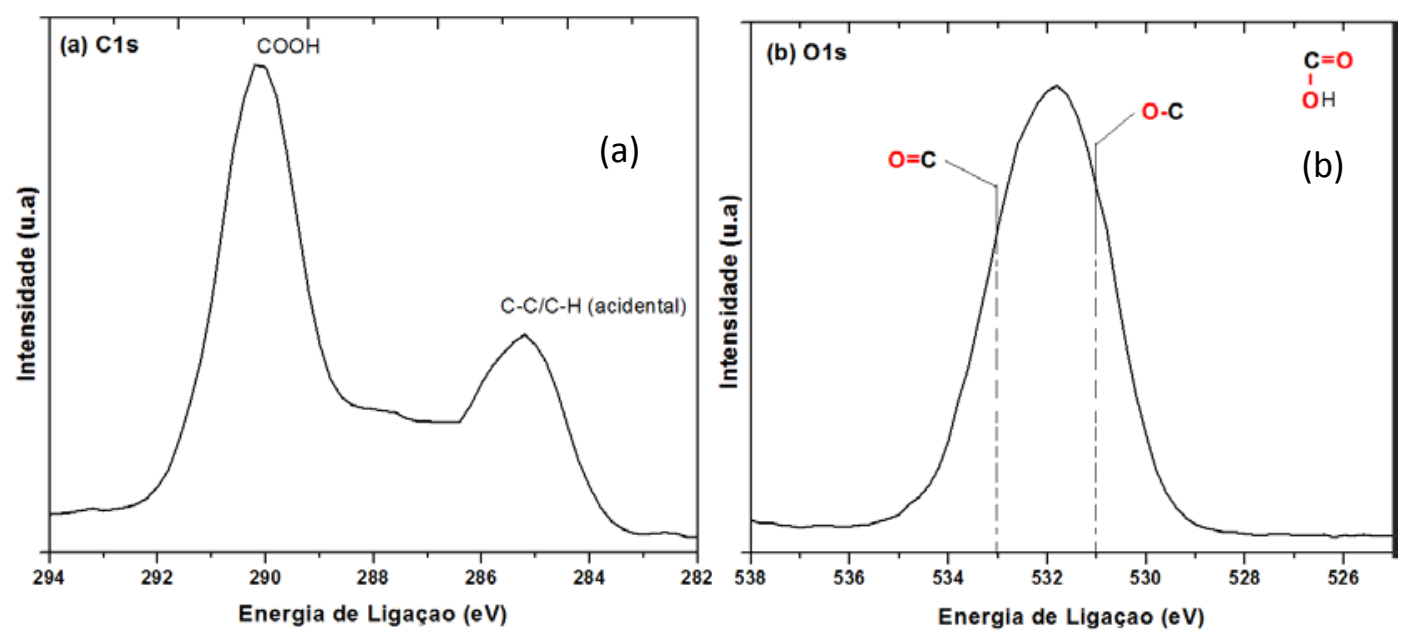

Figura 13: Espectros XPS de alta resolução de carbono (a) C1s e oxigênio (b) O1s obtidos a partir de amostra de ácido oxálico em pó (padrão analítico), (adaptado de Ferreira Jr, 2017). 
Os espectros XPS de alta resolução C1s e O1s e os demais espectros de alta resolução para C1s e O1s, deste trabalho, foram obtidos a partir de 30 espectros com passo de energia de $50 \mathrm{eV}$, área de análise de $400 \mu \mathrm{m}$ e tamanho dos passos de energia de $0,20 \mathrm{eV}$. O intuito ao apresentar estes picos de XPS de alta resolução foi introduzir particularidades desta técnica, que auxiliem na leitura e entendimento do presente trabalho.

Como observado no espectro XPS de alta resolução para carbono C1s, Fig. 13, são evidentes dois picos principais, o primeiro em 285,0 eV e o segundo localizado em 290,1 eV. Estes picos são referenciados como representativos de contaminantes e grupos carboxílicos, respectivamente. A presença de contaminantes e carbono alifático pode causar uma sobreposição de picos em uma mesma estrutura química (Barr, 1995). Esta sobreposição pode ser evitada e a diferenciação apontar para uma resposta satisfatória com a adoção de um valor específico, nos ajustes do pico, para os carbonos alifáticos não contaminantes ou carbono beta, usualmente descrito como carbono ligado ao grupo funcional e posicionado em 285,5 eV. A ausência de carbono alifático deixa apenas a possibilidade do pico em 285 eV representar carbono beta mais carbono de contaminação.

A maioria das superfícies metálicas expostas ao ar apresentam uma camada fina de material carbonáceo conhecido como carbono acidental ou adventício. Mesmo com cuidados extremos de obtenção (síntese) e manipulação, pequenas exposições à atmosfera são suficientes para produzir esses filmes. A constituição química deste carbono passa por uma variedade de espécies de hidrocarbonetos, algumas com funcionalidades de oxigênio com ligações simples e duplas (Castle, 1981). As possíveis fontes deste carbono são discutíveis, com algumas evidências de espécies $\mathrm{CO}$ ou $\mathrm{CO}_{2}$ adsorvidas, as quais podem desempenhar papel no surgimento gradual do carbono em superfícies no vácuo da câmara do espectrômetro XPS. A presença destas espécies em superfícies isolantes proporciona uma referência de carga, estabelecendo a linha principal do espectro C 1s para 285 eV (WILD, U.; PFÄNDER, N.; SCHLÖGL, R).

O pico XPS de alta resolução de zinco é de difícil decomposição e a 
diferenciação química ( $\mathrm{ZnO}, \mathrm{ZnCl}_{2}, \mathrm{Zn}(\mathrm{OH})_{2}$ etc.) só é possível com a aquisição de pico de zinco Auger Zn LMM. As linhas de energia de ligação (eixo $x$ ) e de energia cinética (eixo y) obtidos a partir dos picos de alta resolução Zn2p3/2, e Zn L3M45M45são complementares e apenas com os dois resultados compilados, na forma de Wagner Plot, apresentados na Fig. 14, é que se obtém diferenciação química confiável para o zinco (Moretti, 1998).

$\mathrm{Na}$ Fig. 14 é possível observar o gráfico de Wagner Plot onde as energias cinética e de ligação são correlacionadas para obtenção de uma diferenciação entre espécies químicas que contêm zinco. Neste caso, foram listados os compostos que contêm zincoe que são possíveis no presente trabalho, a saber $\left(\mathrm{Zn}, \mathrm{ZnO}, \mathrm{Zn}(\mathrm{OH})_{2}, \mathrm{ZnCO}_{3}, \mathrm{ZnCl}_{2}, \mathrm{Zn}_{5}\left(\mathrm{CO}_{3}\right)_{2}(\mathrm{OH})_{6}\right.$ e $\left.\mathrm{Zn}\left(\mathrm{CH}_{3} \mathrm{C}(\mathrm{O}) \mathrm{CHC}(\mathrm{O}) \mathrm{CH}_{3}\right)_{2}\right)$. Diante destas condições é possível obter resultados confiáveis, reprodutíveis, que podem ser interpretados e traduzidos em composição superficial por análise XPS.

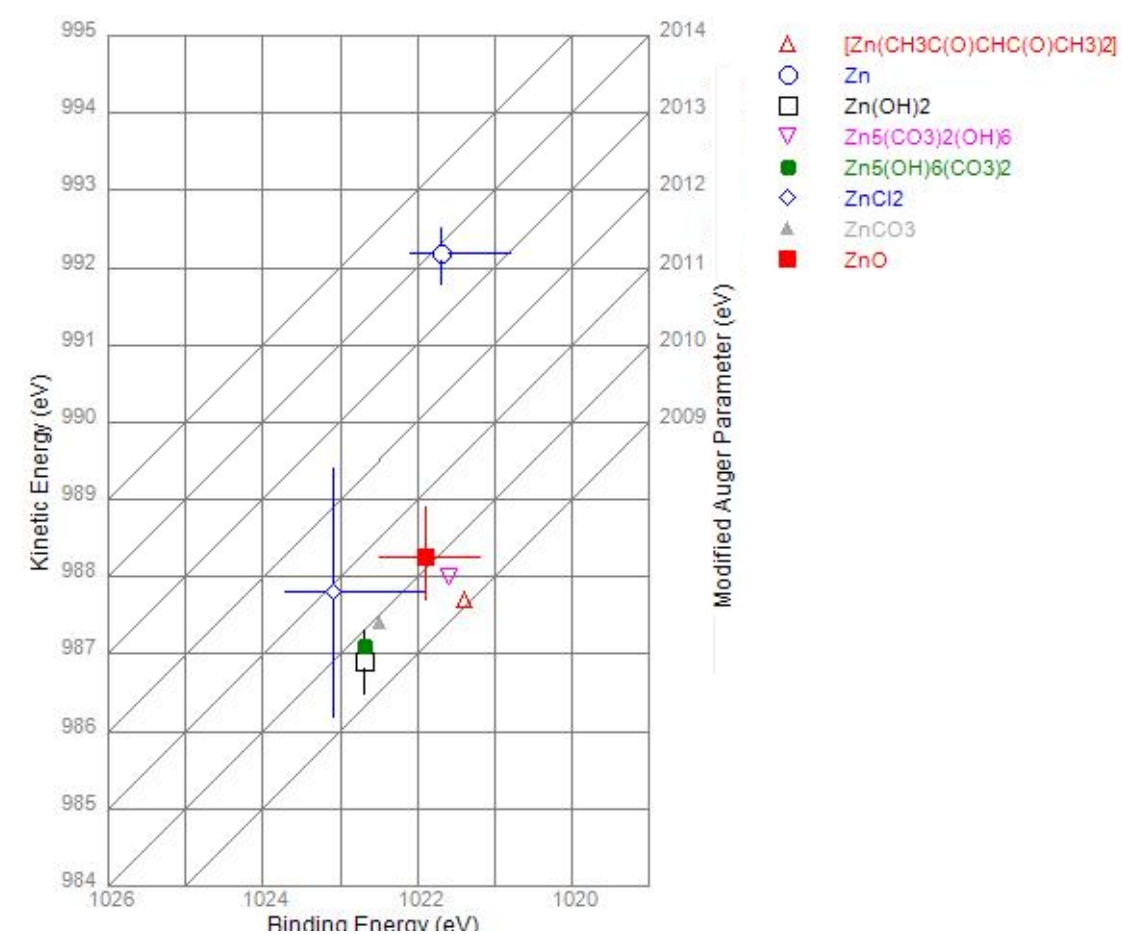

Figura 14: Gráfico de Wagnerde energias de ligação, energias cinéticas Auger e parâmetros Auger modificados para materiais que contêm Zn (linha fotoeletrônica principal: 2p3/2; linha de elétron Auger principal: L3M45M45).(NIST, X. ray Photoelectron Spectroscopy Database, version 3.4 https://srdata.nist.gov/xps/WagnerPlot.aspx) 
Superfície é suficiente para permitir moléculas grandes e não voláteis, com massas até $10.000 \mathrm{amu}$, escaparem sem ou com pouca fragmentação. As partículas emitidas são originárias das duas ou mais monocamadas (Tervahattu, 2002). Esta técnica permite atingir limites de detecção da ordem de 100 partes por bilhão e resolução lateral de $100 \mathrm{~nm}$ a $1 \mathrm{~mm}$.

\subsubsection{Caracterização morfológica e de espessura.}

O sistema de feixe de íons focalizado FIB (do inglês focused ion beam) é muito similar ao do microscópio eletrônico de varredura, com a diferença do uso de feixe de íons $\mathrm{Ga}^{+}$ao invés de feixe de elétrons, caso do MEV.Neste trabalho, ensaios FIB foram realizados em um sistema composto por um microscópio eletrônico de varredura de emissão de campo de alta resolução e uma coluna de feixe de íons de gálio, mostrado na Fig. 16. Esteequipamento usa feixe de íons $\mathrm{Ga}^{+}$com energia de 5-30 keV e uma corrente de sonda de 1 pA-20 nA. Esta técnica foi utilizada para análises das amostras de zinco tratadas em solução de ácido oxálico, antes e após ensaios de corrosão por exposição àsolução $10^{-1} \mathrm{M}$ de cloreto de sódio.

A resolução de feixe iônico $\mathrm{Ga}^{+}$é de $7 \mathrm{~nm}$ com uma corrente de feixe de 1 pA e uma tensão de aceleração fixa de $30 \mathrm{keV}$. O conjunto óptico eletrônico consiste em uma coluna de FEG-SEM (emissão de campo de alta resolução).

Procedimentos utilizados nas imagens por microscopia eletrônica de varredura foram obtidas utilizando-se elétrons secundários e elétrons retroespalhados (Back Scattering Electron Detector - BSED). No caso de elétrons secundários o contraste é devido principalmente ao relevo e no caso de elétrons retro-espalhados é devido à composição, ou seja, quanto maior o número atômico do elemento mais clara é a imagem. Nos espectros obtidos com o espectrômetro por dispersão de energia de raios-X (EDS) a quantificação de todos os elementos presentes foi feita na condição "Standardless".

Equipamento utilizado: Microscopio Eletrônico de Varredura Dual Beam (emissão por efeito de campo - FEG), marca FEI, modelo QUANTA 3D FEG, 
com Espectrômetro por Dispersão de Energia de Raios-X (EDS).

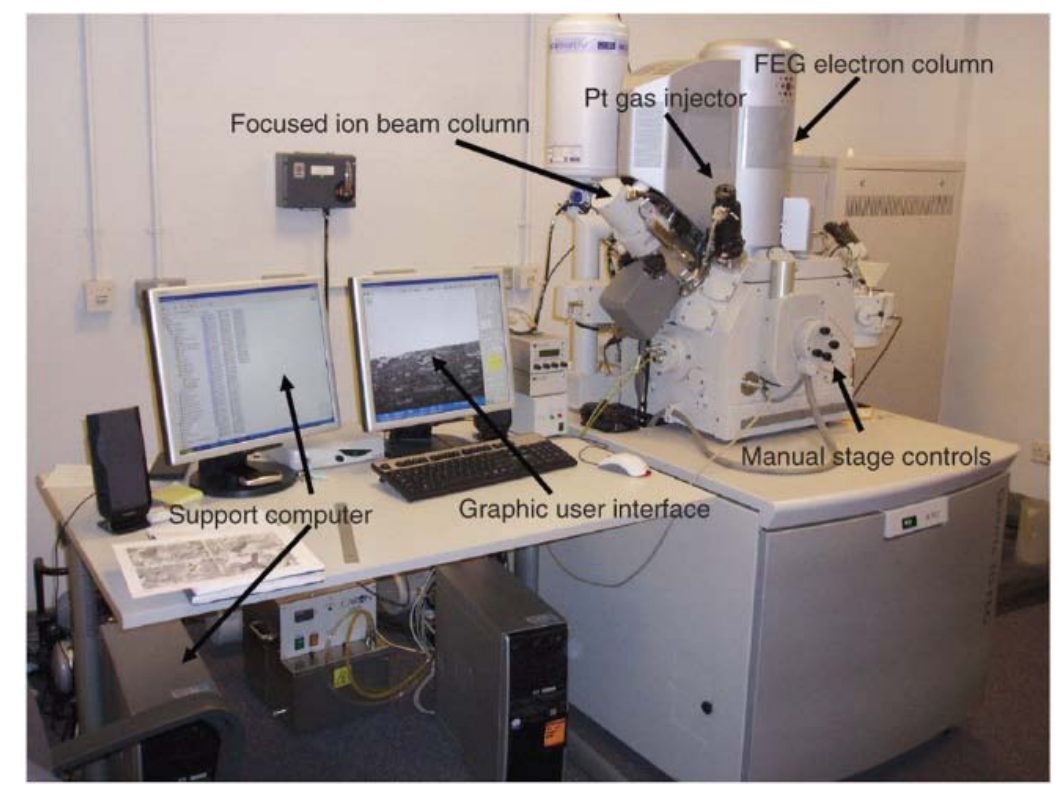

Figura 15: Equipamento FIB utilizado para o presente trabalho, com a descrição e disposição dos componentes. Fonte do Centro de Tecnologia em Metalurgia e Materiais do IPT.

4.3.7. O Instrumento de feixe de íons focados (FIB).

A grande distância de trabalho $(1,5-2 \mathrm{~cm})$ permite a introdução de amostras com topografia variada sem preocupação com variações de campo O estágio da amostra geralmente possui a capacidade de fornecer movimento de 5 eixos ( $X, Y, Z$, rotação e inclinação). O bombardeamento de espécies carregadas na superfície de um isolador pode causar o carregamento da amostra este método de redução de carga, para a base da espécie de revestimento da amostra com os elentros ( $C, W, P t, A u, C r$, etc.) Usa-se de uma arma de inundação de elétrons Imaging ou fresamento com coluna SEM ativada no sistema de plataforma dupla no sistema de feixe de íons focalizado FIB, um sistema de feixe duplo permite que a preparação, imagem e análise da amostra sejam realizadas em uma única ferramenta. O feixe de íons e o feixe de elétrons se complementam em redução de carga, deposições de proteção e informações de imagem. O feixe de elétrons pode ser usado para monitorar a fresagem do feixe de íons até o ponto final precisamente na característica de interesse. O feixe duplo oferece uma flexibilidade inigualável em 3D estrutural análise. A configuração típica da coluna de feixe duplo é uma coluna de 
elétrons vertical com uma coluna de íons inclinada. Neste caso, a amostra será inclinada para 52 graus para moagem normal para a superfície da amostra, conforme figura 16.

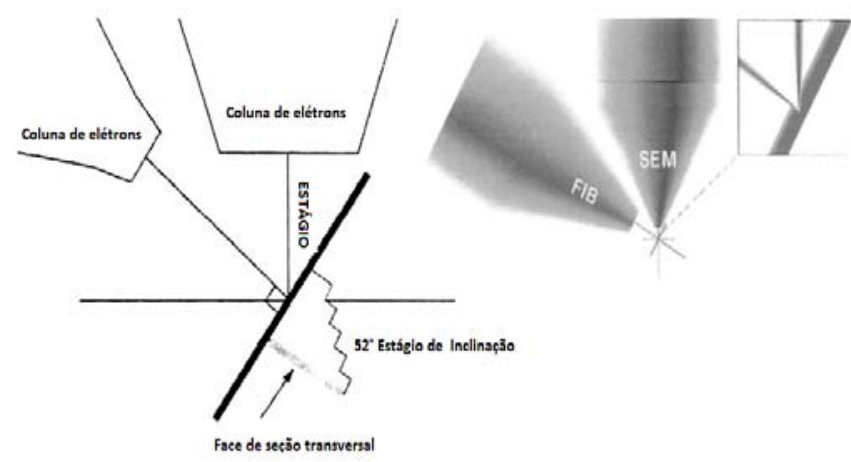

Figura 16: A configuração típica da coluna de feixe duplo é uma coluna de elétrons vertical com uma coluna de íons inclinada. Neste caso, a amostra será inclinada para 52 graus para moagem normal para a superfície da amostra. Fonte Centro de Tecnologia em Metalurgia e Materiais do IPT.

O feixe de elétrons pode ser usado para imagens sem preocupação de pulverização catódica da superfície da amostra. A deposição de materiais de feixes de elétrons pode ser usada para produzir deposição de energia muito baixa que não afetará a superfície subjacente de interesse tão dramaticamente quanto a deposição assistida por feixe de íons. A imagem não destrutiva da amostra pode ser realizada com um SEM integrado. Periféricos adicionais como EDS e EBSD podem ser usados para informações elementares ou cristalográficas.

\subsubsection{Interacão íons-sólido (Sputtering).}

Um diagrama esquemático abaixo na figura 16 B ilustra algumas das possíveis interações do material do feixe de íons que podem resultar do bombardeamento de íons de um sólido. O fresamento ocorre como resultado da pulverização física do alvo. A capacidade de moinho, imagem e depósito de material usando um instrumento FIB, depende criticamente da natureza do 
feixe de íons - Interações sólidas quando o feixe atinge a superfície da amostra, muitas espécies são geradas, incluindo átomos e moléculas pulverizadas, de elétrons secundários e íons secundários

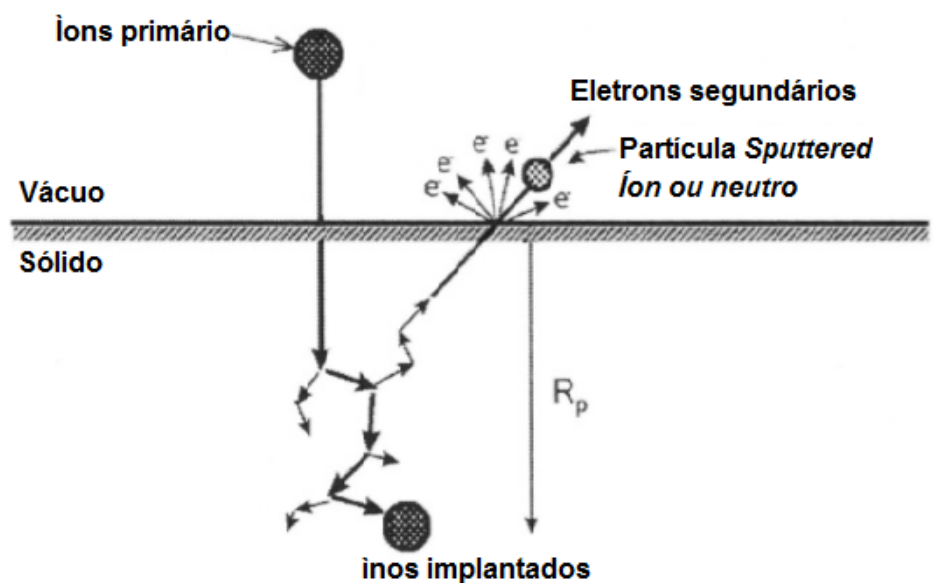

Figura 16.A: Sputtering ocorre como resultado de uma série de colisões elásticas onde o momento é transferido dos íons incidentes para os átomos alvo dentro de uma região em cascata de colisão.

4.3.9. Gases FIB para deposição e gravação avançada.

Os sistemas de entrega de gás podem ser usados em conjunto com o feixe de íons para produzir deposição específica de metais ou isoladores específicos do local ou para proporcionar capacidades de gravura melhoradas. Conforme as moléculas de gás são adsorvidas na superfície nas proximidades do gás de entrada, mas, decompo-se apenas onde o feixe de íons atinge. A adsorção repetida e a decomposição resultam no acúmulo de material na região explorada por íons. Os precursores químicos são obtidos a partir de uma fonte de gás, líquido e/ou sólido que pode ser aquecida se necessário para produzir o pressurizador de vapor desejado. A figura $16 \mathrm{C}$, abaixo mostra a relação espacial da fonte de gás, o feixe de íons focado, a superfície da amostra e as espécies volatilizadas e pulverizadas. 


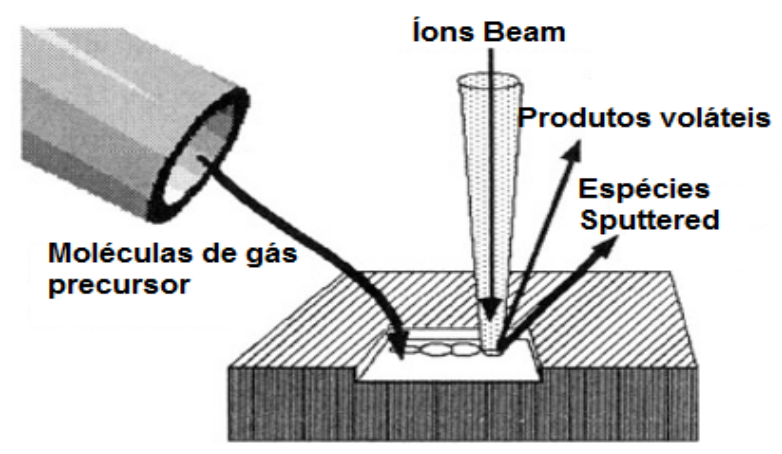

Figura 16.B o desenho esquemático mostra o princípio da deposição / remoção de material controlado. O processo de ataque avançado é mostrado. Se o gás adsorvido se decompõe a produtos não voláteis, a deposição ocorrerá.

4.3.10. Caracterização da resistência à corrosão por ensaio em câmara de névoa salina (ASTM B117).

O ensaio em câmara de névoa salina ASTM B117 (2016) é um ensaioacelerado de corrosão que proporciona um ambiente corrosivo controlado na forma de uma névoa de solução $5 \%$ (massa) de cloreto de sódio. Este ensaio é utilizado para produzir informações relativas à resistência à corrosão de amostrasde metais ou metais com revestimentos orgânicos expostos em câmara de ensaio fechada em que ocorre pulverização contínua da névoa salina que preenche a câmara. A previsão de desempenho em ambientes naturais raramente tem sido correlacionada com os resultados de pulverização salina quando usados como dados isolados (Y. Wan 2012). Apesar disso, esse é um dos ensaios mais aceitos pelas indústrias na avaliação de resistência à corrosão das superfícies.

A reprodutibilidade dos resultados de exposição em câmara de névoa salina é altamente dependente do tipo de amostras e dos critérios de avaliação selecionados, bem como do controle das variáveis operacionais. Em qualquer programa de ensaios, devem ser incluídas repetições suficientes para estabelecer a variabilidade dos resultados. Os ensaios foram realizados em uma câmara de névoa salinamostrada na Fig. 17. 


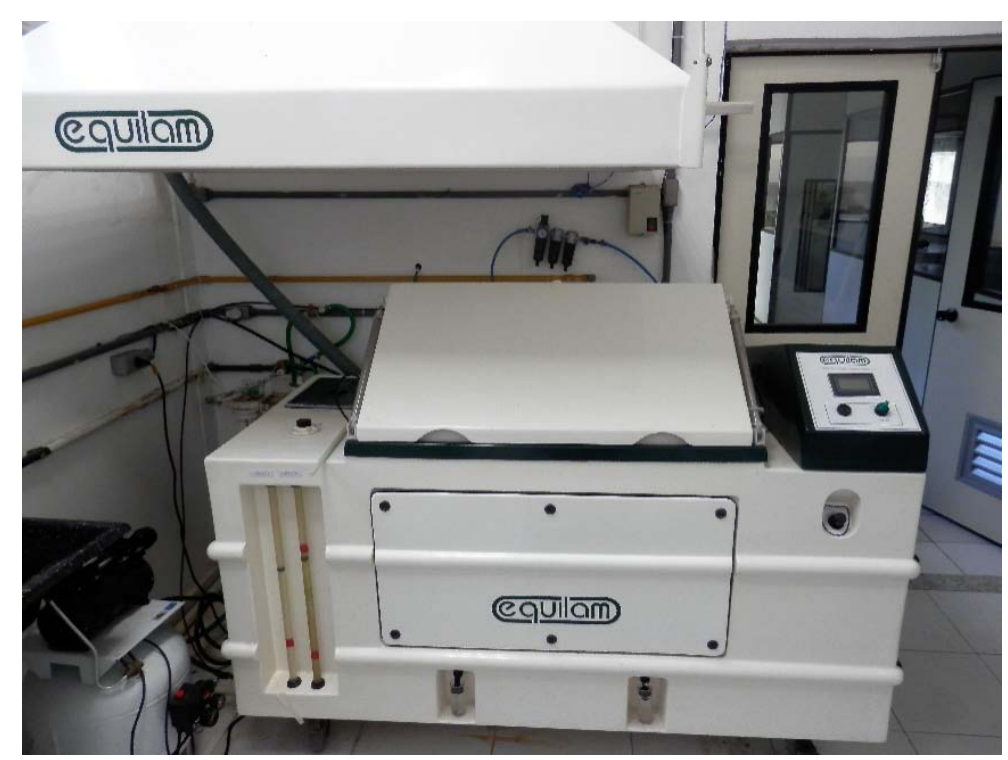

Figura 17: Câmara de névoa salina usada neste estudo. Fonte laboratório de corrosão CCTM IPEN.

O ensaio em câmara de névoa salina foi utilizado como método de avaliação preliminar para selecionar condições de tratamento com potencial para produzir revestimentos com proteção adequada contra a corrosão do substrato de zinco. Apenas os tratamentos que resultassem em superfícies que, deveriam ser continuados para caracterização da camada superficial formada uma vez que várias das técnicas de análise adotadas na caracterização são de custo elevado. As dimensões adotadas dos corpos de prova são $10 \times 5.0 \times 0.01 \mathrm{~cm}$. As bordas foram protegidas com fita, para evitar corrosão de bordas, ainda as peças foram dispostas na câmara sobre um suporte universal de polietileno com fenta de $3.0 \mathrm{~mm}$ e espaçamento de 35 $\mathrm{mm}$, horizontalmente na câmera fechada.

4.3.11. Caracterização eletroquímica da resistência à corrosão por espectroscopia de impedância eletroquímica (EIS).

Os dados de EIS foram adquiridos no modo potenciostático, no potencial de circuito aberto (OCP), utilizando um potenciostato BIOLOGIC mostrado Fig. 18, controlado pelo software EC-Lab V23.10. Foram realizados 5 (cinco) ensaio um após o outro em amostras diferentes de EIS, para cada uma condição testada de forma a avaliar a reprodutibilidade dos resultados. 


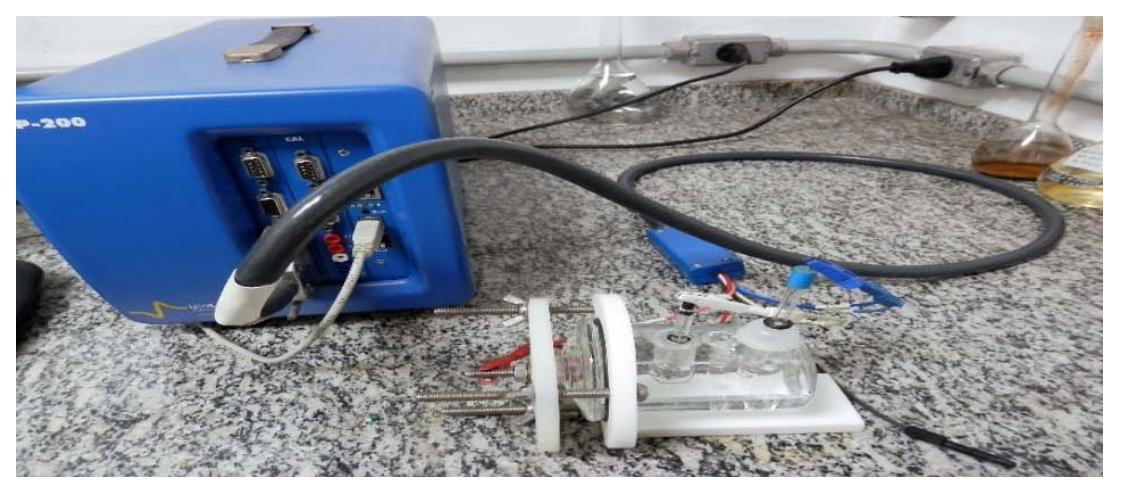

Figura 18: Potenciostato e célula eletroquímica usados nos ensaios eletroquímicos deste estudo. Fonte Laboratório de Corrosao CCTM IPEN

O arranjo experimental utilizado para caracterização eletroquímica consistiude uma célula de três eletrodos, com um fio de platina como eletrodo auxiliar que consistiu deeletrodo de referência de $\mathrm{Ag} / \mathrm{AgCl}, \mathrm{KCl}_{\text {sat }}$ e o material de estudo ( $\mathrm{Zn}$ como recebido e com os vários tratamentos estudados) como eletrodo de trabalho. A área do trabalho do eletrodo expostas ao eletrólito foi de $1 \mathrm{~cm}^{2}$. $\mathrm{O}$ eletrólito utilizado nos ensaios eletroquímicos foi uma solução $10^{-1} \mathrm{M}$ de $\mathrm{NaCl}$, naturalmente aerada e em repouso, a $22 \pm 3{ }^{\circ} \mathrm{C}$. O comportamento eletroquímico das superfícies testadas foi monitorado por ensaio de espectroscopia de impedância eletroquímica (EIS) realizado na faixa de frequências de $100 \mathrm{kHz}$ a $10 \mathrm{mHz}$, com uma perturbação de amplitude de sinal de $10 \mathrm{mV}$ e taxa de aquisição de dados de 10 pontos por década. O período de duração do ensaio de EIS foi de 7 dias. As medidas de potencial de circuito aberto foram realizadas antes do ensaio de EIS para garantir o tempo de estacionaridade do sistema e, dessa forma, validar as medidas de espectroscopia de impedância eletroquímica. 


\section{RESULTADOS E DISCUSSÃO}

Nesta sessão são discutidos os ensaios de exposição em câmara de névoa salina, a caracterização eletroquímica das superfícies de zinco como recebido e com tratamentos em solução de ácido oxálico, a caracterização química da superfície de zinco após tratamento em ácido oxálico, por difração de raios $X$ e após ensaio de corrosão, a caracterização da morfologia da superfície do zinco tratada em solução de ácido oxálico e exposta a ensaio de corrosão, a caracterização da morfologia das superfícies tratadas e sem tratamento e a caracterização química da superfície de zinco após tratamento em solução com oxálico por XPS e após ensaios de corrosão. 
5.1. Ensaios preliminares de corrosão por exposição em câmara de névoa salina.

De forma a realizar uma pré-seleção de condições para investigação e caracterização detalhadas, considerando que as técnicas de caracterização correspondem a análises de alto custo, foram realizados ensaios em câmara de névoa salina, segundo norma ASTM B117, para todas as amostras com tratamentos em soluções com $10^{-3} \mathrm{M}, 10^{-2} \mathrm{M}, 10^{-1} \mathrm{M}, 3 \times 10^{-1} \mathrm{M}, 6 \times 10^{-1} \mathrm{M}, 9 \times 10^{-1} 1$ $M$ de ácido oxálico e também em amostras como recebidas, para efeito de comparação. Os ensaios foram realizados em amostras com e sem revestimento de verniz poliuretano alto brilho 7100, aplicado sobre o processo de dip coude, tempo de imerção de 2 min, cujo objetivo de aplicação foi o de investigar a interação entre a camada formada em ácido oxálico e o revestimento de verniz, este último nas condições sem e com risco para exposição do substrato de dimensões. $10 \times 5.0 \times 0.01 \mathrm{~cm}$, as bordas protegidas com fita adesivas impermeáveis, para evitar corrosão de borda, conforme norma ABNT NBR 11003, Tintas — Determinação da aderência.

O efeito do tratamento em solução de ácido oxálico com $10^{-1} \mathrm{M}$ e $1 \mathrm{M}$ resultando em superfícies com menor quantidade de produtos de corrosão é indicado até $24 \mathrm{~h}$, porém, para $72 \mathrm{~h}$ de ensaio, o efeito de proteção contra a corrosão da camada formada é apenas indicado para o tratamento com $10^{-1} \mathrm{M}$ de ácido oxálico. Para este período de ensaio, a quantidade de produtos é maior para a amostra tratada em solução com $1 \mathrm{M}$ de ácido oxálico do que da superfície sem tratamento, ou, como recebida (Zn). Este comportamento é confirmado para $120 \mathrm{~h}$ de exposição em câmara de névoa salina e, somente após $172 \mathrm{~h}$ de ensaio foram observados produtos de corrosão volumosos sobre a superfície tratada com $10^{-1} \mathrm{M}$ de ácido oxálico, vide Figs. 19 e 20. 


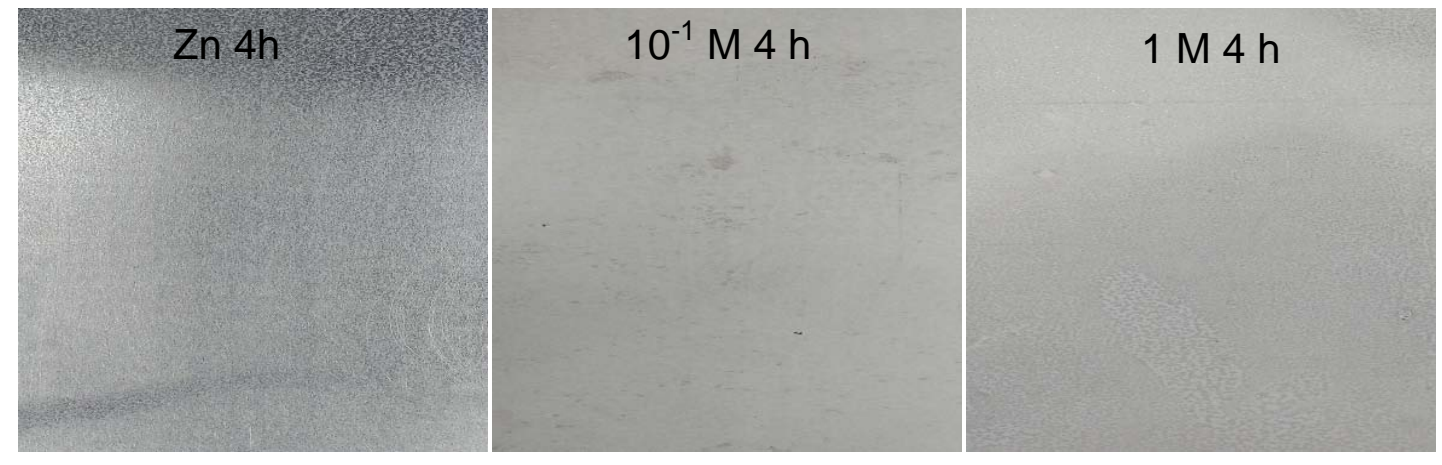

$10^{-1}-\mathrm{M} 24 \mathrm{~h}$

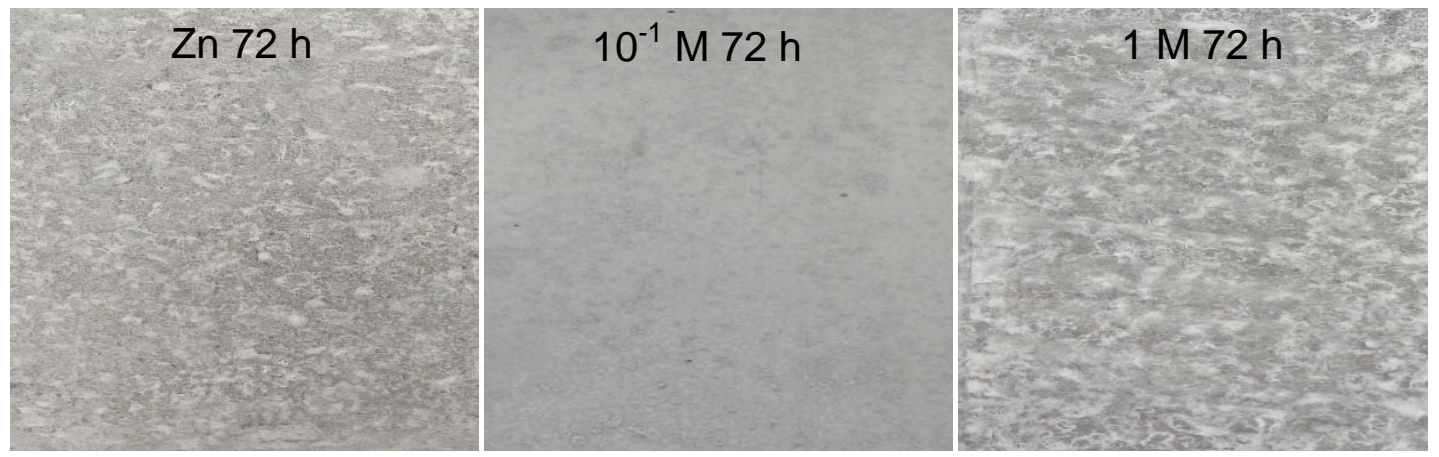

Figura 19: Superfície das amostras de zinco, como recebida (Zn) ou tratadas em solução com $10^{-1} \mathrm{M}$ ou com $10 \mathrm{M}$ após diferentestempos de exposição (4h, $24 \mathrm{~h}$ e 72 h) em câmara de névoa salina (ASTM B117).

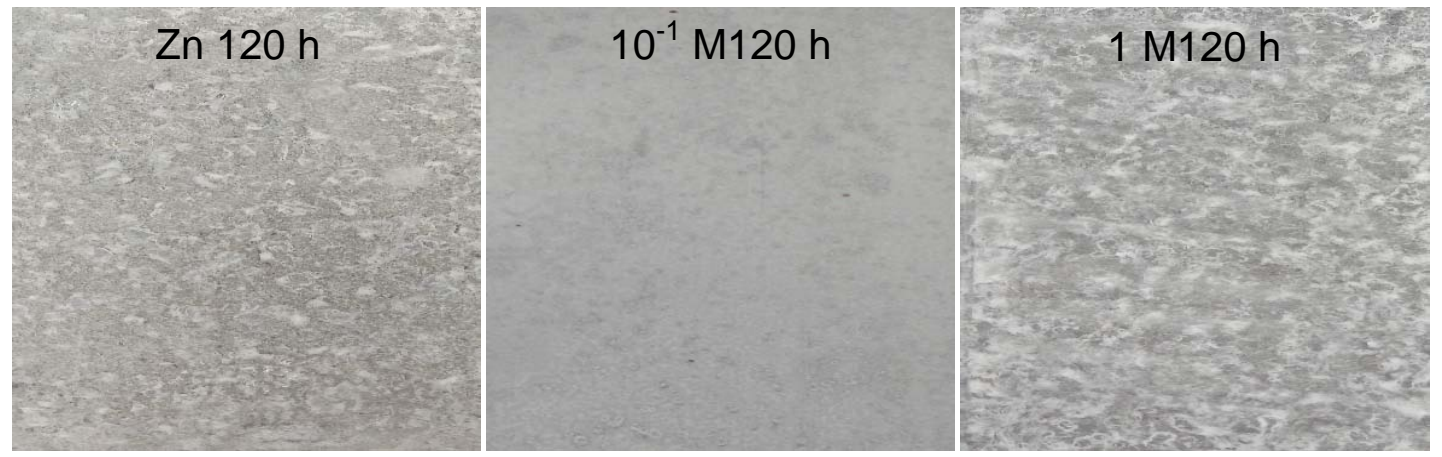




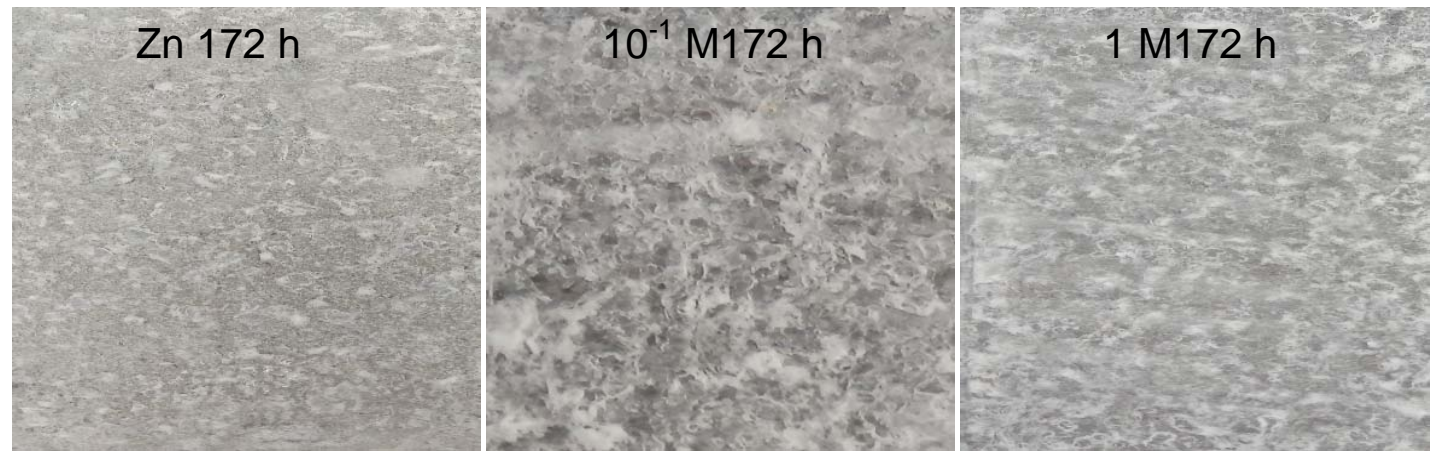

Figura 20: Superfície das amostras de zinco, como recebida $(\mathrm{Zn})$ ou tratadas em solução com $10^{-1} \mathrm{M}$ ou com $1 \mathrm{M}$ de ácido oxálico após diferentestempos de exposição (120 h e 172 h) em câmara de névoa salina (ASTM B117).

As Figuras. 23 e 24 mostram a superfície das amostras como recebidas (Zn) ou tratadas em solução com $10^{-1} \mathrm{M}$ ou $1 \mathrm{M}$ e recobertas com verniz, sem ou com risco para exposição segunda norma ASTM B117, do substrato metálico, após vários tempos de exposição ao ensaio em câmara de névoa salina.
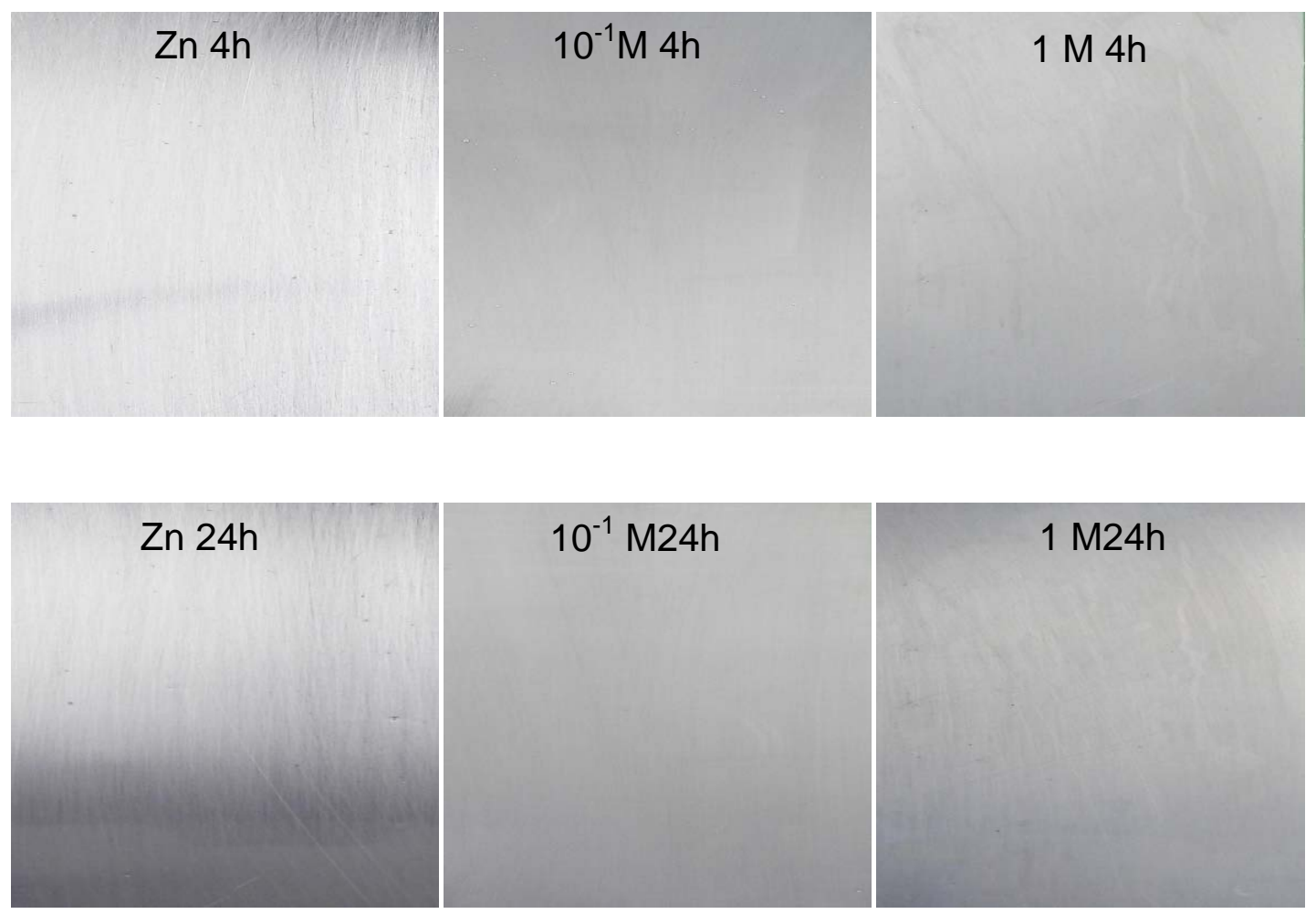

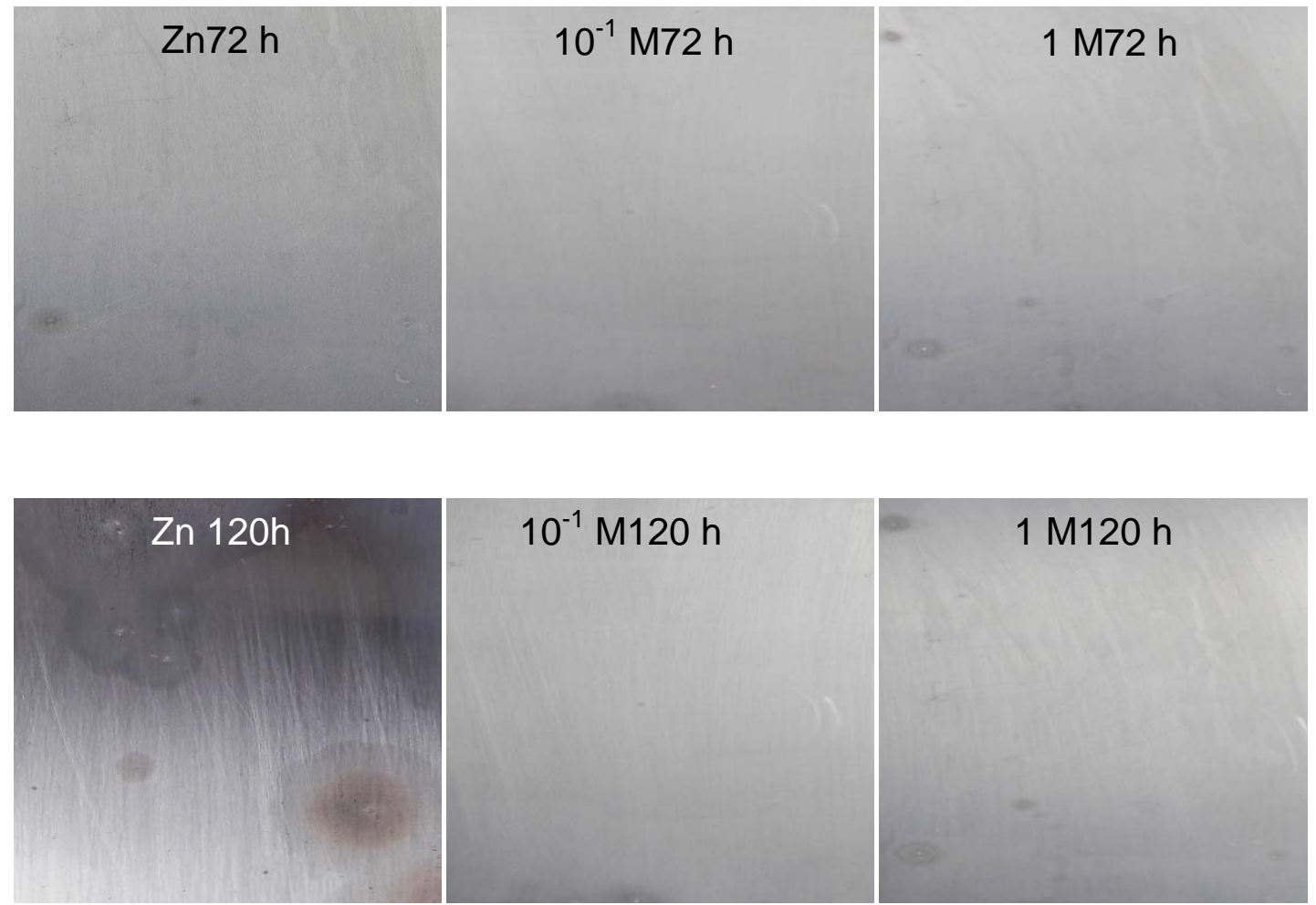

Figura 21: Superfície das amostras de zinco, como recebida ( $Z n)$ ou tratadas em solução com $10^{-1} \mathrm{M}$ ou com $1 \mathrm{M}$ de ácido oxálico e com verniz após vários tempos de exposição ( 4 h, 24h, 72h e 120 h) a ensaio de névoa salina (ASTM B117) e as amostra que tem risco na seção 23 e 24.

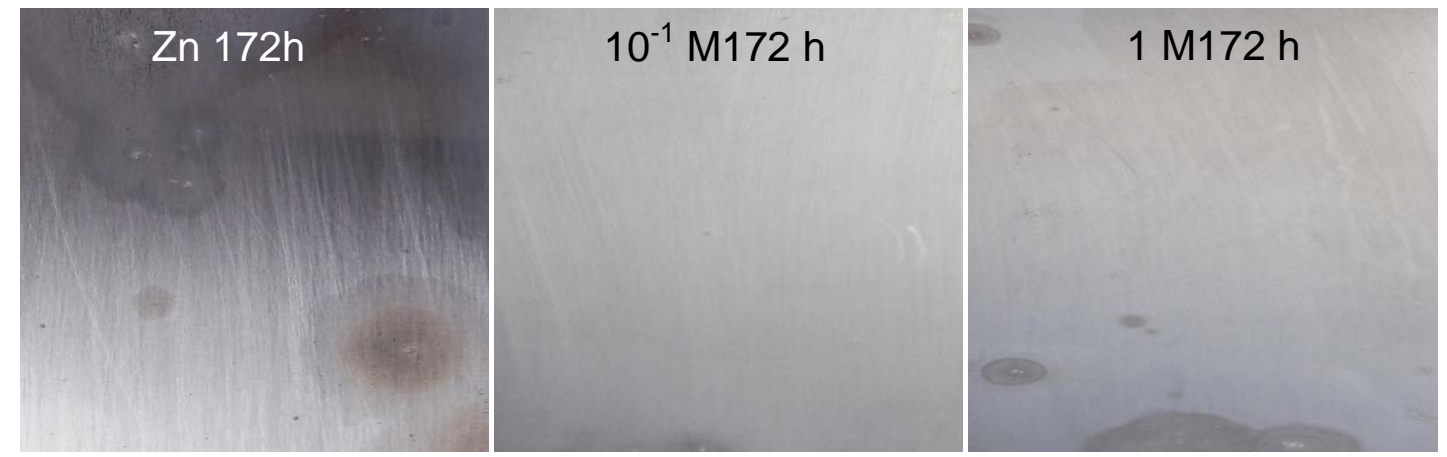

Figura 22: Superfície das amostras de zinco, como recebida ( $\mathrm{Zn}$ ) ou tratadas em solução com $10^{-1} \mathrm{M}$ ou $1 \mathrm{M}$ de ácido oxálico e com verniz após $172 \mathrm{~h}$ de ensaio de névoa salina.

Os resultados do ensaio em câmara de névoa salina com amostras com verniz (Figs. 21 e 22) confirmaram as observações anteriores em que o tratamento com solução de ácido oxálico $10^{-1} \mathrm{M}$ mostrou proteção contra a corrosão superior ao do tratamento com solução de $1 \mathrm{M}$ de ácido oxálico.

Após 72h de ensaio os primeiros sinais de corrosão já eram notados nas amostras como recebida e tratada em $1 \mathrm{M}$ de ácido oxálico, os quais evoluíram 
com o tempo, mas de forma mais acelerada nas amostras não tratadas, para as amostras tratadas em solução com $10^{-1} \mathrm{M}$ de ácido oxálico, apenas um pequeno ponto de corrosão foi identificado na parte inferior da amostra.

Os resultados também mostraram uma boa interaçãoe entre a camada formada pelo tratamento em ácido oxálico e o verniz, com pouco descolamento catódico tendo sido notado na superfície das amostras tratadas e com verniz. Por outro lado, descolamento catódico foi observado em várias áreas da amostra sem tratamento e com verniz. A Figs. 23 e 24 mostram a superfície das amostras ensaiadas com verniz e defeito aplicado.
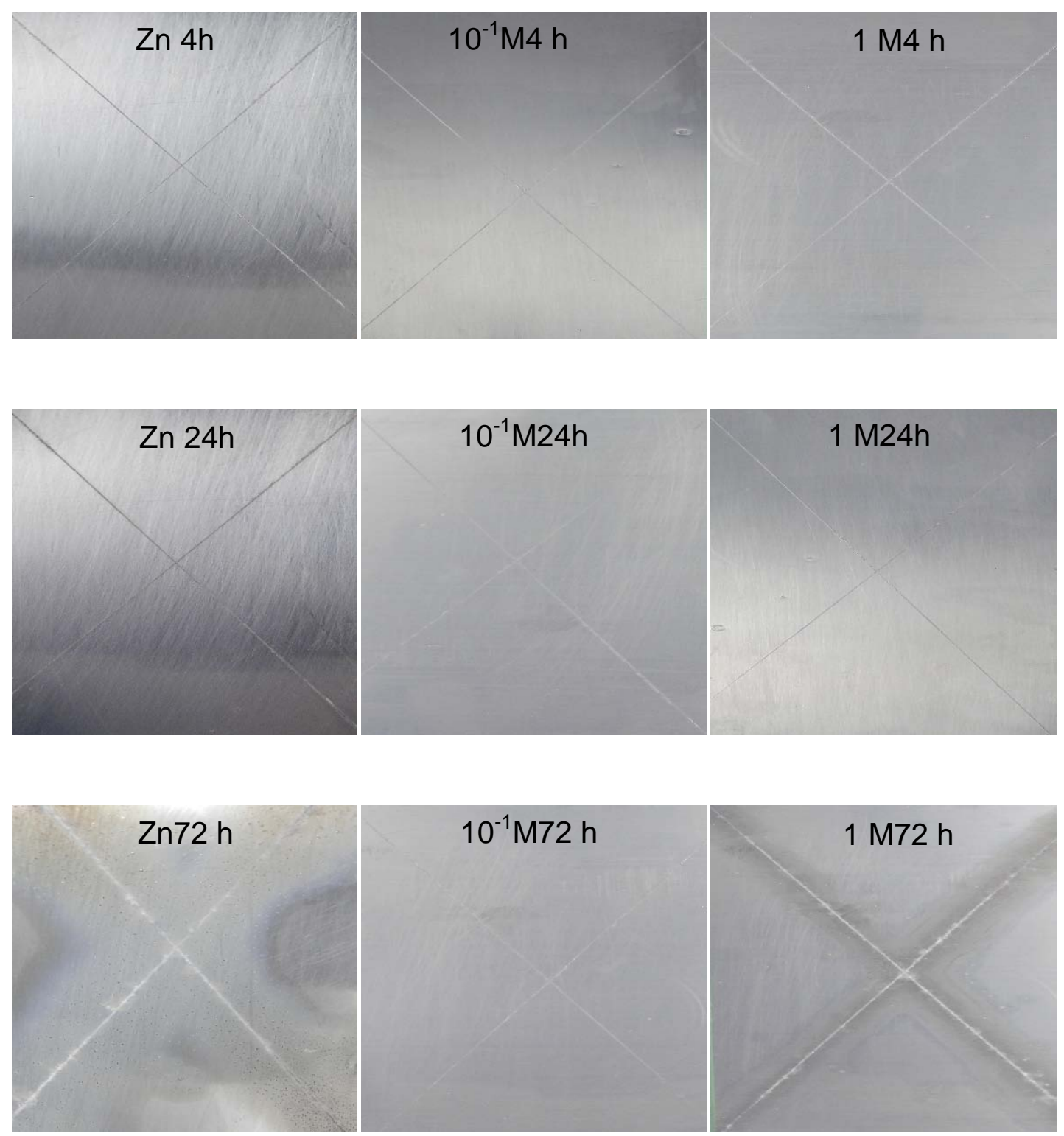


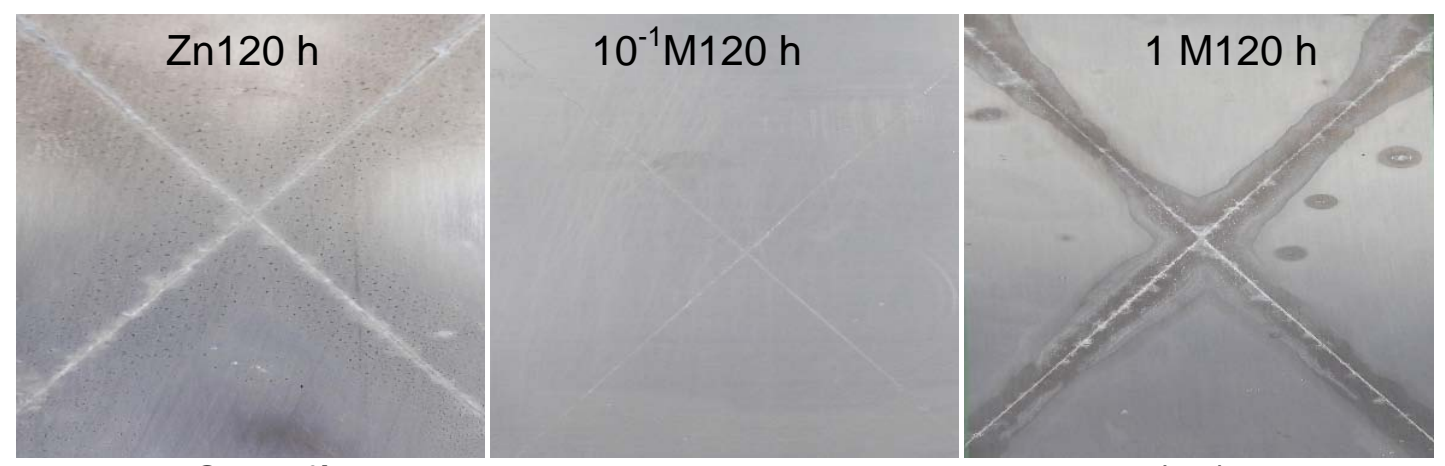

Figura 23: Superfície das amostras de zinco, como recebida (Zn) ou tratadas em solução com $10^{-1} \mathrm{M}$ ou com $1 \mathrm{M}$ de ácido oxálico, com verniz e com risco, após vários tempos de exposição (4 h, 24h, 72h e 120 h) ao ensaio de névoa salina.

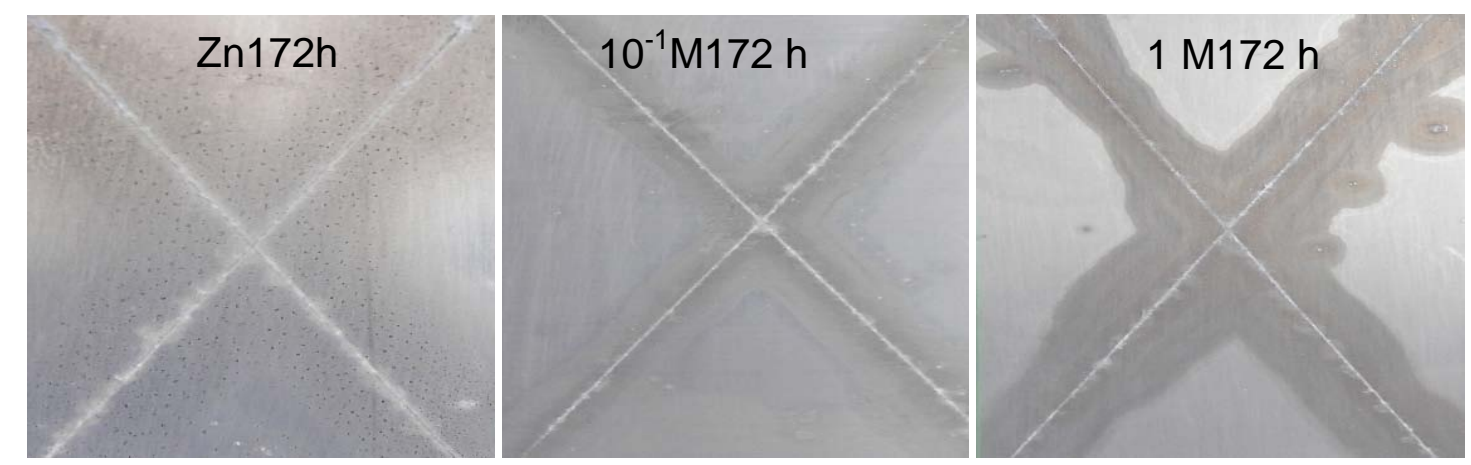

Figura 24: Superfície das amostras de zinco, como recebida ( $\mathrm{Zn}$ ) ou tratadas em solução com $10^{-1} \mathrm{M}$ ou com $1 \mathrm{M}$ de ácido oxálico, com verniz e com risco, após 172 h de exposição a ensaio de névoa salina (ASTM B117).

Os resultados das amostras ensaiadas com verniz e risco apoiaram os resultados anteriores mostrando efeito de proteção devido à interação entre a camada formada em solução com ácido oxálico $1 \mathrm{M}$ até $72 \mathrm{~h}$ de ensaio em câmara de névoa salina, porém para tempos superiores às $72 \mathrm{~h}$ ocorreu intenso ataque ao longo da linha do risco e o aparecimento de pontos de corrosão também fora da região do risco para esta última amostra. Por outro lado, a proteção contra a corrosão do substrato pela interação entre camada formada em solução com $10^{-1} \mathrm{M}$ de ácido oxálico e o verniz foi evidente ao longo de todo o período de ensaio e, apenas após $172 \mathrm{~h}$ de ensaio em câmara de névoa salina são observados produtos de corrosão brancos ao longo da linha do risco.

É observado sobre inspeção visual que também a aderência entre o verniz e a camada formada durante imersão na solução com $1 \mathrm{M}$ de ácido oxálico foi baixa e o descolamento catódico se espalhou por uma larga 
distância a partir do risco, o que não ocorreu para a superfície tratada em $10^{-1} \mathrm{M}$ de ácido oxálico. Este resultado coloca em evidência a maior eficiência de proteção da camada formada nesta última solução em relação à de $1 \mathrm{M}$. A partir destes resultados preliminares foi decidido pela continuação dos estudos e caracterização das camadas formadas na faixa de concentração entre $10^{-3} \mathrm{M}$ e $10^{-1} \mathrm{M}$. No entanto, as demais concentrações foram descontinuadas efetivamente por que apresentaram resultados ruins, comparados a essas concentrações $10^{-3} \mathrm{M}$ e $10^{-1} \mathrm{M}$.

5.2. Caracterização eletroquímica das superfícies de zinco como recebido e com tratamentos em solução com $10^{-1} \mathrm{M}$ e $1 \mathrm{M}$ de ácido oxálico.

A evolução do comportamento eletroquímico das superfícies de zinco sem tratamento e com tratamentos em soluções com $10^{-1} \mathrm{M}$ e $1 \mathrm{M}$ de ácido oxálico é mostrada de forma comparativa, na forma de diagramas de Nyquist, em função do tempo de exposição ao meio $\left(10^{-1} \mathrm{M}\right.$ de $\left.\mathrm{NaCl}\right)$ nas Figs. 25 a 27 , para os tempos de 4h, 1 dia, 3 dias, 5 dias e 7 dias de ensaio.

Nas Figs. 25a 27 são indicadas duas constantes de tempos (2 arcos achatados) para todas as superfícies ensaiadas, sendo que o segundo arco é incompleto para a faixa de frequências estudadas. A primeira constante de tempo (frequências mais altas) é relacionada com a camada formada pelos tratamentos em solução de ácido oxálico, ou, no caso da superfície sem tratamento (Zn), a produtos de corrosão já formados na superfície, enquanto a segunda constante de tempo (frequências mais baixas) é associada com processos de transferência de carga na parte exposta do substrato sob os defeitos acoplados com o carregamento da dupla camada elétrica. 

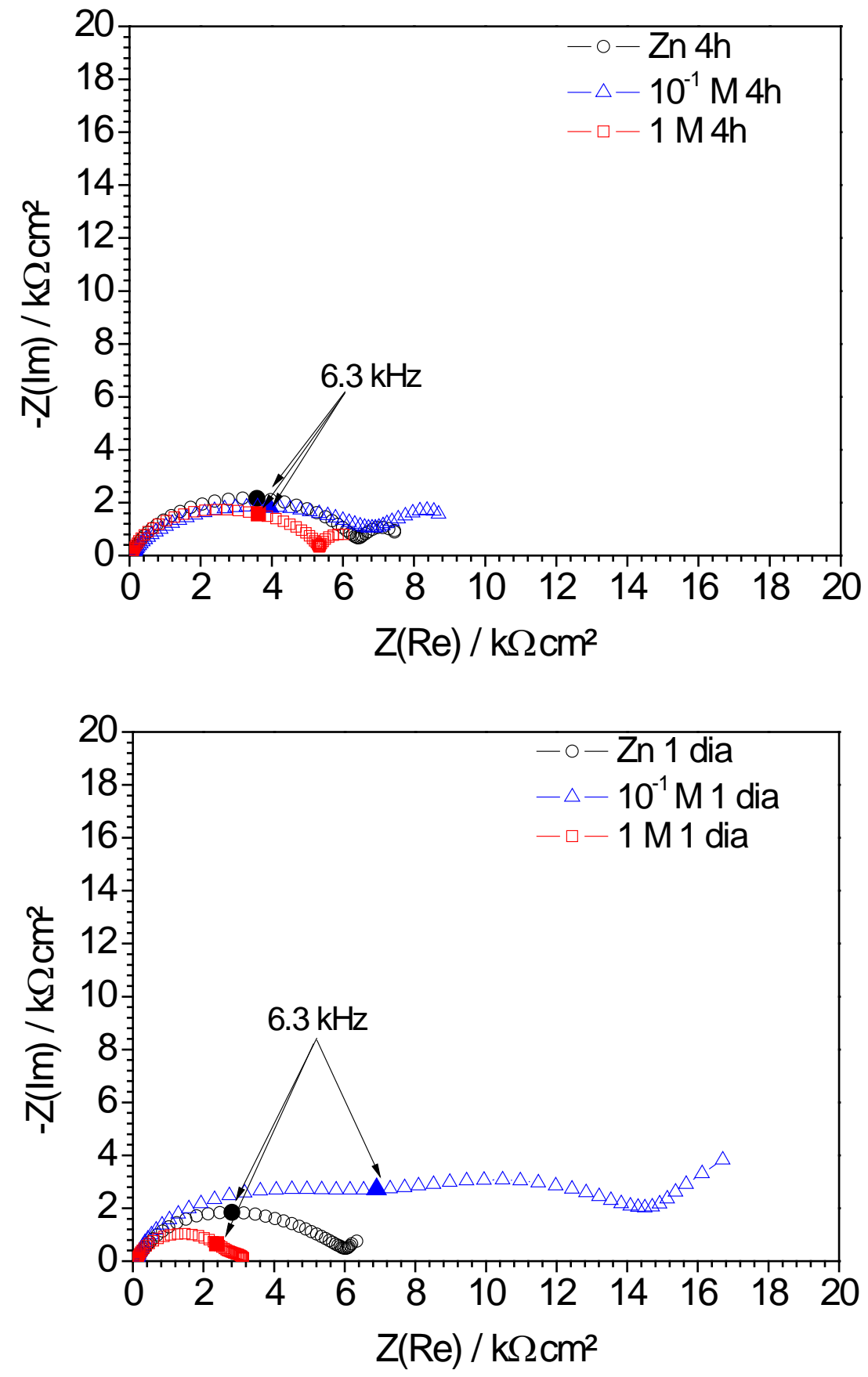

Figura 25:Diagramas de Nyquist para amostras de zinco como recebido ou tratadas em soluções com $10^{-1} \mathrm{M}$ e $1 \mathrm{M}$ de ácido oxálico e expostas à meio de ensaio com $10^{-1} \mathrm{M}$ de $\mathrm{NaCl}$ por $4 \mathrm{~h}$ e 1 dia. 

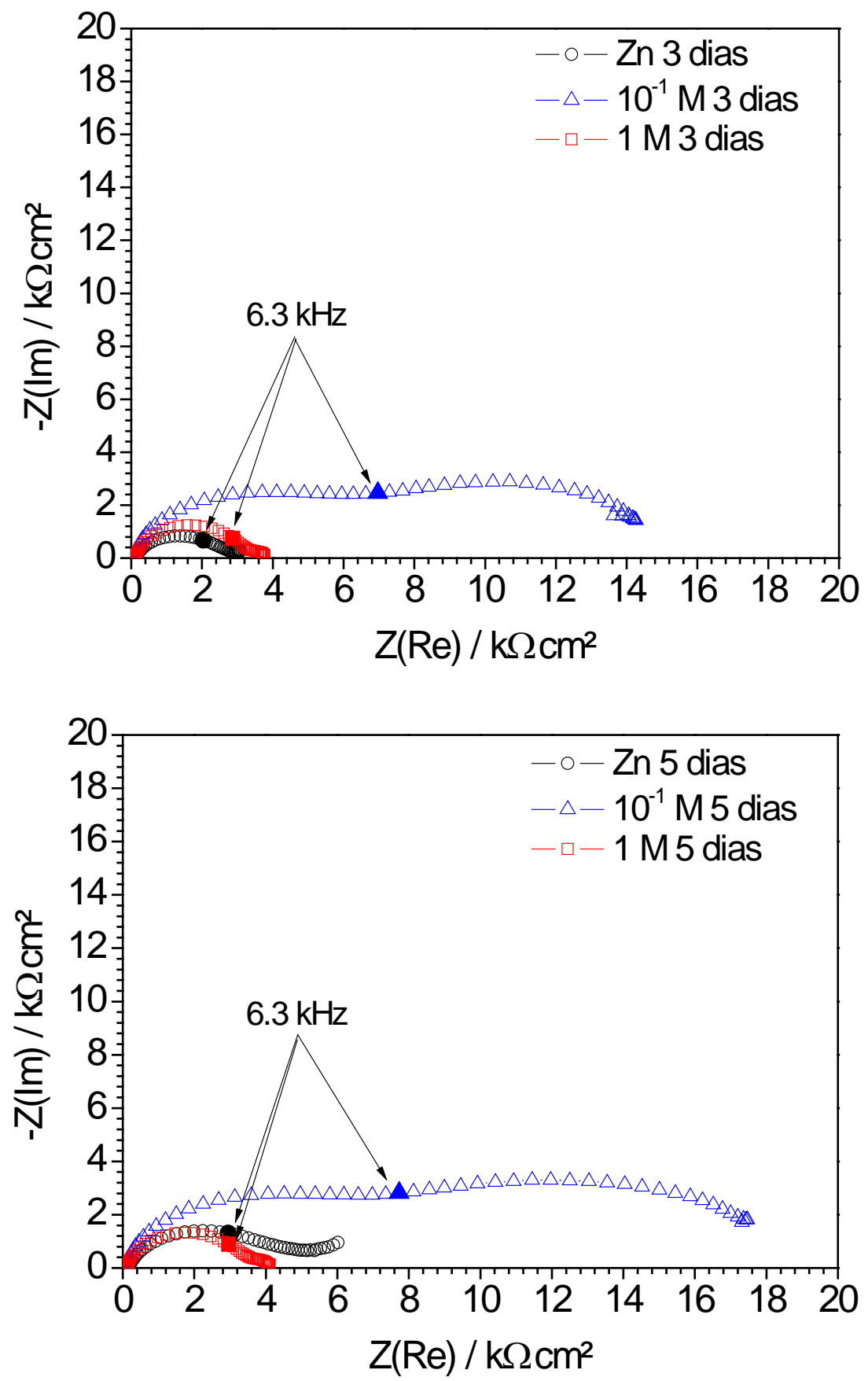

Figura 26: Diagramas de Nyquist para amostras de zinco como recebido ou tratadas em soluções com $10^{-1} \mathrm{M}$ e $1 \mathrm{M}$ de ácido oxálico e expostas a meio de ensaio com $10^{-1} \mathrm{M}$ de $\mathrm{NaCl}$ por 3 dias e 5 dias. 


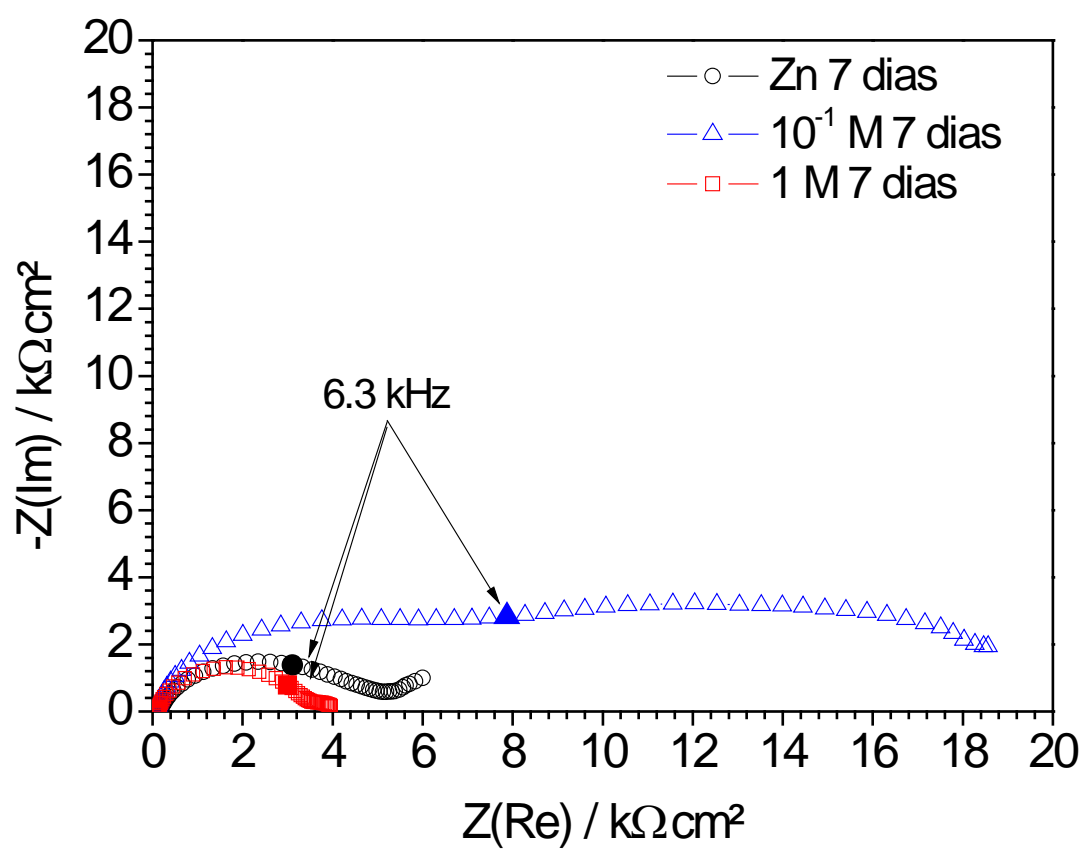

Figura 27: Diagramas de Nyquist para amostras de zinco como recebido ou tratadas em soluções com $10^{-1} \mathrm{M}$ e $1 \mathrm{M}$ de ácido oxálico e expostas a meio de ensaio com $10^{-1} \mathrm{M}$ de $\mathrm{NaCl}$ por 7 dias.

Os resultados das Figs. 25 a 27também mostram que desde as primeiras horas de ensaio a superfície tratada em solução como $1 \mathrm{M}$ de ácido oxálico apresenta menores impedâncias do que a superfície de zinco não tratada. Este resultado não era esperado uma vez que o tratamento conferiu melhor proteção contra a corrosão quando testado junto com o verniz em câmara de névoa salina. Todavia, este ensaio também mostrou que para tempos de exposição à névoa salina de $72 \mathrm{~h}$ ou superiores, a quantidade de produtos de corrosão presentes na superfície das amostras tratadas foi maior do que para o zinco como recebido, Figs. 19 e 20.

É possível notar também na Fig.19 que a impedância das amostras tratadas em solução com $1 \mathrm{M}$ de ácido oxálico diminuiu entre $4 \mathrm{~h}$ e 1 dia de exposição ao meio de ensaio, indicando ataque corrosivo intenso da superfície. Todavia, a impedância relacionada com esta superfície aumentou entre 1 dia (24h) e 3 dias (72h), o que corresponde à precipitação de produtos de corrosão na superfície da amostra, como foi indicado pelo ensaio de névoa salina. No caso da amostra como recebida (Zn), a impedância diminuiu entre 4 h e 3 dias de ensaio e só apresentou aumento a partir de 3 dias de ensaio. Estes 
resultados sugerem que o ataque neste último tipo de superfície (Zn) teve cinética mais lenta do que na superfície tratada em solução com $1 \mathrm{M}$ de ácido oxálico.

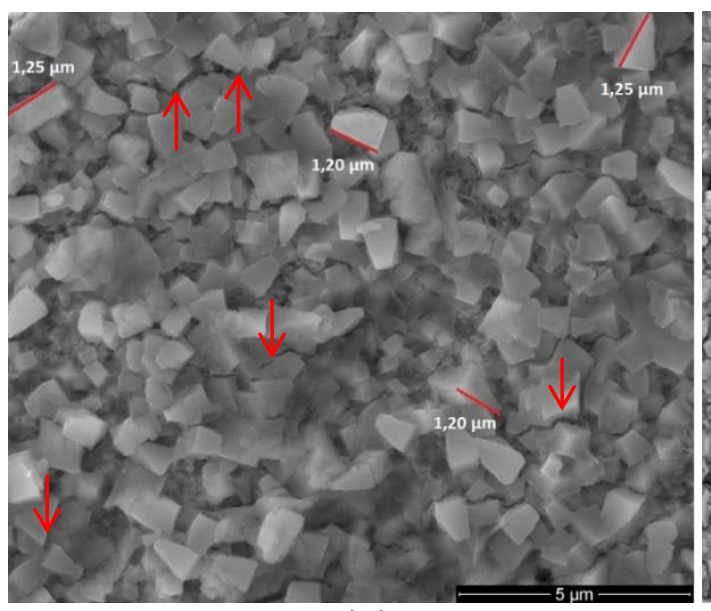

(a)

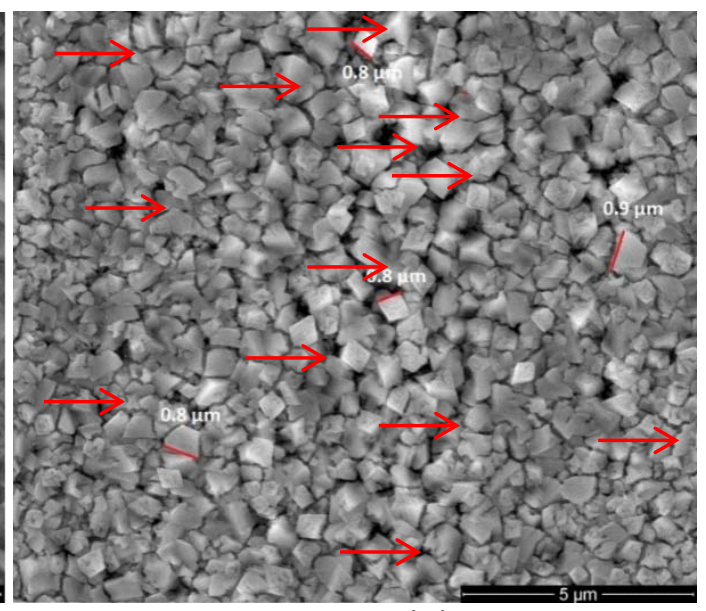

(b)

Figura 28: Micrografias obtidas por microscopia eletrônica de varredura da superfície de amostras zinco após tratamentos em soluções com (a) $10^{-1} \mathrm{M}$ e (b) $1 \mathrm{M}$ de ácido oxálico. Antes do ensaio de corrosão.

O ataque corrosivo acelerado nas superfícies tratadas neste último meio é explicado pela solução de elevada agressividade $(\mathrm{pH}=0,89)$ resultar em uma superfície com camada defeituosa (porosidades e trincas). De fato, quando se compara as duas superfícies pós-tratamentos em soluções com $10^{-1} \mathrm{M}$ e $1 \mathrm{M}$ de ácido oxálico, por micrografias eletrônicas de varredura, Fig. 28, pode ser observado que a camada formada nesta última solução apresenta trincas e cristais de menor tamanho mas em maior números que a primeira, o que apoia a hipótese de cinética de ataque mais rápida na solução de tratamento e tendência à menor proteção do substrato metálico pela camada mais defeituosa do que a formada em solução code ácido oxálico. De fato, o tratamento em solução com $1 \mathrm{M}$ de ácido oxálico resultou na formação de uma camada altamente defeituosa nos quais os defeitos atuam como frestas favorece o ataque acelerado na base dos defeitos da camada devido às condições muito agressivas ali geradas.

A Fig. 29 (a) e (b) mostra a evolução do comportamento eletroquímico das superfícies ensaiadas com o tempo de exposição ao meio corrosivo permitindo uma comparação entre estas superfícies para os vários tempos de 
ensaio .É importante observar nos diagramas de Nyquist da Fig. 29 (a) que a impedância da superfície tratada em $10^{-1} \mathrm{M}$ de ácido oxálico aumenta continuamente com o tempo de ensaio. Nota-se também que os arcos dos diagramas de Nyquist desta superfície são muito achatados, o que é típico de superfícies altamente heterogêneas como de fato é observado nas micrografias da Fig. 28.

Apesar de a camada formada em $10^{-1} \mathrm{M}$ de ácido oxálico ser mais compacta do que em $10^{-3} \mathrm{M}$, esta apresenta alguns defeitos (Fig. 28) e, desde os minutos iniciais de contato com a solução corrosiva, há penetração da solução de cloreto de sódio e formação de produtos de corrosão de zinco, como mostra a Fig. 30. As imagens desta figura mostram que os produtos de corrosão crescem da base, substrato de zinco metálico, através da camada de conversão de oxalato em direção a superfície. Estas imagens também possibilitam constatar que parte da camada formada é consumida, ou seja, além do substrato metálico, os cristais da camada de oxalato de zinco também reagem em contato com o meio e novos produtos são formados.
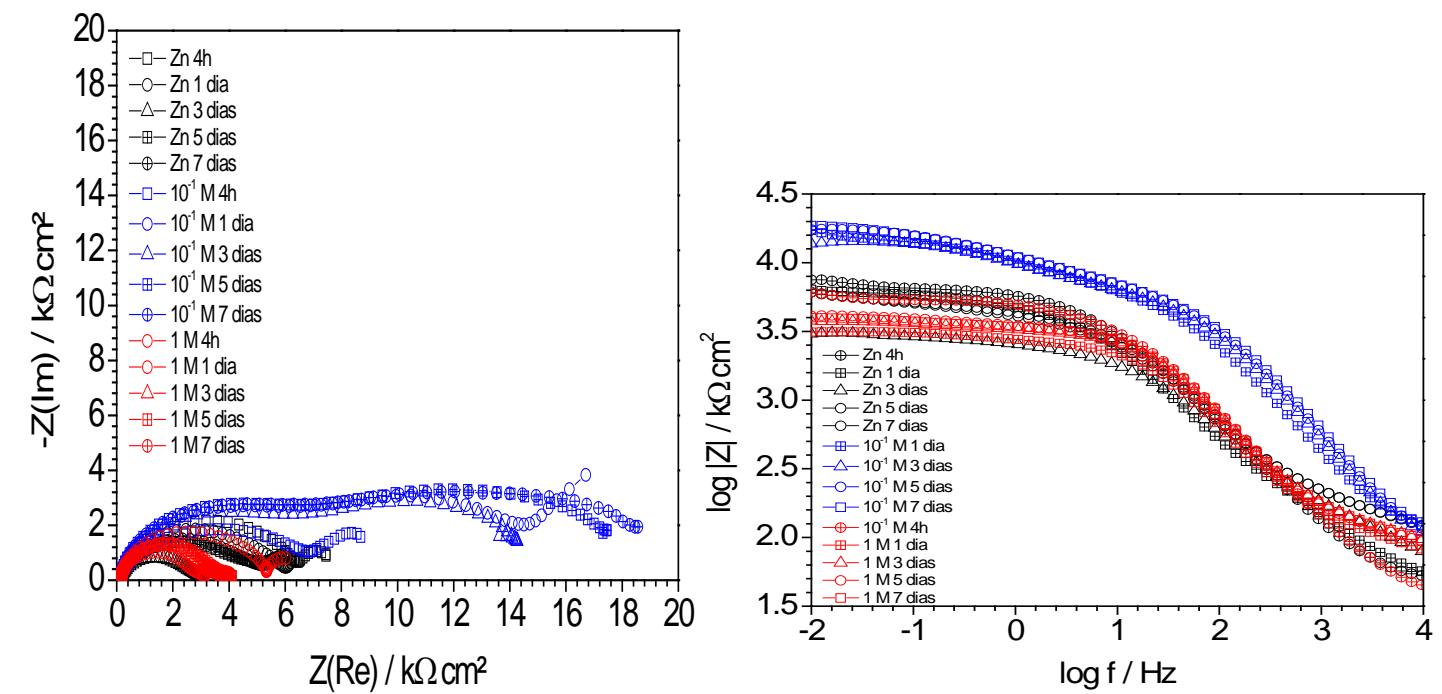

Figura 29: Resultados de EIS como (a) diagramas de Nyquist e (b) diagramas de Bode $|Z|$ vs $f$ para amostras de zinco como recebido ou tratadas em soluções com $10^{-1} \mathrm{M}$ e $1 \mathrm{M}$ de ácido oxálico após 7 dias de imersão em solução com $10^{-1} \mathrm{M}$ de $\mathrm{NaCl}$. 

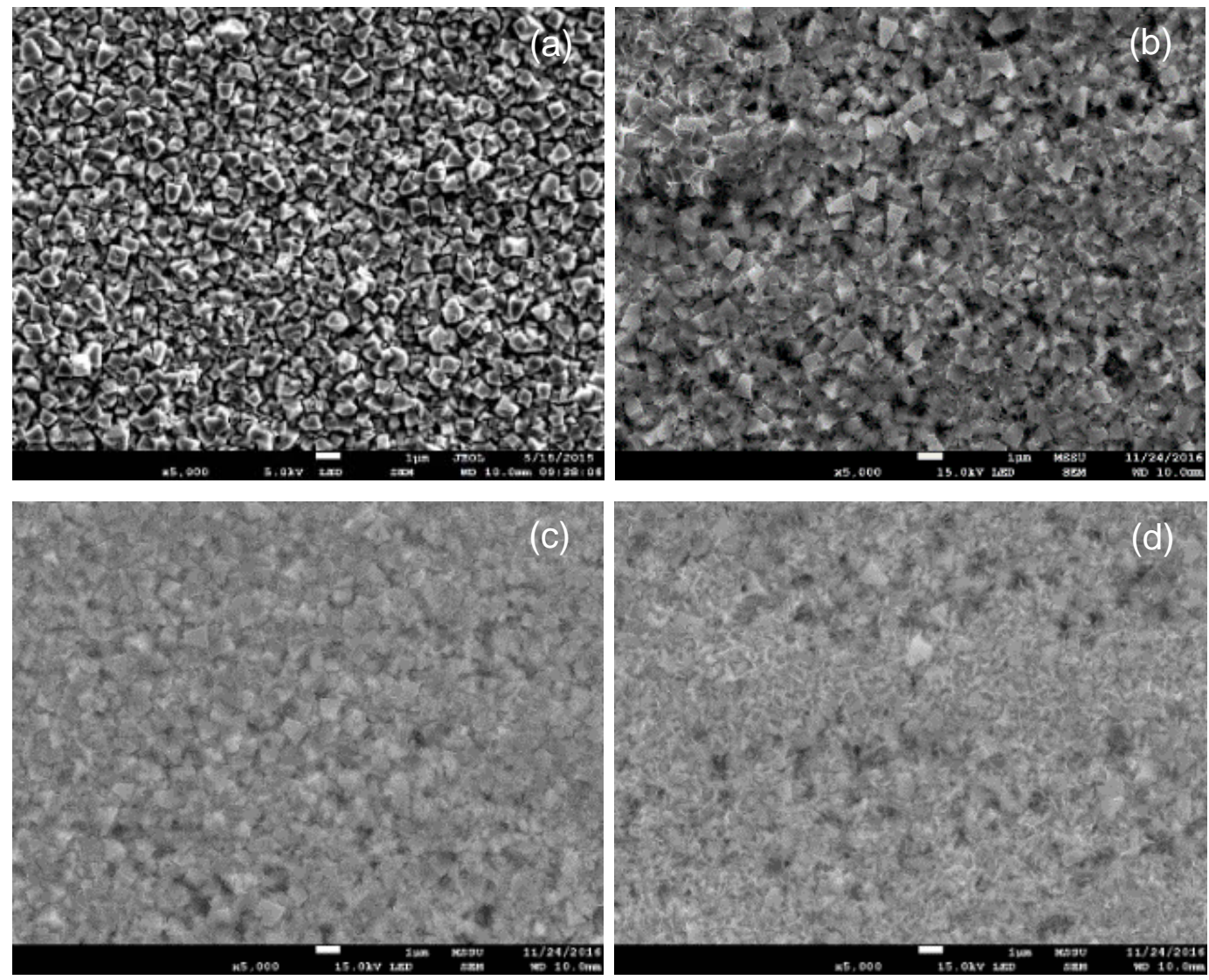

Figura 30: Micrografias de MEV das superfícies tratadas em solução $\operatorname{com~} 10^{-1} \mathrm{M}$ de ácido oxálico e (a) antes de exposição ao meio corrosivo e após (b) 10 min.; (c) 30 min. e (d) 60 min. de exposição a solução de cloreto de sódio $10^{-1} \mathrm{M}$ de $\mathrm{NaCl}$.

As micrografias obtidas por microscopia eletrônica de varredura mostram que para tempos superiores a $1 \mathrm{~h}$ de imersão em solução corrosiva e até o final do ensaio (7 dias), a forma dos grãos da camada formada mudou significativamente com ataque aos grãos de morfologia geométrica e, consequentemente, a morfologia da superfície, conforme observação da superfície, Fig. 31.Esta observação mostra o crescente ataque do revestimento de oxalato formado após contato com o meio corrosivo e a formação de produtos de corrosão que permanecem aderidos ao substrato. $O$ ataque intenso ao substrato metálico de zinco nas áreas anódicas (base dos poros/defeitos da camada) resulta em diminuição localizada do pH, e esta, por sua vez, produz ataque à camada formada. Já nas áreas catódicas, há aumento do $\mathrm{pH}$ e, consequentemente, deposição de hidróxido de zinco, os quais atuam como inibidores de corrosão ao permanecerem aderidos à 
superfície.
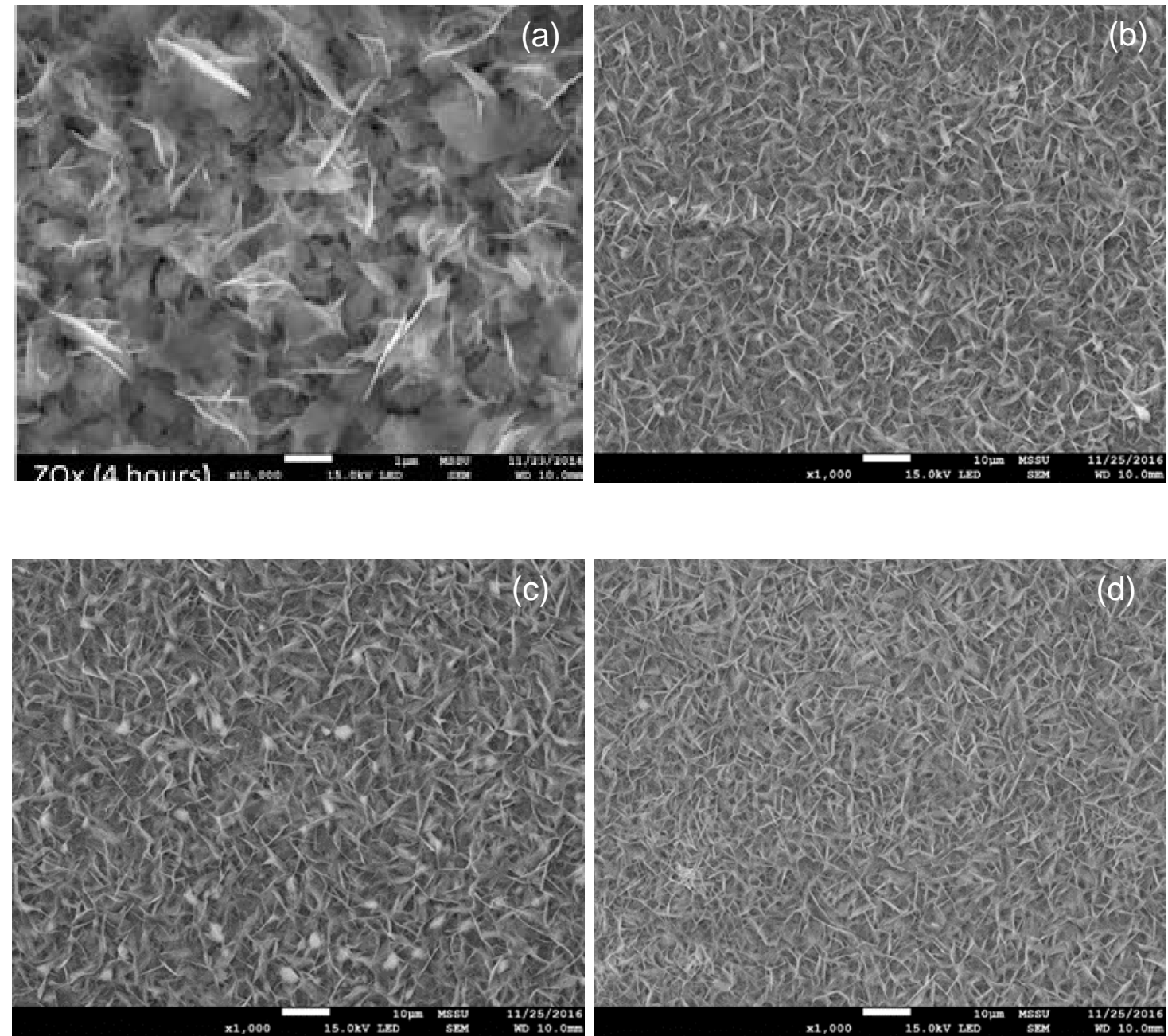

Figura 31: Micrografias das superfícies tratadas em solução com $10^{-1} \mathrm{M}$ de ácido oxálico após (a) 4h, (b) 3 dias; (c) 5 dias e (d) 7 dias em solução $10^{-1} \mathrm{M}$ de $\mathrm{NaCl}$.

Os diagramas de Bode ( $\log |Z|$ vs $\log$ f), Fig. 29 b, mostram claramente a maior resistência da superfície tratada em solução com $10^{-1} \mathrm{M}$ de ácido oxálico em comparação às demais superfícies ensaiadas ao longo de todo o ensaio de corrosão. Vale ressaltar que ensaios de espectroscopia de impedância de eletroquímica foram também realizados para as superfícies tratadas em soluções com $3 \times 10^{-1} \mathrm{M}, 6 \times 10^{-1} \mathrm{M}$ e $9 \times 10^{-1} \mathrm{M}$ de ácido oxálico, porém todos os resultados mostraram impedâncias inferiores às obtidas para as superfícies tratadas em $10^{-1} \mathrm{M}$ deste ácido. Este comportamento foi atribuído à maior quantidade de defeitos formados nas soluções de concentração de ácido oxálico entre $3 \times 10^{-1} \mathrm{M}$ e $1 \mathrm{M}$, como indica a Fig. 32 . 


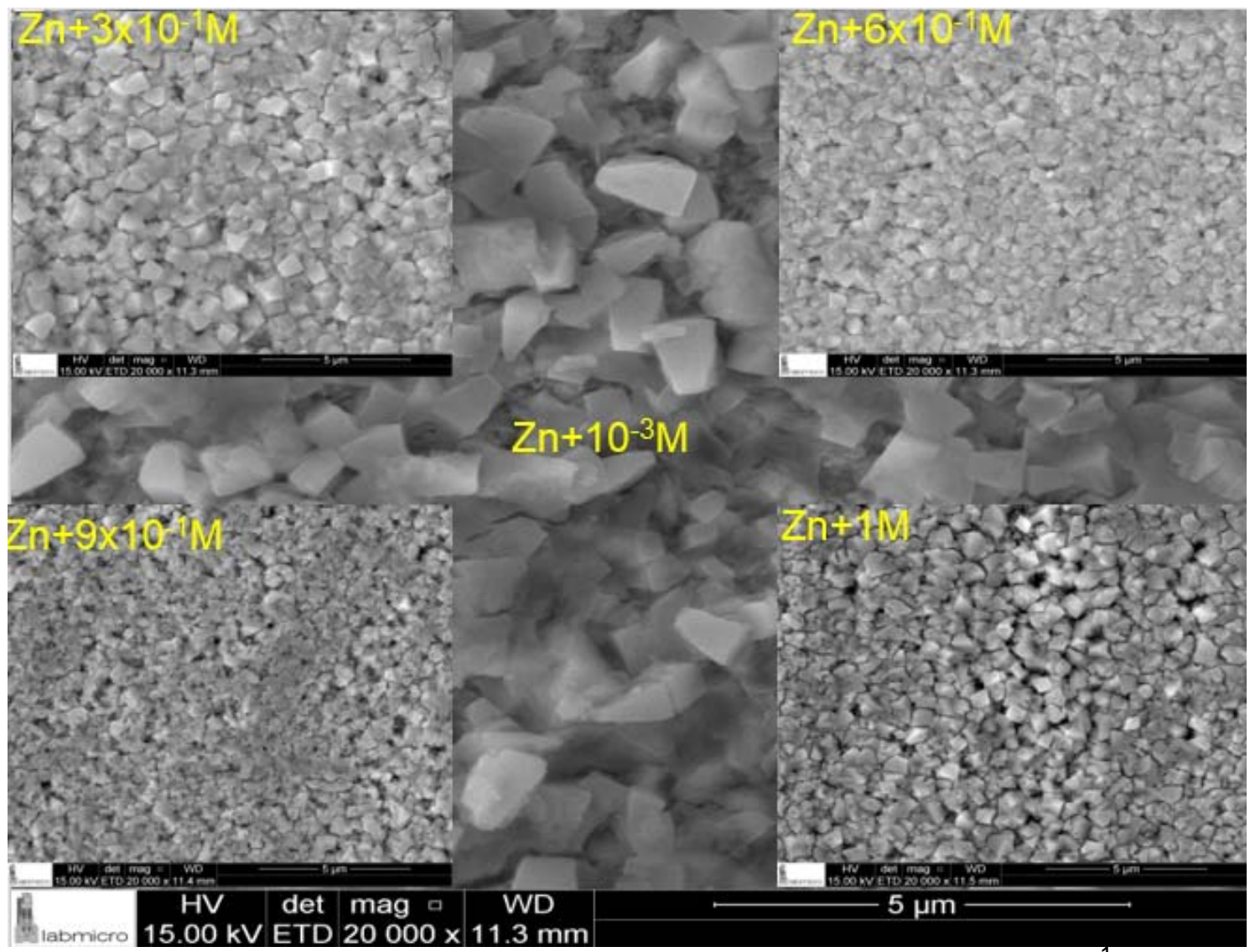

Figura 32: Micrografias das superfícies tratadas em soluções com $10^{-1} \mathrm{M}, 3 \times 10^{-}$ ${ }^{1} \mathrm{M}, 6 \times 10^{-1} \mathrm{M}, 9 \times 10^{-1} \mathrm{M}$ e $1 \mathrm{M}$ de ácido oxálico antes de exposição ao meio corrosivo. Todas a micrografias $20000 \times$ de $5 \mu \mathrm{m}$.

A maior quantidade de defeitos nas camadas formadas em concentrações superiores a $10^{-1} \mathrm{M}$ é explicada pela alta agressividade das soluções de tratamentode elevada acidez (Tabela 2), resultando em intenso ataque da superfície de zinco. A partir dos resultados dos ensaios em câmara de névoa salina e ensaios eletroquímicos, o tratamento em solução com $10^{-3} \mathrm{M}$ e $1 \mathrm{M}$ de ácido oxálico foram escolhidos para continuação do estudos e caracterização da camada superficial formada.

5.3. Caracterização da morfologia das superfícies tratadas e sem tratamento.

As micrografias das superfícies sem tratamento e após tratamento em soluções de ácido oxálico com de $10^{-3} \mathrm{M}$; (c) $10^{-2} \mathrm{M}$; e (d) $10^{-1} \mathrm{M}$ são mostradas na Figura 3 (a) a (d). 


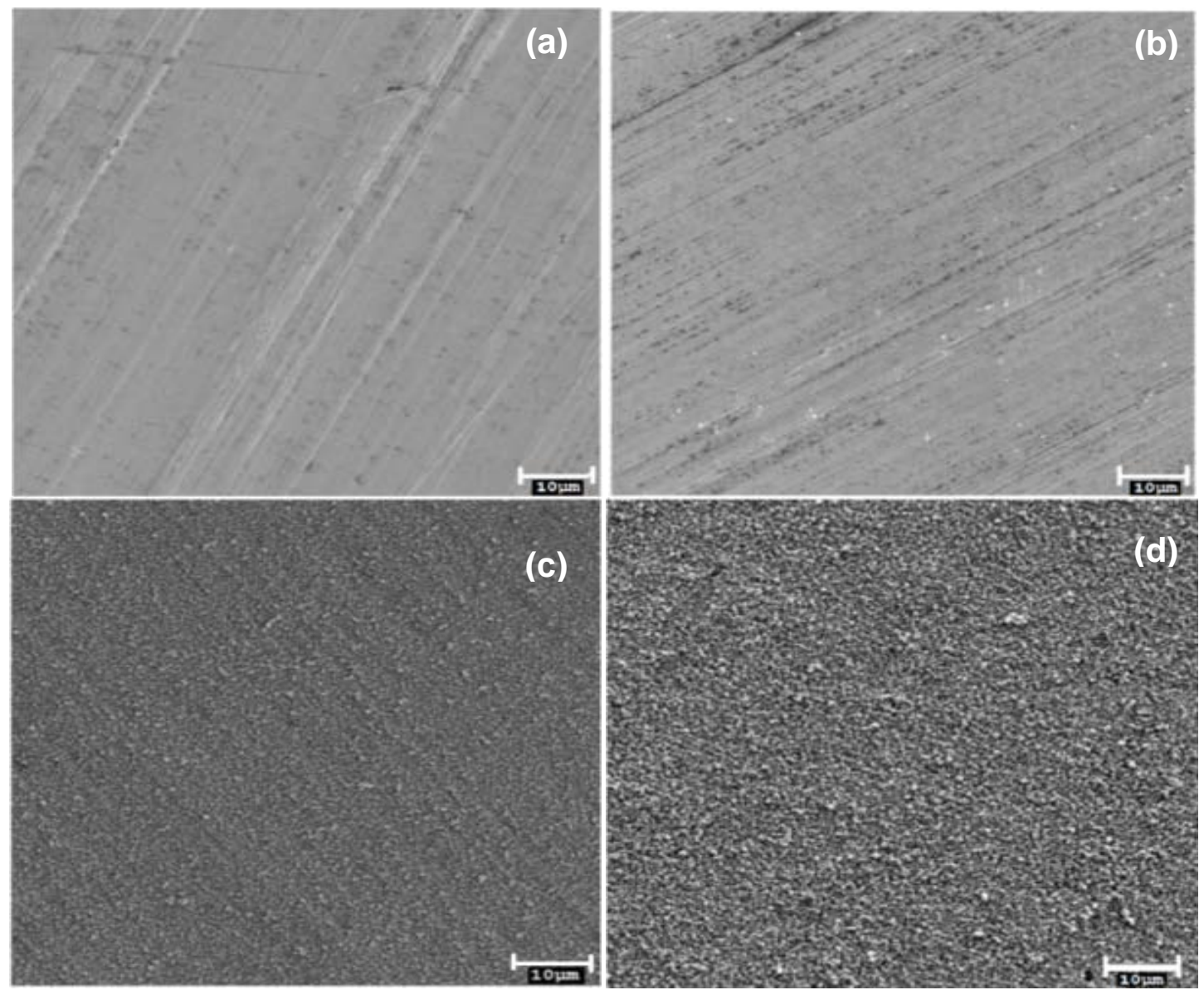

Figura 33: MEV da superfície de zinco (a) não tratada, e após tratamento por 5 min. em soluções de ácido oxálico com concentrações, (b) $10^{-3} \mathrm{M}$; (c) $10^{-2} \mathrm{M}$; e (d) $10^{-1} \mathrm{M}$.

As linhas paralelas visíveis nas micrografias das Figs. 33 (a) e (b) são características de peças de zinco produzidas pelo processo de laminação. $O$ fato destas linhas serem visíveis nas superfícies de amostras tratadas em solução com concentração de $10^{-3} \mathrm{M}$ de ácido oxálico mostra que o filme superficial formado nessa concentração é fino e não cobre a superfície do substrato. Esta concentração foi considerada insuficiente para a formação de um filme com boa cobertura da superfície e, portanto, ineficiente. Para a camada formada em solução com concentração de $10^{-2} \mathrm{M}$, as linhas de deformação estão pouco visíveis mas há indicação de formação de precipitados na superfície e, para a concentração de $10^{-1} \mathrm{M}$, uma camada que cobre o substrato é claramente observada. Estas observações mostram de forma evidente o efeito da concentração do ácido oxálico na formação de camadas superficiais em presença de ácido oxálico. 
A seguinte hipótese é proposta para a interação do zinco com as soluções de ácido oxálico. Dois processos ocorrem concomitantemente durante a exposição do zinco metálico à solução de ácido oxálico, quais sejam, a dissolução do zinco na solução e a interação de íons oxalato com íons de zinco formando produtos que se precipitam na superfície. Em baixas concentrações de íons oxalato $\left(10^{-3} \mathrm{M}\right)$, a dissolução de zinco predomina e o teor de oxalato é insuficiente para a formação de uma camada contínua sobre toda a superfície. Esta concentração foi considerada inadequada e os ensaios de caracterização não foram realizados nas superfícies com tratamentos nesta solução. Para a concentração de ácido oxálico de $10^{-2} \mathrm{M}$ o ataque da superfície de zinco é significativo, mas a concentração de íons oxalato disponíveis já permite a formação de produtos de corrosão na forma de uma camada conversão que praticamente cobre a superfície exposta ao meio. Finalmente, para a concentração de $10^{-3} \mathrm{M}$, o ataque do zinco pelo meio produzquantidade significativa de cátions metálicos os quais reagem com íons oxalato em quantidade suficiente para cobrir toda a superfície.

Com base nos resultados obtidos, entre as concentrações estudadas, a concentração de $10^{-1} \mathrm{M}$ foi a que apresentou resultados mais promissores para investigação e caracterização. Todavia, de forma a avaliar se maiores teores de ácido oxálico resultariam em resultados mais promissores que a de $10^{-1} \mathrm{M}$, foram realizados ensaios em soluções com concentrações de $3 \times 10^{-1} \mathrm{M}, 6 \times 10^{-}$ ${ }^{1} \mathrm{M}, 9 \times 10^{-1} \mathrm{M}$ e $1 \mathrm{M}$, porém todas estas concentrações resultaram em camadas com baixa resistência à corrosão. Foi decidido, portanto, pela não caracterização das superfícies com tratamentos nestas soluções. Com base nos resultados obtidos, foi escolhida a superfície tratada em solução com concentração de $10^{-1} \mathrm{M}$ de ácido oxálico para caracterização química, física e eletroquímica.

Uma das amostras com revestimento obtido pelo tratamento em solução com $10^{-1} \mathrm{M}$ de ácido oxálico teve parte da camada removida por meio de um risco Corte em $X$ e a região de defeito foi analisada por MEV e EDS. As micrografias e os mapas químicos obtidos são mostrados na Fig.34. 


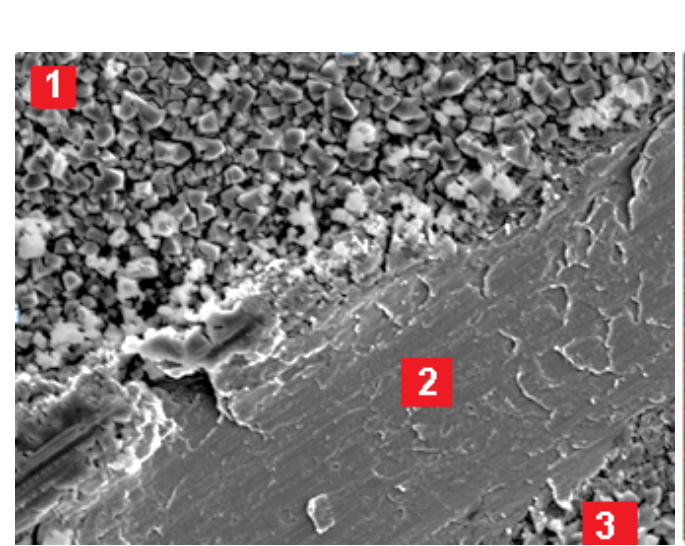

(a)

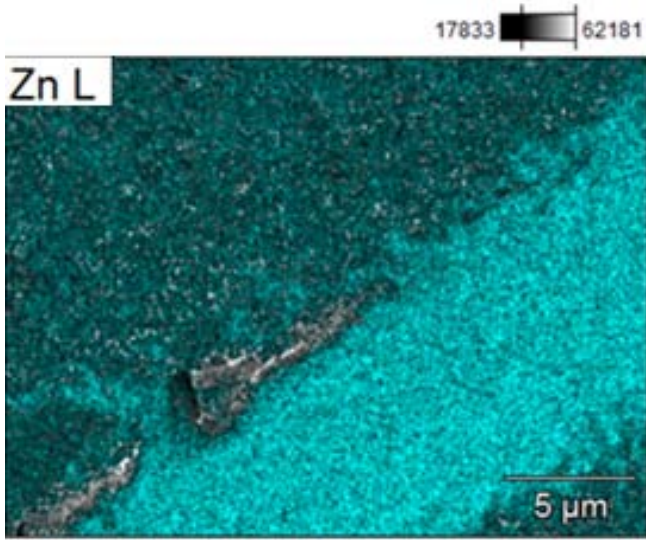

(c)

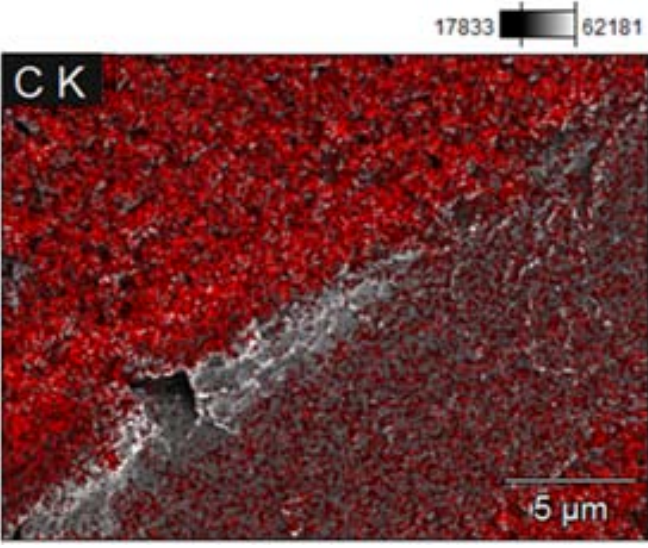

(b)

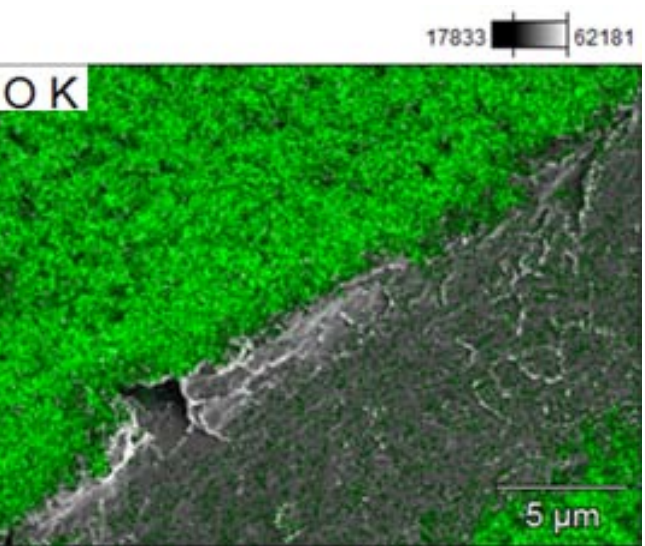

(d)

Figura 34: (a) Micrografias por microscopia eletrônica de varredura da superfície de zinco após tratamento de imersão em solução de ácido oxálico $100 \mathrm{mM}$ durante 5 min e com remoção parcial da camada por risco para expor o substrato metálico. Mapas elementares (EDS) sobre a área arranhada e regiões circunvizinhas, (b) carbono; (c) zinco e (d) oxigênio.

Os mapas elementares (EDS) mostram que o defeito criado removeu o revestimento resultante do tratamento e exposição à solução com ácido oxálico, expondo o substrato. Foram observadas concentrações elevadas de carbono nas regiões 1 e 3 (Fig.34) onde o revestimento está intacto, devido à camada formada, provavelmente de oxalato. O substrato de zinco subjacente é claramente visível na região 2 . As imagens mostram uma distribuição uniforme dos cristais com formato geométrico do revestimento obtido.

Análise por EDS das superfícies da amostra de zinco preparada em solução $10^{-1} \mathrm{M}$ de ácido oxálico, Fig.35, mostra a presença dos elementos zinco, carbono e oxigênio. Estes são elementos também presentes no oxalato de zinco $\left(\mathrm{ZnC}_{2} \mathrm{O}_{4}\right)$. 


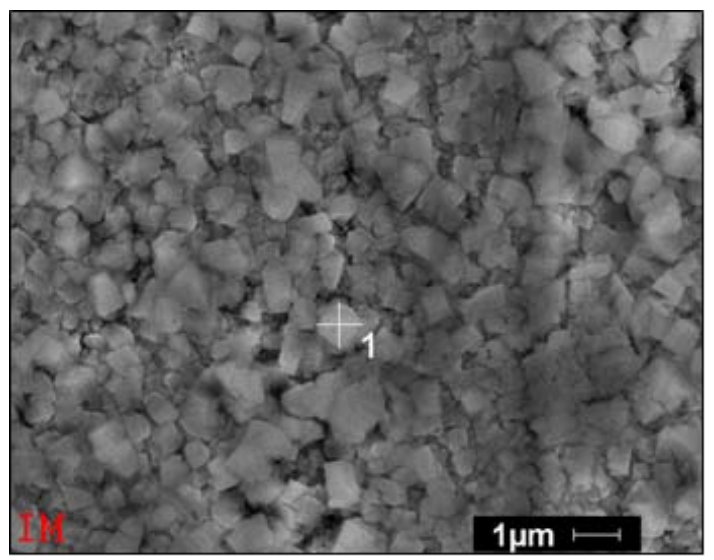

\begin{tabular}{|c|c|c|}
\hline Elemento & $\begin{array}{c}\% \\
\text { massa }\end{array}$ & Atômica \\
\hline CK & 18,17 & 48,16 \\
\hline$O K$ & 7,99 & 15,89 \\
\hline$Z n K$ & 73,84 & 35,95 \\
\hline
\end{tabular}

Figura 35:(a) Micrografia obtida por microscopia eletrônica de varredura da superfície de zinco e (b) resultados da análise por EDS para amostra preparada por imersão em solução de ácido oxálico $10^{-1} \mathrm{M}$ durante $5 \mathrm{~min}$.

5.4. Caracterização da morfologia da superfície do zinco tratada em solução com $10^{-1} \mathrm{M}$ de ácido oxálico e exposta a ensaio de corrosão.

A morfologia da superfície da camadaobtida do tratamento em solução com $10^{-1} \mathrm{M}$ de ácido oxálicoapós exposição a solução de $\mathrm{NaCl}\left(10^{-1} \mathrm{M}\right)$ por 10 min., 30 min. e 60 min., respectivamente, são mostradas nas micrografias da Fig.36. As micrografias apresentadas evidenciam que tempos relativamente curtos (10 min.) de exposição ao meio corrosivo (solução $10^{-1} \mathrm{M}$ de $\mathrm{NaCl}$ ), são suficientes para causar mudança na morfologia das camadas indicada pela mudança no formato dos grãos. O aumento gradativo da exposição à solução corrosiva além de modificar a morfologia dos grãos, resulta na formação de produtos de corrosão, os quais são observados a partir de 30 min de ensaio Fig.36. 

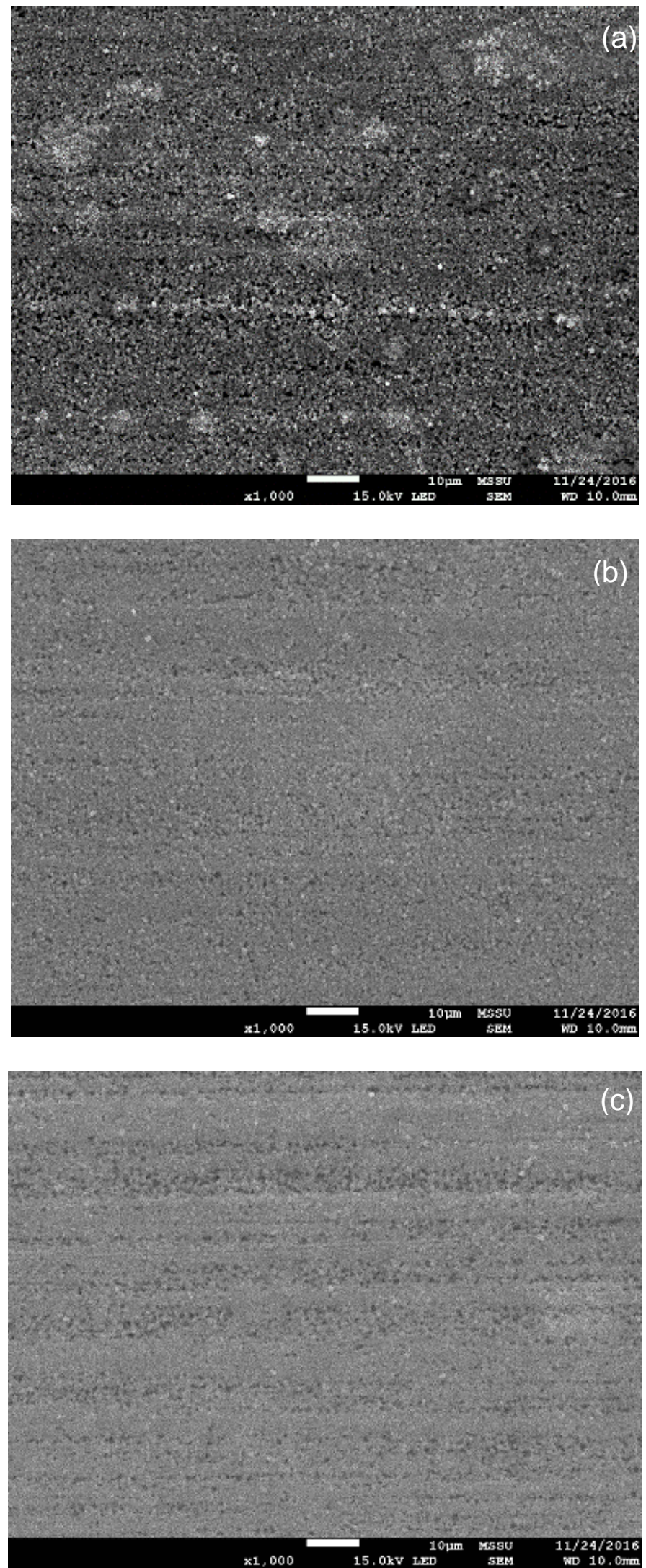

Figura 36: Micrografias obtidas por MEV da superfície de zinco após tratamento por imersão em solução de ácido oxálico $10^{-1} \mathrm{M}$ seguida porimersão em solução deNaCl 10-1Mpor (a) 10 min., (b) 30 min. e (c) 60 min. 

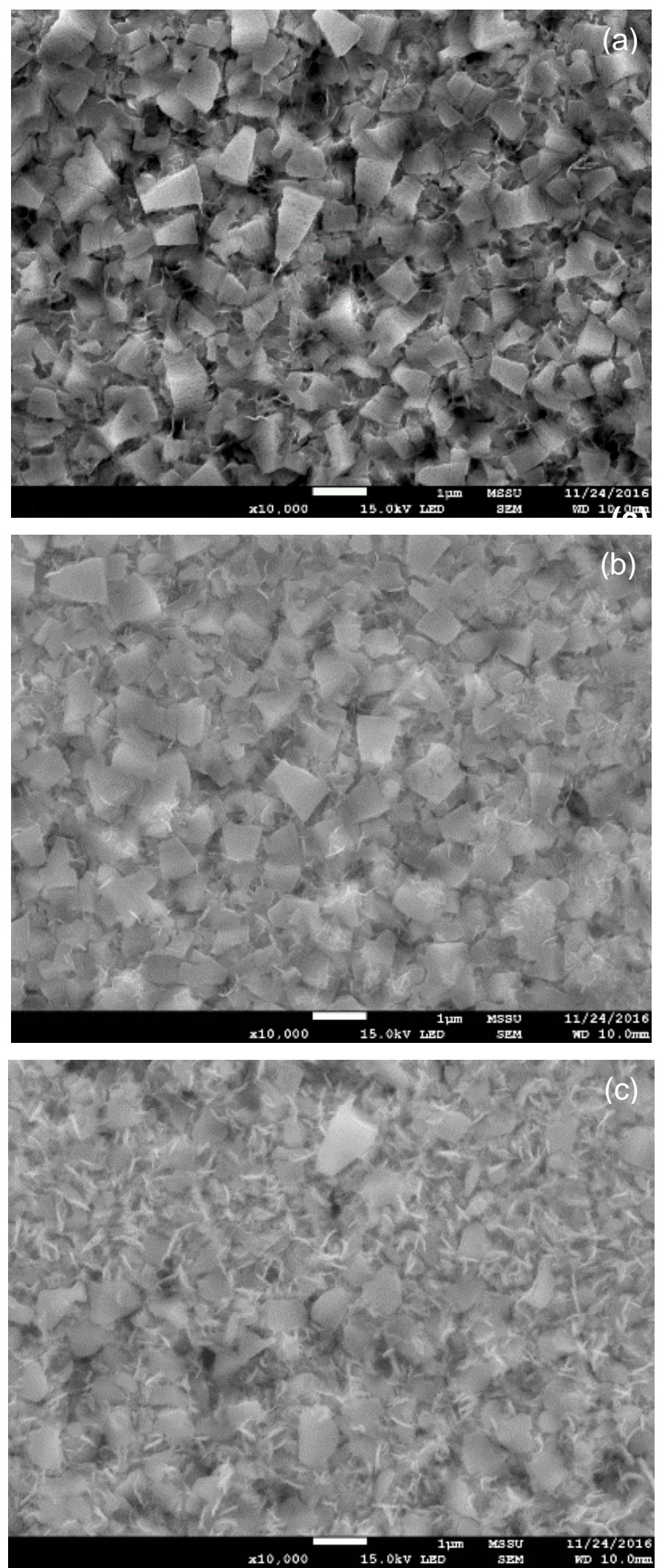

Figura 37: Micrografias obtidas por MEV da superfície de zinco após tratamento em solução com ácido oxálico $10^{-1} \mathrm{M}$ e exposição a solução de ensaio $\left(10^{-1} \mathrm{M}\right.$ de $\mathrm{NaCl}$ ) por (a) 10 min.; (B) 30 min. e (c) 60 min. 
$\mathrm{O}$ ataque corrosivo do substrato de zinco com produtos de corrosão ilustrados na Fig.37, mostra que a camada formada em solução de concentração $10^{-1} \mathrm{M}$ éporosa o que possibilita sua rápida penetração e corrosão do substrato metálico. De fato, ele cria condições de fresta nos poros da camada. Aparentemente, os produtos de corrosão formados permanecem presos entre os cristais da camada formada, a qual proporciona ancoragem (suporte) para os produtos de corrosão de zinco, entre os quais, o hidróxido de zinco $\left(\mathrm{Zn}(\mathrm{OH})_{2}\right)$, atua como inibidor de corrosão.

5.5 Caracterização química da superfície de zinco após tratamento em solução com $10^{-1} \mathrm{M}$ de ácido oxálico por difração de raios $\mathrm{X}$.

Os difratogramas foram obtidos das superfícies do zinco como recebido (a), e após tratamento por imersão em solução $10^{-1} \mathrm{M}$ de ácido oxálico (b) os quais são mostrados na Fig.38.

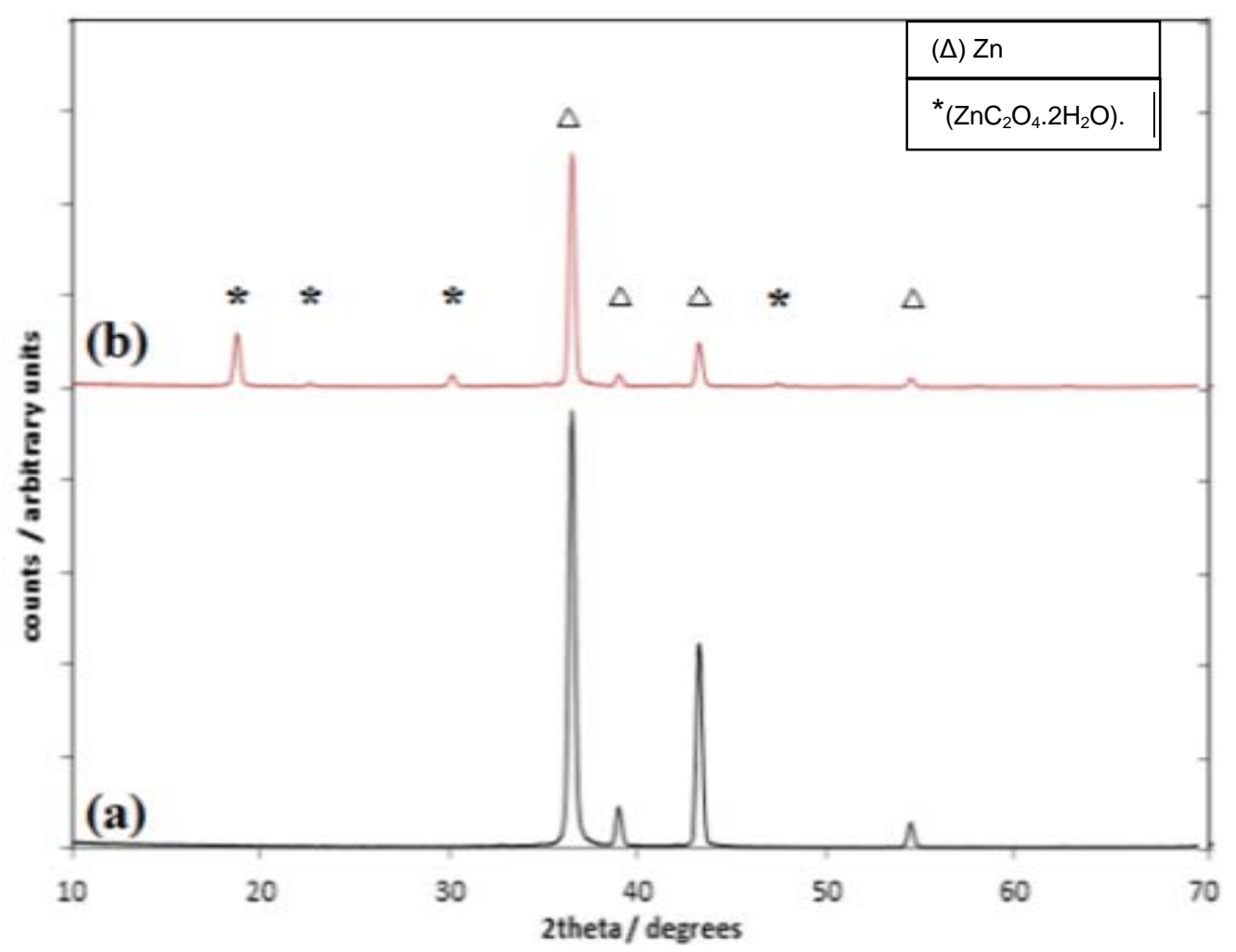

Figura 38: Difratogramas de raios $X$ obtidos de amostras de zinco (a) como recebido e (b) com tratamento em solução com $10^{-1} \mathrm{M}$ de ácido oxálico por 5 $\min$. 
Os picos referentes a zinco metálico são observados em ambos difratogramas $\mathrm{Zn}(\Delta)$, todavia, apenas para as superfícies tratadas são observados picos referentes ao oxalato de zinco hidratado $\left(\mathrm{ZnC}_{2} \mathrm{O}_{4} \cdot 2 \mathrm{H}_{2} \mathrm{O}\right)$, a $18,5^{\circ} ; 22,6^{\circ}$ e $30,2^{\circ}\left(^{*}\right)$. Este resultado mostra que o tratamento em solução com $10^{-1} \mathrm{M}$ de ácido oxálico resultou na deposição de camada de oxalato de zinco. Os picos estreitos também mostram a cristalização da camada formada. Entretanto, picos correspondentes a $\mathrm{ZnO}$ e $\mathrm{Zn}(\mathrm{OH})_{2}$ não foram observados. A camada obtida serádenominada doravante de camada de oxalato de zinco.

5.6. Caracterização química da superfície de zinco após tratamento em solução com $10^{-1} \mathrm{M}$ de ácido oxálico por difração de raios $\mathrm{X}$ e após ensaio de corrosão.

A Fig.39 mostra os difratogramas DRX para amostras de zinco (a) como recebida após 7 dias de exposição a solução de $10^{-1} \mathrm{M}$ cloreto de sódio e (b) após tratamento em solução $10^{-1} \mathrm{M}$ de ácido oxálico e após exposição a solução de $10^{-1} \mathrm{M}$ cloreto de sódio por (b) 5 dias e (c) 7 dias.

Os resultados de DRX mostram picos referentes a zinco metálico e ao ZnO em todas as amostras. A presença de óxido de zinco é observadaapós exposição à solução corrosiva por longos períodos de tempo, 5 dias e 7 dias, representando diferentes estágios de oxidação das superfícies do zinco não tratado (Figura 39 a) e camada de oxalato de zinco (Fig.39 b e c). Hidroxicloreto de zinco hidratado ou simonkolleite $\left(\mathrm{Zn}_{5}(\mathrm{OH})_{8} \mathrm{Cl}_{2} \cdot \mathrm{H}_{2} \mathrm{O}\right)$ $(\diamond)$ responsável por redução da taxa de corrosão), é apenas levemente indicado, sugerindo que está em quantidades muito pequenas. Em geral, este produto é formado dentro de 3 a 4 semanas de exposição de peças de zinco à ambiente marinho, mais corrosivo que a solução $10^{-1} \mathrm{M}$ de cloreto de sódio adotada neste trabalho. A formação deste produto é descrita como ocorrendo próximo à interface entre zinco e os produtos de corrosão de zinco, ZnO e $\mathrm{Zn}(\mathrm{OH})_{2}$. A presença de simonkolleite após7 dias de exposição a solução corrosiva de cloreto de sódio pode indicar que a camada de oxalato de zinco atue como catalisador da formação deste produto de corrosão. 


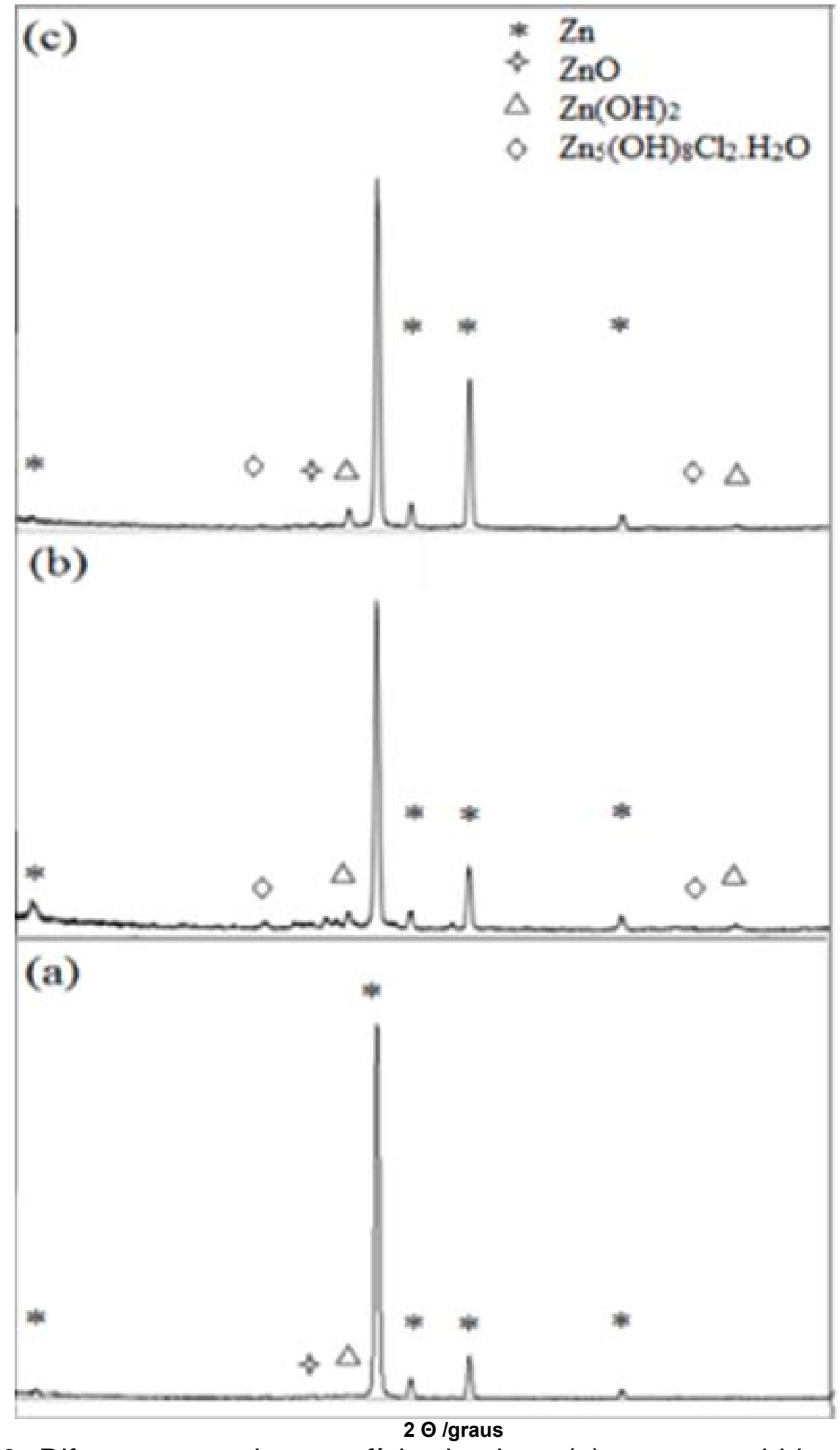

Figura 39: Difratogramas da superfície de zinco (a) como recebido e exposto por 7 dias a solução $10^{-1} \mathrm{M}$ de $\mathrm{NaCl}$; e com tratamento em solução com $10^{-1} \mathrm{M}$ de ácido oxálico após exposição a solução $10^{-1} \mathrm{M}$ de $\mathrm{NaCl}$ por (b) 5 dias e (c) 7 dias. 
A Fig. 40 mostra os espectros Survey para as amostras de zinco como recebido e após tratamentos em soluções com diferentes concentrações de ácido oxálico $\left(10^{-3} \mathrm{M}, 10^{-2} \mathrm{M}, 10^{-1} \mathrm{M}\right)$. Os espectrosdeXPS de alta resolução para Zn2p, C1s, O1s e Zn LMM são mostrados na Fig. 41 e os picos, energias de ligações e concentrações destes elementos são apresentados na Tab. 3.

Nos espectros Survey, três observações principais podem ser feitas para as amostras tratadas na solução de mais alta concentração de ácido oxálico comparativamente com as menores concentrações de ácido oxálico: (i) a razão $\mathrm{Zn} / \mathrm{O}$ muito menor; (ii) o pico C1s tem intensidade muito menor; (iii) o sinal de background associado com o sinal dos picos Zn2p e Zn LMM decresce.

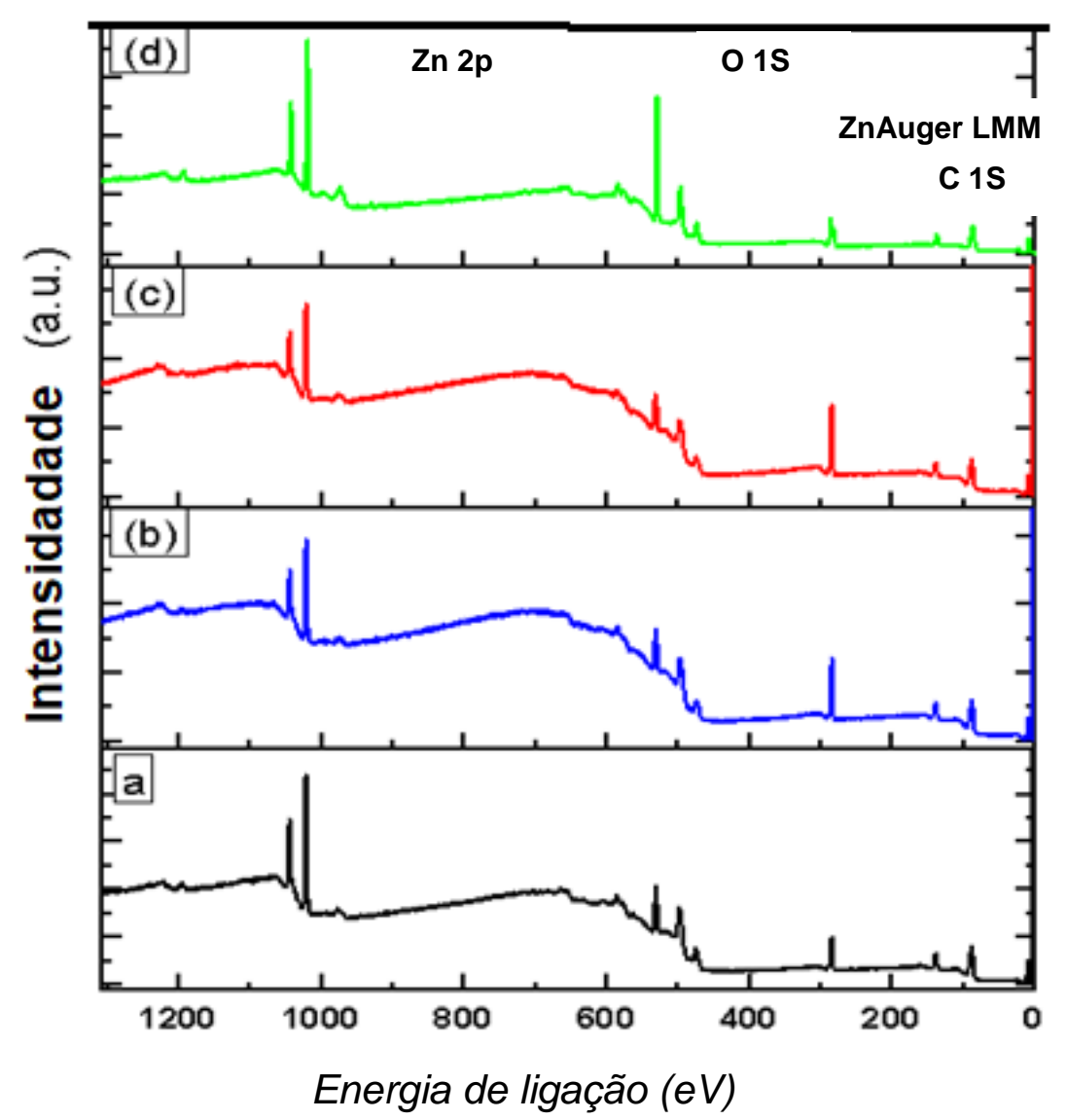

Figura 40: Espectros Survey (XPS) para: (a) zinco sem tratamento; ou zinco com tratamento por imersão em soluções de ácido oxálico concentrações: (b) $10^{-3} \mathrm{M}$; (c) $10^{-2} \mathrm{M}$; (d) $10^{-1} \mathrm{M}$.

Os picos de C1s para o zinco como recebido ou tratado em soluções de 
ácido oxálico com concentrações de $10^{-3} \mathrm{M}$ e $10^{-2} \mathrm{M}$ têm formatos similares e a componente principal deste pico corresponde a C-C/C-H, em 285,0 eV. Consequentemente, nestas baixas concentrações de ácido oxálico, a formação de oxalato de zinco não é favorecida. Já a superfície tratada em solução com maior concentração de ácido oxálico $\left(10^{-1} \mathrm{M}\right)$ apresenta picos distintos, com o pico principal em uma energia de ligação de 289,4 eV. Esta componente pode ser dividida em duas outras componentes, especificamente $289 \mathrm{eV}$, referente a carbono do grupo carboxil (-O-C=O-) pertencente ao oxalato de zinco e/ou grupos carbonatos adsorvidos, $\mathrm{CO}$ e $\mathrm{CO}_{2}(\mathrm{C}=\mathrm{O})$, e a componente em 290,1 $\mathrm{eV}$, é relacionada aos grupos $-\mathrm{COOH}$ de ácidos carboxílicos. Este último pico é frequentemente relatado como evidência de ligações entre diferentes tipos de metais e ácido oxálico, ou seja, oxalato metálico. Em apoio a esta hipótese, os picos com referências a energias de ligações de C1s, O1s, Zn2p e Zn Auger, obtidos por XPS para as amostras zinco sem tratamento e tratadas em soluções com $10^{-3} \mathrm{M}, 10^{-2} \mathrm{M}$, e $10^{-1} \mathrm{M}$ são mostrados na Fig. 41.

Tabela 3: Energia de ligação dos picos obtidos por XPS, concentrações elementares para zinco não tratado, e zinco tratado em solução de ácido oxálico com várias concentrações.

\begin{tabular}{cccc}
\hline Superfície & pico XPS & BE (eV) & $\begin{array}{c}\text { Concentração } \\
\text { elementar (at.\%) }\end{array}$ \\
\hline \multirow{3}{*}{ Como recebida } & $\mathrm{C} 1 \mathrm{~s}$ & 285,0 & 46,5 \\
\cline { 2 - 4 } & $\mathrm{O} 1 \mathrm{~s}$ & 532,0 & 32,5 \\
\cline { 2 - 4 } $10^{-3} \mathrm{M}$ & $\mathrm{Zn2p3/2}$ & 1021,5 & 21,0 \\
\cline { 2 - 4 } & $\mathrm{C} 1 \mathrm{~s}$ & 285,0 & 63,6 \\
\cline { 2 - 4 } & $\mathrm{O} 1 \mathrm{~s}$ & 532,2 & 24,1 \\
\hline \multirow{3}{*}{$10^{-2} \mathrm{M}$} & $\mathrm{Zn} 2 \mathrm{p} 3 / 2$ & 1021,3 & 12,3 \\
\cline { 2 - 4 } & $\mathrm{C} 1 \mathrm{~S}$ & 285,0 & 68,6 \\
\cline { 2 - 4 } & $\mathrm{On} 2 \mathrm{p} 3 / 2$ & 1021,4 & 20,8 \\
\hline \multirow{2}{*}{$10^{-1} \mathrm{M}$} & $\mathrm{C} 1 \mathrm{~s}$ & 289,4 & 10,6 \\
\cline { 2 - 4 } & $\mathrm{O} 1 \mathrm{~s}$ & 532,0 & 47,4 \\
\cline { 2 - 4 } & Zn2p3/2 & 1022,8 & 46,5 \\
\hline
\end{tabular}



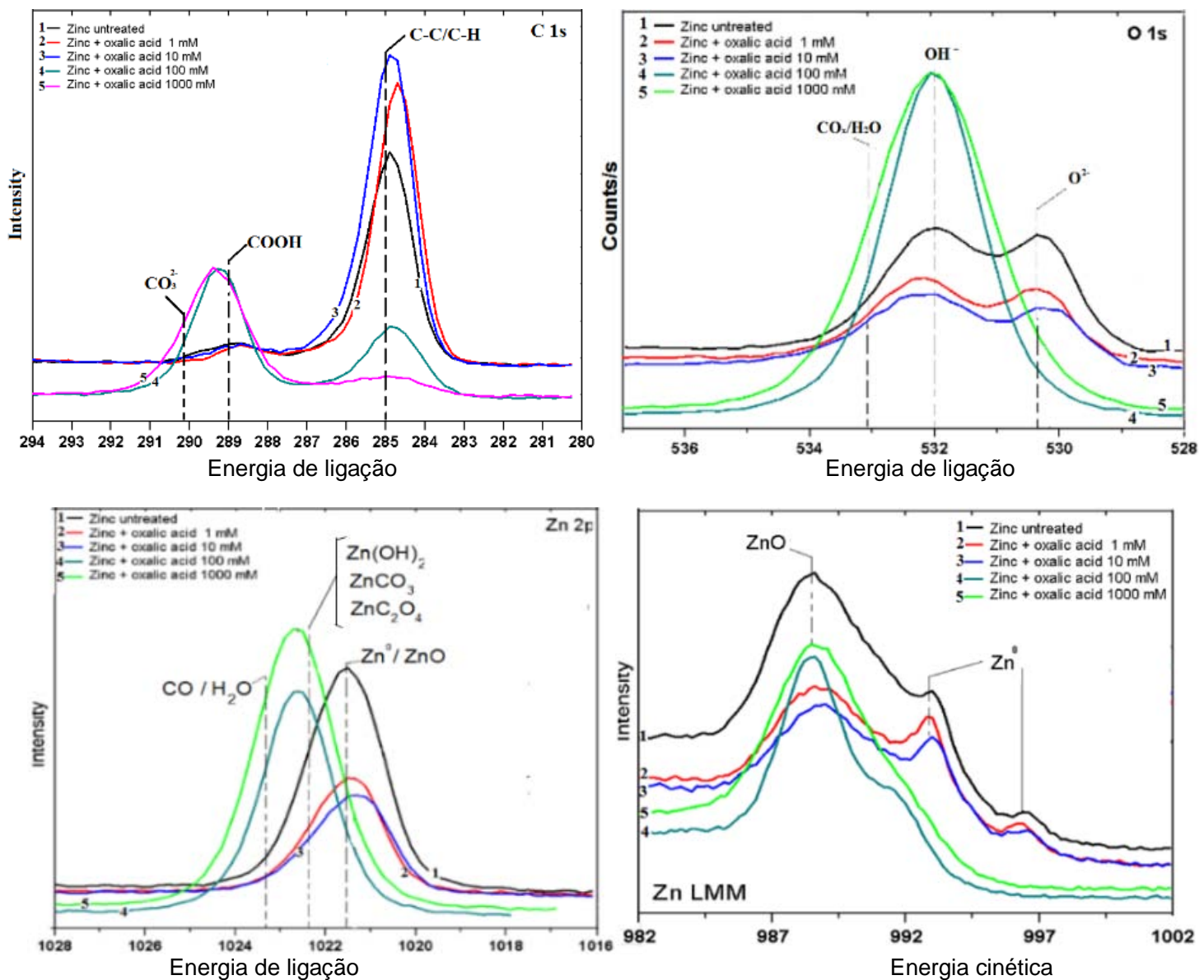

Figura 41: Sobreposição dos espectros de XPS de alta resolução para: (a) Carbono (C1s); (b) Oxigênio (O1s); (c) Zinco (Zn2p3/2) e (d) Zinco Auger (Zn L3M45N45).

De forma similar ao observado para o pico C1s, o pico O1s mostra que a superfície de zinco como recebida ou tratada em soluções combaixas concentrações de ácido oxálico $\left(10^{-3} \mathrm{M}\right.$ e $\left.10^{-2} \mathrm{M}\right)$, apresentam dois picos intensos nas energias de ligação de 530,2 eV e 532,0 eV. Para as amostras tratadas em soluçãocom concentração de $10^{-1} \mathrm{M}$ de ácido oxálico, somente um pico com energia de ligação em 532,0 eV é observado, o qual corresponde a $\mathrm{ZnO}$. O pico em 532,0 eV pode ser referenciado como $\mathrm{Zn}(\mathrm{OH})_{2}$ para zinco com recebido ou tratado em baixas concentrações de ácido oxálico $\left(10^{-3} \mathrm{M}\right.$ e $\left.10^{-2} \mathrm{M}\right)$, oua oxalato de zinco para amostras tratadas em solução com concentração de $10^{-1} \mathrm{M}$ de ácido oxálico. Embora esta afirmação pareça ambígua, ela está relacionada àpequena faixa de variação de energia de ligação para substratos de zinco.

Foram realizadas análises de pós de zinco e oxalato de zinco padrão 
analítico (Merck) e foi observado apenas um pico simétrico centrado em 532,0 eV, o que comprova o uso desta energia de ligação como referência, tanto para óxido de zinco como para oxalato de zinco.

Os picos de XPS para Zn2p3/2 zinco como recebido ou tratado em soluções com baixas concentrações de ácido oxálico $\left(10^{-3} \mathrm{M}\right.$ e $\left.10^{-2} \mathrm{M}\right)$ mostram picos em 1021,5 eV, correspondente a Zn/ZnO. Um ombro em altas energia de ligação é associado à presença de $\mathrm{Zn}(\mathrm{OH})_{2}$ e/ouZnCO $\mathrm{Zn}_{3}$, em concordância com o observado para o pico O1s. Entretanto, as superfícies tratadas em solução com $10^{-1} \mathrm{M}$, apresentaram uma única componente, descrita como oxalato de zinco. O pico Zn Auger LMM revela a presença de três picos para zinco como recebido ou tratado em soluções de baixas concentrações de ácido oxálico (10${ }^{3} \mathrm{M}$ e $10^{-2} \mathrm{M}$ ). Estes picos são relacionados com o zinco metálico, o qual não foi detectado para amostras tratadas em soluçãocom $10^{-1} \mathrm{M}$ de ácido oxálico. Isto se deve à espessura da camada formada ser maior e a cobertura total da superfície para amostras tratadas em soluções com concentração de $10^{-1} \mathrm{M}$ de ácido oxálico, em concordância com os resultados obtidos da caracterização morfológica das várias superfícies testadas.

5.7 Caracterização química da superfície de zinco após tratamento em solução com $10^{-1} \mathrm{M}$ de ácido oxálico por XPS e após ensaio de corrosão.

Os espectros XPS de alta resolução para C1s, O1s, Zn2p, Zn LMM e Na1s da superfície da amostra tratada em solução com $10^{-1} \mathrm{M}$ de ácido oxálico são apresentados na Fig. 42 paradiferentes tempos de exposição a solução 10 ${ }^{1} \mathrm{M}$ de $\mathrm{NaCl}$. A quantificação dos picos e as energias de ligação são mostrados na Tab. 4. 

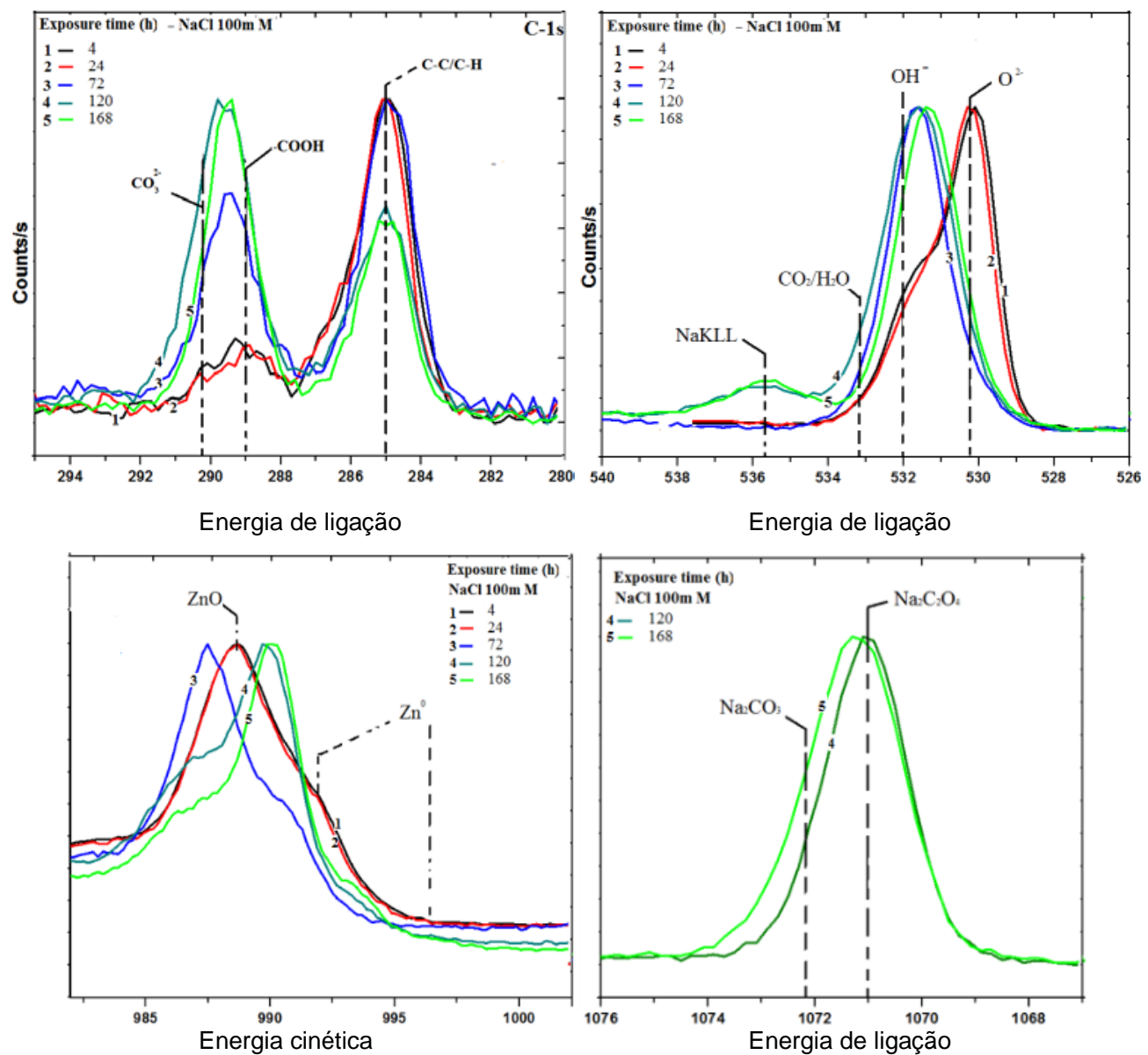

Figura 42: Sobreposição de espectros de XPS de alta resolução para vários tempos de exposição à solução de ensaio $\left(10^{-1} \mathrm{M}\right.$ de $\left.\mathrm{NaCl}\right)$. (a) carbono (C1s); (b) oxigênio (O1s); (c) zinco (Zn2p3/2), (d) zinco Auger (Zn L3M45N45) e (e) sódio (Na1s).

Os resultados de XPS para o pico C1s, antes e após o ensaio de corrosão, são qualitativamente similares. Após o ensaio de corrosão, os picos em 285,0 eV e 289,4 eV foram associados respectivamente a carbono alifático $(\mathrm{C}-\mathrm{C} / \mathrm{C}-\mathrm{H})$ e ao carbono do grupo carboxil $(\mathrm{COOH})$ e/ou carbonatos $\left(\mathrm{CO}_{3}{ }^{2-}\right)$. Devido à ausência do carbono alifático na estrutura química do ácido oxálico, o pico em 285,0 eV é considerado contaminante e sua intensidade decresce com o tempo de exposição à solução corrosiva uma vez que o contaminante se encontra na superfície do substrato de zinco. A presença de cloretos na forma de simonkolleite que foram observados por DRX após ensaio de corrosão, não foi observada por XPS. Isto se deve ao fato que as análises de XPS são superficiais, detectando alguns nanômetros da superfície. Este resultado indica que a formação de simonkolleite ocorre na interface entre o 
zinco e o oxalato de zinco, ou próximo a ela.

Antes da exposição à solução de ensaio de corrosão, as amostras como preparadas apresentavam pequenas quantidades de carbono alifático (Fig. 42 a). Após os primeiros dias de exposição, ocorreu aumento na intensidade do pico em 285,0 eV, mostrando que produtos de corrosão continuam a ser formados durante exposição ao meio corrosivo. Após 5 dias de ensaio de corrosão, o pico em 285,0 eV diminuiu devido à formação de produtos de corrosão cristalinos, de maior densidade e mais estáveis. O pico de O1s evoluiu de óxido para hidróxido e a carbonato ao longo de dias de exposição à solução $10^{-1} \mathrm{M}$ de $\mathrm{NaCl}$. Os espectros de alta resolução de Zn2p3/2mostra simetria deste pico que, por via de regra, mostra zinco em múltiplos estados químicos. O pico Zn2p3/2é próximo do valor padrão para ZnO, indicando que os átomos de zinco estão no estado de oxidação 2+.

Tabela 4: Energias de ligação de picos XPS e concentrações elementares observadas para amostra de zinco tratada em solução de ácido oxálico $\left(10^{-1} \mathrm{M}\right)$ após ensaio de corrosão em solução $10^{-1} \mathrm{M}$ de $\mathrm{NaCl}$.

\begin{tabular}{|c|c|c|c|}
\hline $\begin{array}{l}\text { Tempo (h)de } \\
\text { ensaio }\end{array}$ & Pico XPS & $\mathrm{BE}(\mathrm{eV})$ & Concent.elementar (at.\%) \\
\hline \multirow{3}{*}{4} & C 1s & 285,0 & 12,9 \\
\hline & O1s & 530,2 & 45,3 \\
\hline & $\mathrm{Zn} 2 \mathrm{p}_{3 / 2}$ & 1021,2 & 41,7 \\
\hline \multirow{3}{*}{24} & C 1s & 285,0 & 13,7 \\
\hline & O1s & 530,3 & 44,4 \\
\hline & $\mathrm{Zn} 2 \mathrm{p}_{3 / 2}$ & 1021,3 & 41,4 \\
\hline \multirow{3}{*}{72} & C 1s & 285,0 & 19,0 \\
\hline & O1s & 531,6 & 50,1 \\
\hline & $\mathrm{Zn} 2 \mathrm{p}_{3 / 2}$ & 1021,7 & 30,7 \\
\hline \multirow{6}{*}{120} & C 1s & 289,4 & 19,6 \\
\hline & O1s & 531,0 & 44,1 \\
\hline & Zn2p3/2 & 1022,8 & 12,5 \\
\hline & Na1s & 1071,0 & 23,6 \\
\hline & $\mathrm{C} 1 \mathrm{~s}$ & 289,5 & 18,3 \\
\hline & O1s & 531,6 & 44,7 \\
\hline
\end{tabular}




\begin{tabular}{cccc}
\hline \multirow{3}{*}{172} & Zn2p3/2 & 1021,9 & 9,2 \\
\cline { 2 - 4 } & Na1s & 1071,2 & 27,7 \\
\hline
\end{tabular}

Comportamento similar foi observado para os picos de Zn2p, zinco $(1021,2 \mathrm{eV})$ para $\mathrm{ZnCO}_{3} / \mathrm{Zn}(\mathrm{OH})_{2}(1023,9 \mathrm{eV})$. Os picos entre $1018 \mathrm{eV}$ a 1020 eV são considerados impurezas e podem estar ligados a compostos de sódio formados pela oxidação da camada de conversão. É possível que alguns dos átomos de zinco na camada de conversão estejam sendo substituídos por sódio resultando em uma mistura de $\mathrm{Na}_{2} \mathrm{C}_{2} \mathrm{O}_{4}$ e $\mathrm{ZnC}_{2} \mathrm{O}_{4}$.

As reações que resultam nos produtos de corrosão identificados são indicadas nas Eq.3 a 7. Os íons hidroxila gerados nas áreas catódicas reagem com íons de zinco formando hidróxido e / ou complexos com zinco (Eq. 5 e 6) solubilizando o produto de corrosão. Em meios corrosivos contendo cloretos, eventualmente os íons cloreto migram para as áreas anódicas e formam hidroxicloretos de zinco (Eq. 7). Isto ocorreu para a amostra não tratada exposta à solução corrosiva, mas não ocorreu para amostras com camada de conversão de oxalato de zinco após 172 horas de ensaio de corrosão.

$$
\begin{aligned}
& \mathrm{O}_{2}+2 \mathrm{H}_{2} \mathrm{O}+4 \mathrm{e}^{-} \rightarrow 4 \mathrm{OH}^{-}(\text {aq) } \\
& \mathrm{Zn} \rightarrow \mathrm{Zn}^{2+}+2 \mathrm{e}^{-} \\
& \mathrm{Zn}^{2+}+2 \mathrm{OH}^{-} \rightarrow \mathrm{Zn}(\mathrm{OH})_{2} \\
& \mathrm{Zn}(\mathrm{OH})_{2}+2 \mathrm{OH}^{-} \rightarrow \mathrm{Zn}(\mathrm{OH})_{4}^{2-} \\
& 5 \mathrm{Zn}(\mathrm{OH})_{2}+2 \mathrm{Cl}^{-}+\mathrm{H}_{2} \mathrm{O} \rightarrow 5 \mathrm{Zn}_{5}(\mathrm{OH})_{8} \mathrm{Cl}_{2}+2 \mathrm{OH}^{-}
\end{aligned}
$$

A presença de carbonato de zinco foi também detectada por XPS após $120 \mathrm{~h}$ e $168 \mathrm{~h}$ de exposição à solução de $\mathrm{NaCl}$. A formação destes produtos depende da dissolução do dióxido de carbono atmosférico na solução corrosiva (Eqs. 8 e 9).

$$
\begin{aligned}
& \mathrm{CO}_{2}+2 \mathrm{OH}^{-} \rightarrow \mathrm{CO}_{3}{ }^{2-}+\mathrm{H}_{2} \mathrm{O} \\
& \mathrm{CO}_{3}{ }^{2-}+\mathrm{H}_{2} \mathrm{O} \rightarrow \mathrm{HCO}_{3}+\mathrm{OH}^{-}
\end{aligned}
$$

O pico de Na1s foi ajustado com três componentes, especificamente 1071,0 eV, 1071,2 eV e 1072,2 eV, os quais correspondem a oxalato de sódio $\left(\mathrm{Na}_{2} \mathrm{C}_{2} \mathrm{O}_{4}\right)$, bicarbonato de sódio $\left(\mathrm{NaHCO}_{3}\right)$ e carbonato de sódio $\left(\mathrm{Na}_{2} \mathrm{CO}_{3}\right)$ respectivamente. A reação entre íons de sódio $\left(\mathrm{Na}^{+}\right)$e íons carbonato resulta 
na formação de hidrogenocarbonato de sódio e carbonato de sódio (Eqs. 10 e 11).

$$
\begin{aligned}
& \mathrm{Na}^{+}+\mathrm{HCO}_{3}^{-} \rightarrow \mathrm{NaHCO}_{3} \\
& \mathrm{Na}^{+}+\mathrm{NaHCO}_{3} \rightarrow \mathrm{Na}_{2} \mathrm{CO}_{3}
\end{aligned}
$$

De acordo com os resultados de XPS, uma camada contendo carbonato/bicarbonato de sódio e oxalato de sódio é formada após 5 a 7 dias de exposição à solução $10^{-1} \mathrm{M}$ de $\mathrm{NaCl}$. Este produto provém da reação entre o dióxido de carbono e o oxalato de zinco com íons de sódio da solução. A relação zinco e oxigênio mostra que as superfícies de oxalato de zinco foram enriquecidas com oxigênio quando expostas ao ar e à umidade. Uma vez que a camada de oxalato foi exposta à solução corrosiva, o cloreto de sódio ativa a superfície e os valores da relação zinco e oxigênio $(\mathrm{Zn} / \mathrm{O})$ aumentam. O período mais longo de exposição permitiu a formação de hidróxido de zinco e simonkolleite (Eq. 12). O excesso de oxigênio pode ser explicado pela presença de outros carbonatos, como carbonato de sódio na superfície da amostra.

$$
2 \mathrm{Na}^{+}+2 \mathrm{Cl}^{-}+\mathrm{ZnC}_{2} \mathrm{O}_{4} \rightarrow \mathrm{Na}_{2} \mathrm{C}_{2} \mathrm{O}_{4}+\mathrm{ZnCl}_{2}
$$

A natureza do efeito inibidor do revestimento de oxalato de zinco contendo carbonato e/ou óxido de zinco não foi ainda completamente esclarecido. O efeito passivador do revestimento de oxalato de zinco pode ocorrer devido à limitação ao transporte de íons cloreto para o substrato metálicoseja devido à maior densidade de carga que melhora a retenção do carbonato na superfície, ou pela repulsão de íons cloreto pelo filme superficial carregado negativamente.

O comportamento do zinco sob o revestimento de oxalato de zinco em eletrólito de $\mathrm{NaCl}$ provavelmente está relacionado às diferenças nas propriedades de troca iônica da camada externa. Neste caso, quantidades reduzidas de defeitos resultam em taxa de difusão mais restrita de oxigênio pelas porosidades do revestimento. Consequentemente, a taxa da reação de redução de oxigênio é mais lenta, o que favorece a formação de simonkolleite com o tempo de exposição à solução de cloreto de sódio. 
Algumas questões surgem dos resultados obtidos como, por exemplo, a corrosão ocorre ao longo da camada de oxalato? A camada de oxalato é consumida? Como se distribuem os elementos do meio de ensaio de corrosão na camada de oxalato? Estas questões podem ser respondidas parcialmente por análises de XPS.

Os perfis de profundidade obtidos por XPS para amostras tratadas em solução de ácido oxálico antes da exposição ao meio corrosivo e após exposição por diferentes tempos de ensaio de corrosão, entre $10 \mathrm{~min}$. e 7 dias, Fig. 43 e imagens obtidas (FIB), Fig. 44, podem ser usadas para responder as questões apresentadas. As concentrações atômicas elementares foram apresentadas em função do tempo de desbastamento (etching time), sendo este convertido em profundidade, considerando-se uma taxa de desbastamentodefinida.

A camada formada é representada pelo perfil de carbono (pico de carboxila a $289 \mathrm{eV}$ ). Pode-se observar que esta é mais espessa nas amostras com os menores tempos de ensaio de corrosão e a espessura diminui com o tempo de ensaio (7 dias) mostrando que a camada de oxalato é consumida ao longo do processo de corrosão.

Em relação aos sinais de íons eletrólito $\left(\mathrm{Na}^{+} \mathrm{e} \mathrm{Cl}^{-}\right)$na camada formada, o sódio é observado em todas amostras e em todos os níveis, incluindo na interface óxido-metal. O cloreto, por outro lado, só é observado após 60 min. de ensaio de corrosão, sendo muito mais intenso para a amostra com 7 dias de ensaio. Estes resultados apoiam os resultados de DRX que identificaram simonkolleite $\left(\mathrm{Zn}_{5}(\mathrm{OH})_{8} \mathrm{Cl}_{2}\right)$. No último nível de perfis (250), a relação $\mathrm{O} / \mathrm{Zn}$, mais elevada para a amostra ensaiada por 7 dias, mostra que a camada de produtos de corrosão é mais espessa do que nas ensaiadas por menos tempo.

Os resultados indicam que na superfície das amostras tratadas em solução de ácido, antes do ensaio de imersão, a camada de oxalato liga-se ao óxido de zinco, Figura 13 (a), o que é indicado pelo desaparecimento do sinal de carbono ao nível 150, em que a razão O/Zn é 1:1. Com o tempo de ensaio ocorre o consumo gradual da camada de oxalato. No entanto, mesmo após sete dias de ensaio ainda são observados resquícios da camada de oxalato. É 
importante notar que os picos de carbono observados em todos os perfis de profundidade estão relacionados ao grupo carboxílico $(289 \mathrm{eV})$, tendo que o pico referente ao contaminante e carbono alifático $(285 \mathrm{eV})$ é removido após os primeiros níveis de ataque.
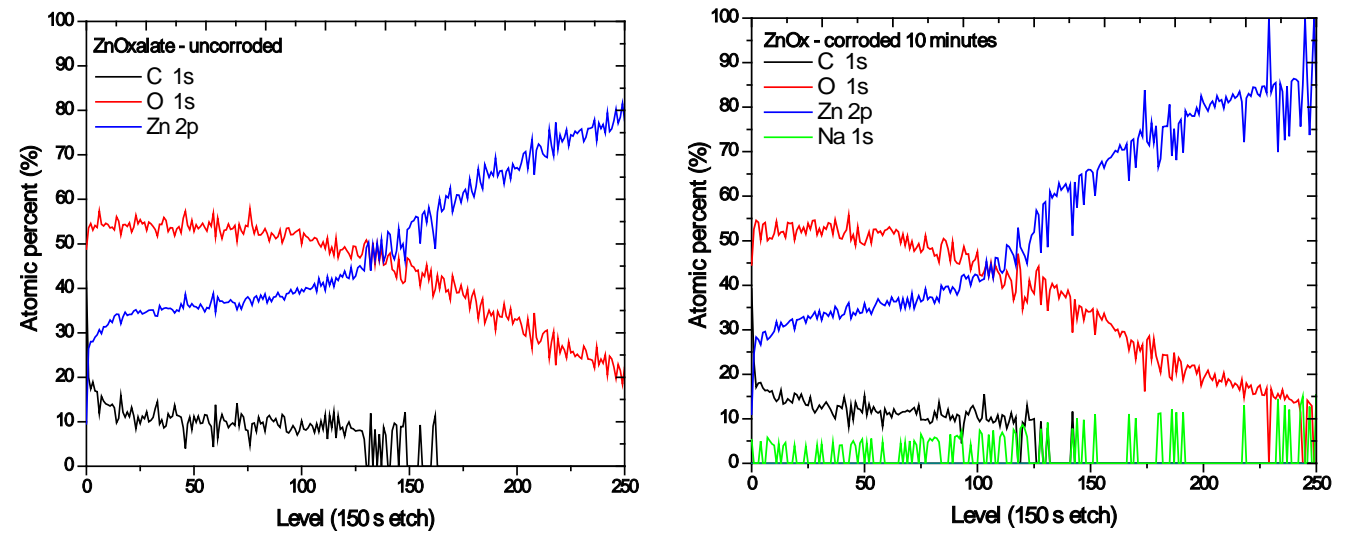

Figuras 43: Perfil de profundidade obtido por XPS para a camada de oxalato de zinco (a) e (b) antes do ensaio de corrosão.
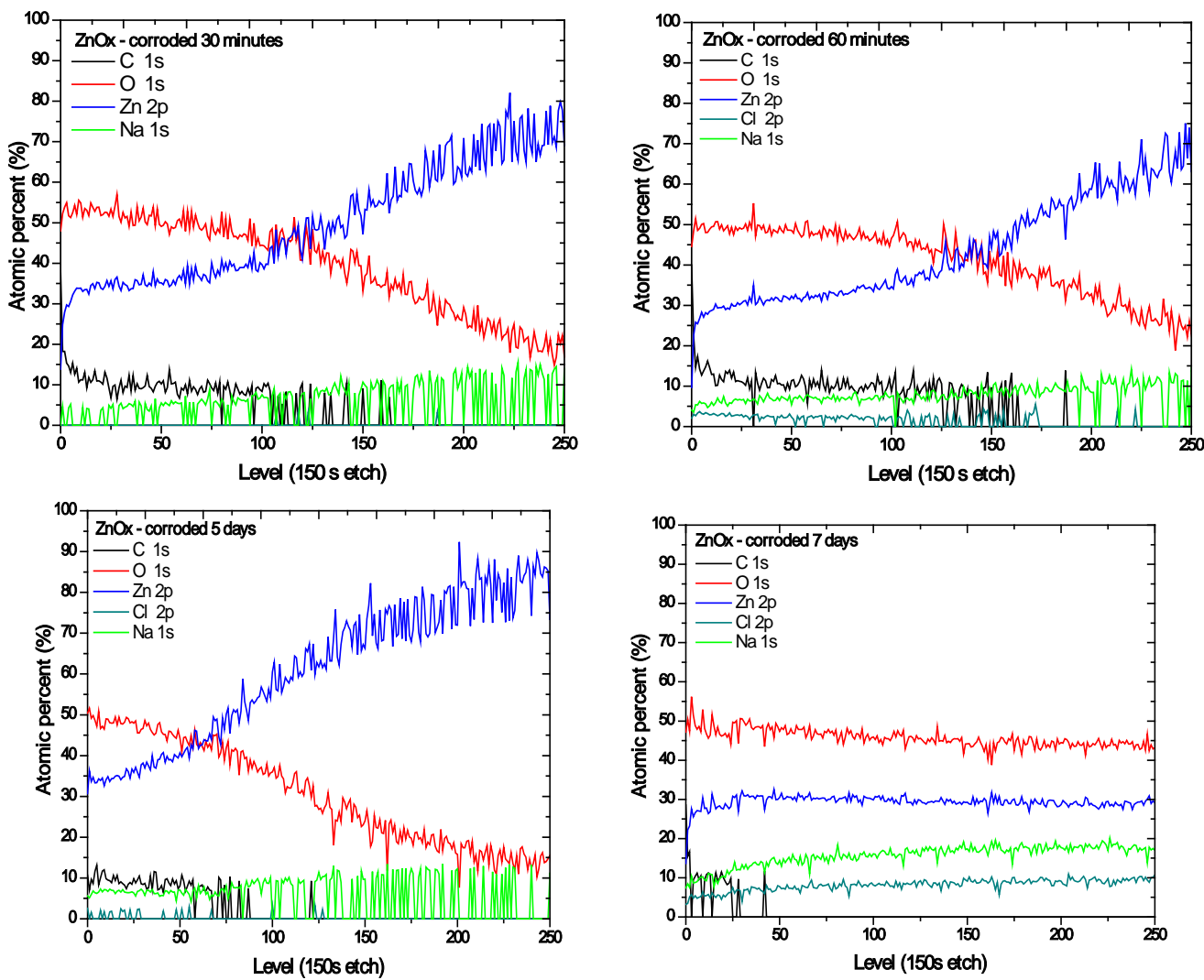

Figuras 44: Perfil de profundidade obtido por XPS para a camada de oxalato de zinco (a) antes do ensaio de corrosão, e após ensaio de corrosão por; (a) 30 min.; (b) 60 min.; (c) 5 dias e (d) 7 dias. 
O sódio tem fácil penetração através da camada de oxalato e atinge a interface entre zinco e o oxalato após 10 min. de imersão e, mesmo pós sete dias de ensaio, a quantidade deste elemento é maior do que a quantidade de cloreto.

O cloreto apresenta penetração mais lenta, em comparação com o sódio. Após uma hora (Fig. 44) é possível observar os primeiros sinais de cloreto. Nos tempos de corrosão seguintes, o sinal de cloreto é seguido de ruído, provavelmente pela sua instabilidade na superfície do zinco. É possível observar que após sete dias de ensaio, o sinal de cloreto é mais intenso nas partes mais internas da amostras em relação à superfície, isto é, mais uma evidência para a presença de cloreto na forma de simonkolleite como descrito nos resultados de XRD (Fig. 44).

A utilização dos mesmos parâmetros utilizados para desbastamento (etch) navárias amostras permitiu comparação entre os diferentes perfis de profundidade XPS em função do tempo de ensaio. Utilizando o sinal de zinco, que atinge altas concentrações e representa zinco metálico do substrato, podese afirmar que após 7 dias de ensaio a camada presente na superfície é praticamente homogênea em relação aos seus constituintes e que estes produtos são mais estáveis e difíceis de remover pelo argônio.

5.8 Caracterização morfológica e da espessura das camadas na superfície do zinco tratado em soluções com $10^{-1} \mathrm{M}$ e $1 \mathrm{M}$ de ácido oxálico em amostras preparadas pela técnica (FIB) antes do ensaio de corrosão.

As micrografias e resultados de análises de EDS de amostras preparadas pela técnica FIB, Fig. 45, permitiram estimar as espessuras das camadas de conversão de oxalato de zinco obtidasdos tratamentos nas soluções com $10^{-1} \mathrm{M}$ e $1 \mathrm{M}$ de ácido oxálico. 


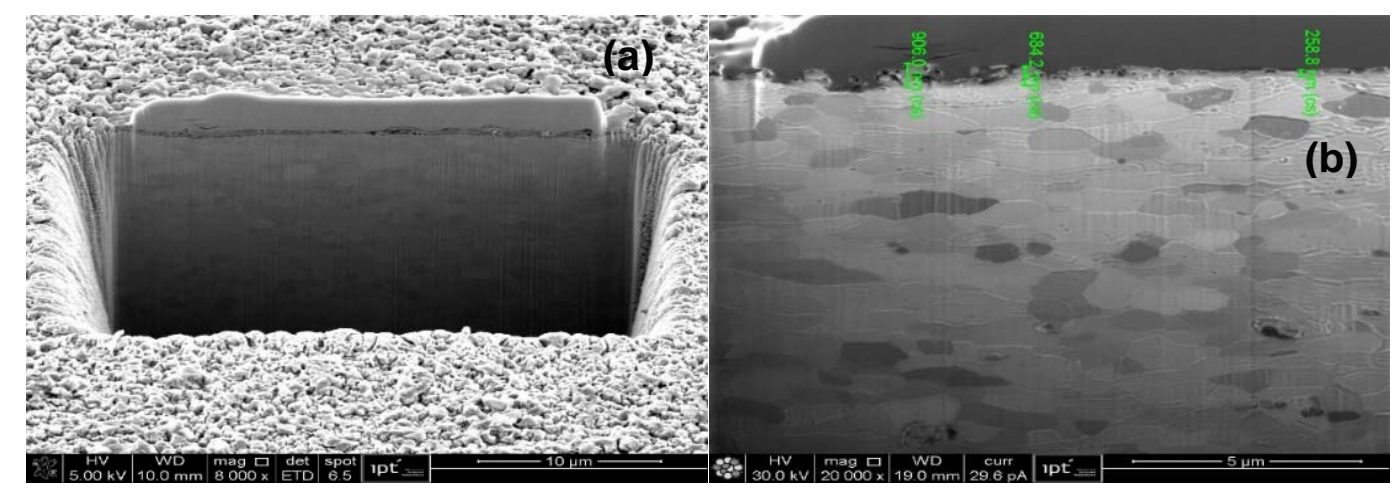

Figura 45:(a) Preparação de amostra por desbaste por feixe de íons de argônio. (b) Micrografias das seção da amostra preparada pela técnica FIB para observação da camada de oxalato formada a partir detratamentos em solução com $10^{-1} \mathrm{M}$ de ácido oxálico.

As espessuras médias para as camadas de conversão de oxalato de zinco preparadas a partir de soluçõescom $10^{-1} \mathrm{M}$ e $1 \mathrm{M}$ de ácido oxálico foram respectivamente $600 \mathrm{~nm}$ e $300 \mathrm{~nm}$. Estes resultados mostram que a concentração de $1 \mathrm{M}$ causou ataque corrosivo da superfície mais intenso do que a de $10^{-1} \mathrm{M}$ e menor tendência ao crescimento da camada neste meio, devido à elevada acidez desta última solução.

5.9. Caracterização morfológicae da espessura das camadas na superfície do zinco tratado em soluçõescom $10^{-1} \mathrm{M}$ e $1 \mathrm{M}$ de ácido oxálico em amostras preparadas pela técnica FIB após ensaio de corrosão.

As imagens por microscopia eletrônica de varredura foram obtidas utilizando-se elétrons secundários e elétrons retro-espalhados (BackScattering Electron Detector - BSED). No caso de elétrons secundários o contraste é devido principalmente ao relevo e no caso de elétrons retro-espalhados é devido à composição, ou seja, quanto maior o número atômico do elemento mais clara é a imagem. Nos espectros obtidos com o espectrômetro por dispersão de energia de raios-X (EDS) a quantificação de todos os elementos presentes foi feita na condição "Standardless". Micrografias das secções de amostras expostas ao meio corrosivo por 7 dias, foram preparadas por FIB e os resultados são apresentados nas Figs. 46 e 47. 

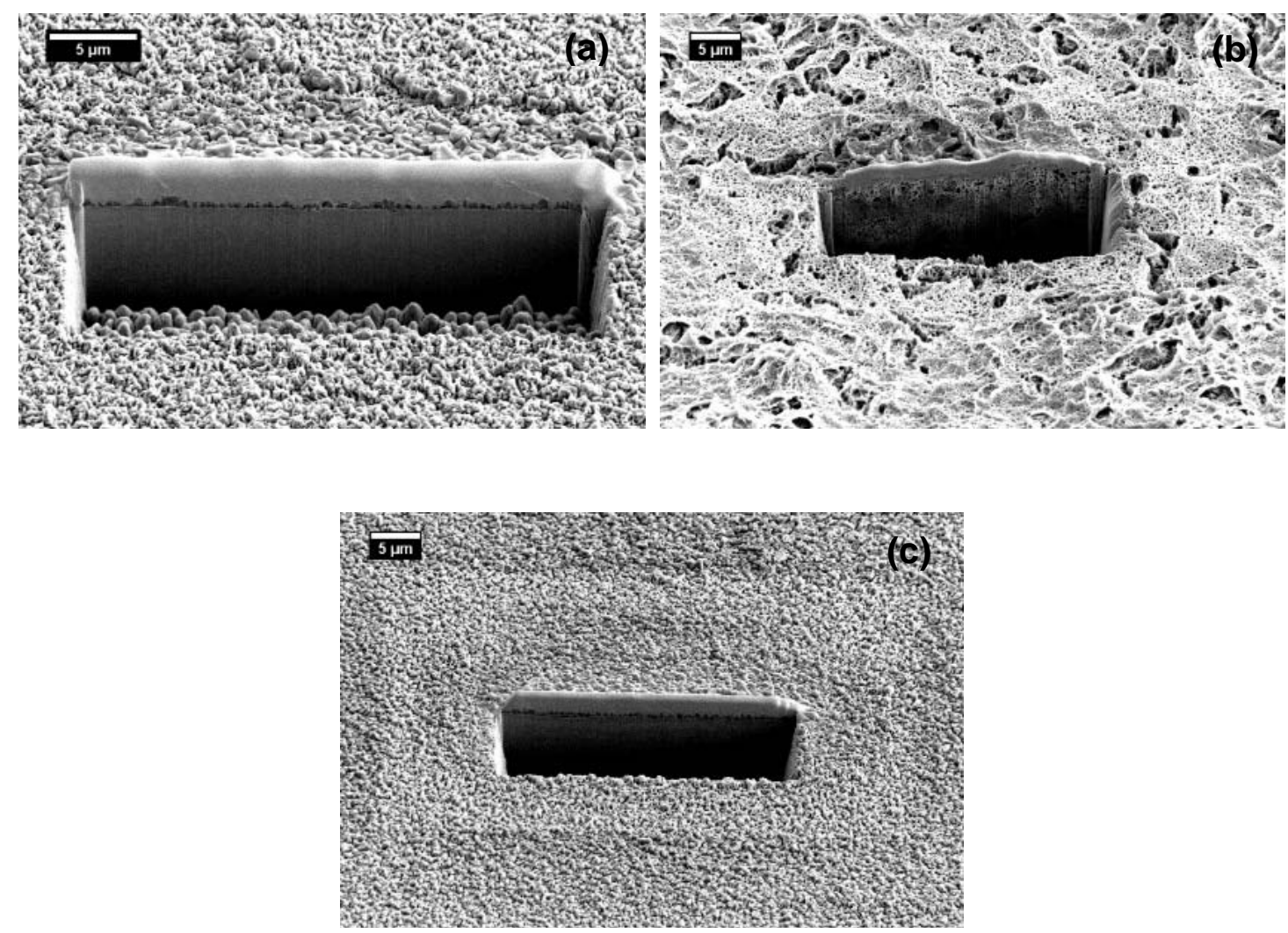

Figura 46: Micrografias das seções de amostras preparadas pela técnica FIB para observação da camada de oxalato formada a partir detratamentos em solução com $10^{-1} \mathrm{M}$ de ácido oxálico (a) antes e após exposição a solução $10^{-}$ ${ }^{1} \mathrm{M}$ de $\mathrm{NaCl}$ por (b) 30 min. e (c) 3 dias.

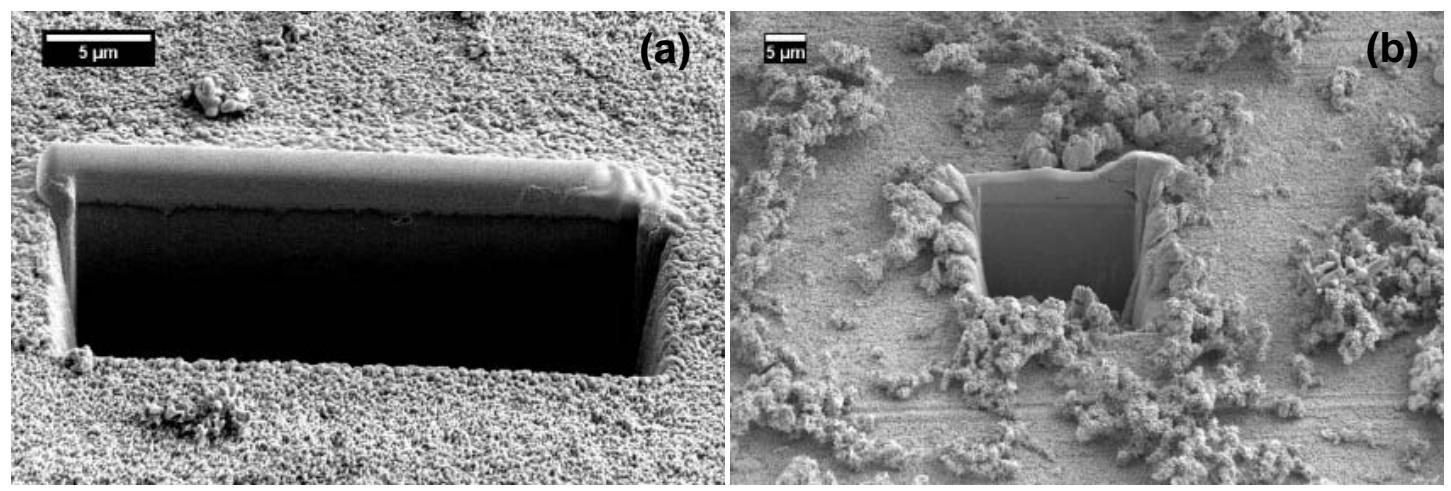




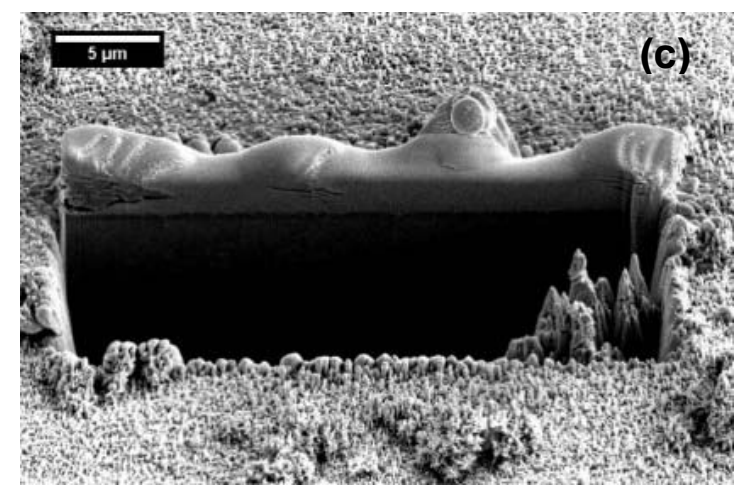

Figura 47:Micrografias das seções transversais de amostras preparadas pela técnica FIB para observação da camada de oxalato formada a partir de tratamentos em solução com $10^{-1} \mathrm{M}$ de ácido oxálico após exposição a solução $10^{-1} \mathrm{M}$ de $\mathrm{NaCl}$ (a) por 5 dias (b) 7 dias e (c) amostras como recebidasapós 7 dias de ensaio de corrosão.

As micrografias obtidas por FIB permitem avaliar a evolução da morfologia da camada de oxalato de zinco em função do tempo de ensaio de corrosãoe comparar a morfologia da superfície da amostra como recebida e ensaiada durante o mesmo tempo de ensaio.A alteração mais significativa na morfologia ocorreu entre 1 e 3 dias do ensaio de corrosão. Produtos de corrosão foram observados em todas as amostras ensaiadas, porém estes forma mais volumosos na amostra de zincosem tratamento (como recebida), (Fig.47 b). A Fig. 48 mostra a evolução da camada obtida em solução com 10 ${ }^{1} \mathrm{M}$ de ácido oxálico em função do tempo de exposição à solução $10^{-1} \mathrm{M}$ de $\mathrm{NaCl}$, através da de observação da secção.

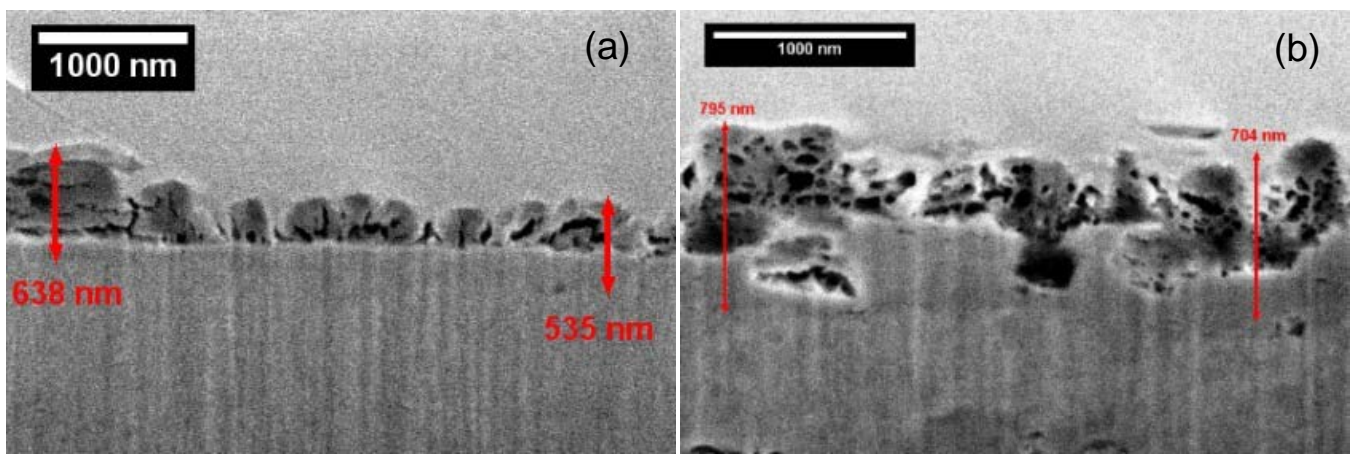

(c) 

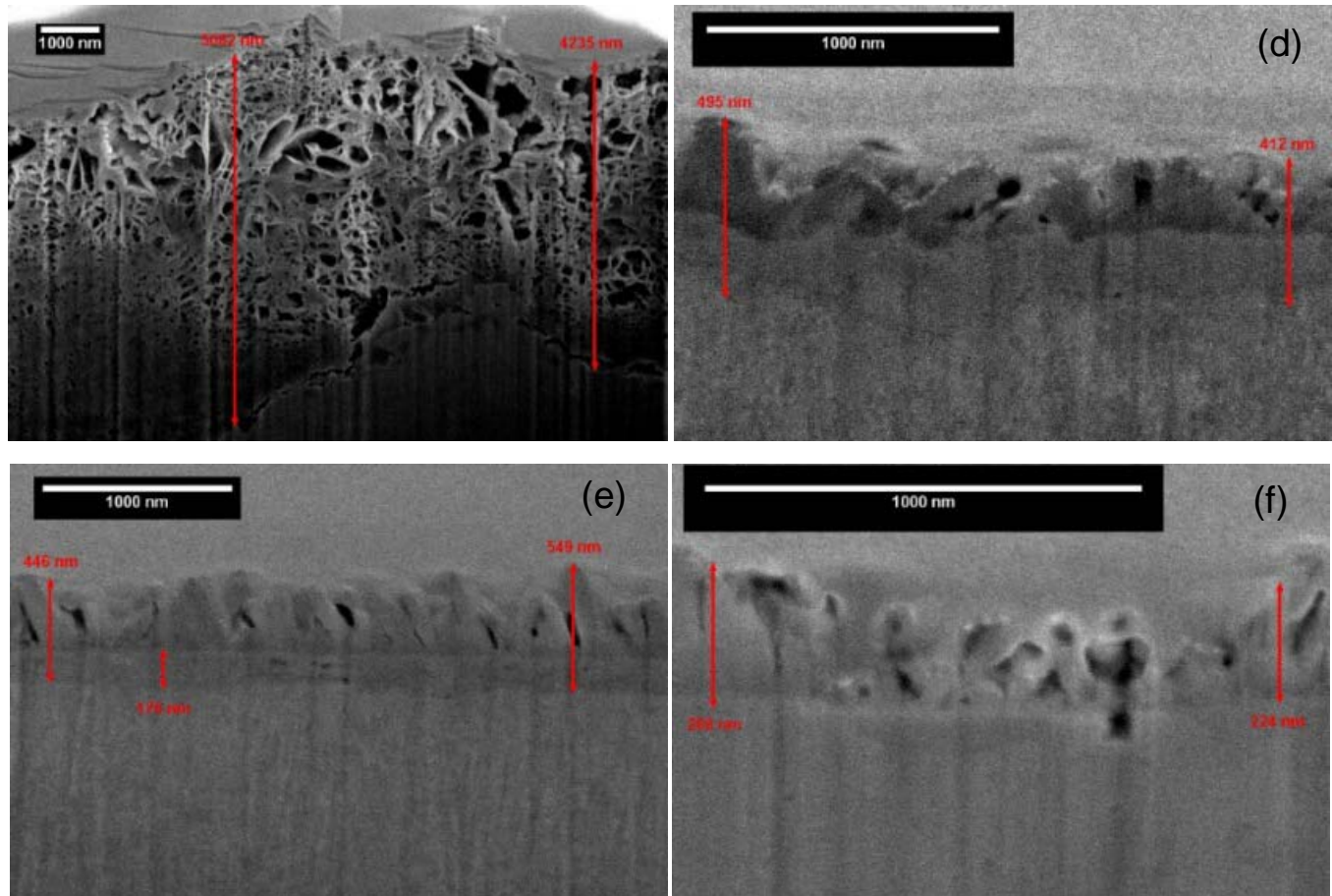

Figura 48: Micrografias das seçõesde amostras obtidas por (FIB) de amostra com camada de oxalato (a) antes do ensaio de corrosão e após imersão em solução $10^{-1} \mathrm{M}$ de $\mathrm{NaCl}$ por(b) 30 min.; (c) 3 dias; (d) 5 dias e (e) 7 dias; e (f) amostra como recebida após 7 dias de exposição a solução de ensaio $\left(10^{-1} \mathrm{M}\right.$ de $\mathrm{NaCl})$.

É possível notar que a camada de oxalato apresenta porosidades/defeitos e tem espessura uniforme, Fig. 48(a). Com o tempo de ensaio, o ataque da camada de oxalato pela solução corrosiva torna o revestimento mais poroso e mais espesso, particularmente após 3 dias de ensaio. Após este período as camadas se tornam mais finas, mais compactas e a porosidade diminui entre $05^{\circ}$ e o $7^{\circ}$ dia de do ensaio de corrosão. Estes resultados apoiam os obtidos por perfil de profundidade (Fig. 43) onde foi que a camada que se forma com o tempo de exposição ao meio corrosivo é mais estável e mais difícil de ser removida por desbastamento com íons argônio.

A Figura 48(e) sugerea presença de duas camadas na superfície do zinco tratado em solução $10^{-1} \mathrm{M}$ de ácido oxálico e exposto por 7 dias ao meio corrosivo. A primeira camada $(270 \mathrm{~nm})$ contém óxido/hidróxido de zinco e, aparentemente foi atacada de modo cristalográfico. A segunda camada (176 $\mathrm{nm})$, embora não seja particularmente evidente, tem aparênciacristalina e possui uma fração baixa de poros e vazios. É observado também que a 
porosidade na camada de óxido/hidróxido de zinco diminuiu com o tempo em resultado da acumulação de produtos de corrosão que tornam acamada mais espessa e mais compacta. O conhecimento detalhado da porosidade e composição da camada formada é essencial para a compreensão do processo de corrosão.

5.10. Proposta de mecanismo de proteção contra a corrosão para camada formada em solução com $10^{-1} \mathrm{M}$ de ácido oxálico.

Um modelo foi proposto neste trabalho para o mecanismo de proteção contra a corrosão proporcionado pela camada de oxalato formada pela interação da superfície de zinco com solução com $10^{-1} \mathrm{M}$ de ácido oxálico. A Fig. 49 ilustra o modelo proposto neste trabalho em que defeitos na camada expõem o substrato metálico dando início a processos de corrosão do substrato com formação íons de zinco $\left(\mathrm{Zn}^{2+}\right)$ nas áreas anódicas e de íons hidroxila $\left(\mathrm{OH}^{-}\right)$nas áreas catódicas. A migração dos íons $\mathrm{Zn}^{2+}$ para a parte externa da camada resulta na deposição de hidróxido de zinco sobre a superfície externa da camada, incluindo os defeitos destacamada, resultando em aumento de proteção com o tempo de ensaio. A camada de oxalato de zinco também é atacada pelo meio corrosivo (solução de $\mathrm{NaCl}$ ) e oxalato de sódio é formado em consequência deste ataque. Os produtos de corrosão do substrato de zinco e da camada de oxalato, ao ficarem retidos na superfície das camadas de oxalato, bloqueiam, no início de forma parcial (ocorrendo processos de corrosão controlados por difusão) mas acabam cobrindo, não apenas os defeitos, mas toda a superfície exposta ao meio corrosivo. 


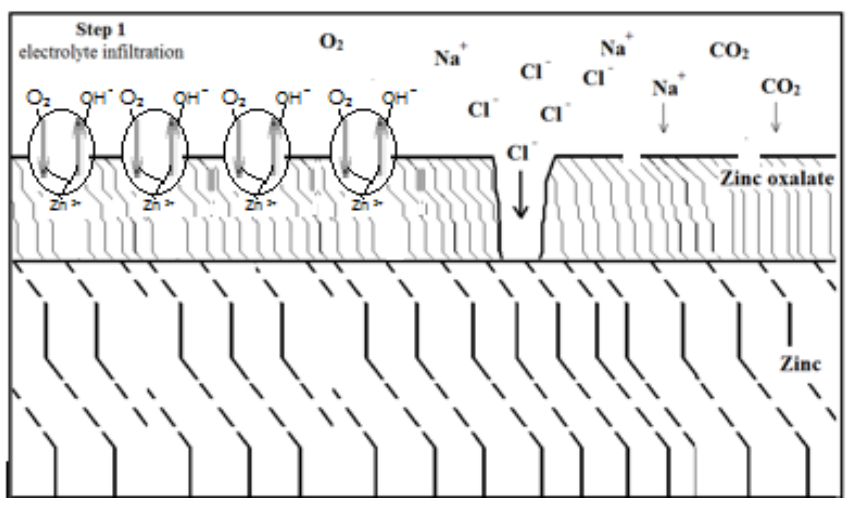

(a)

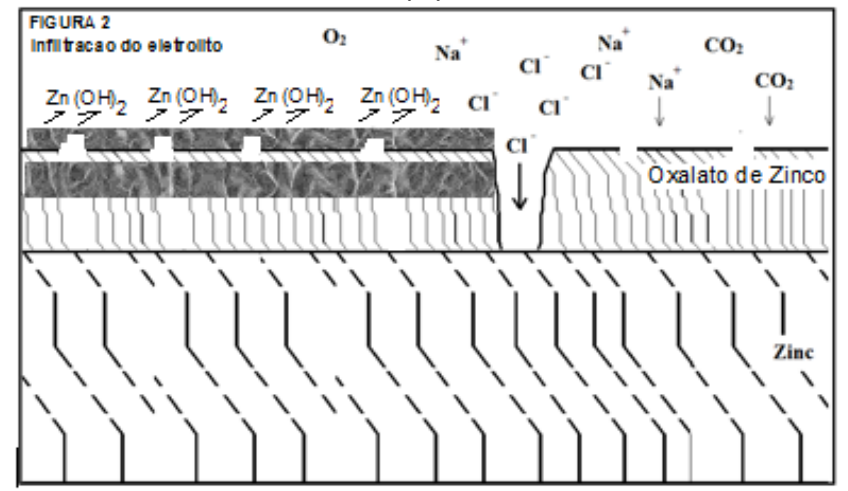

(b)

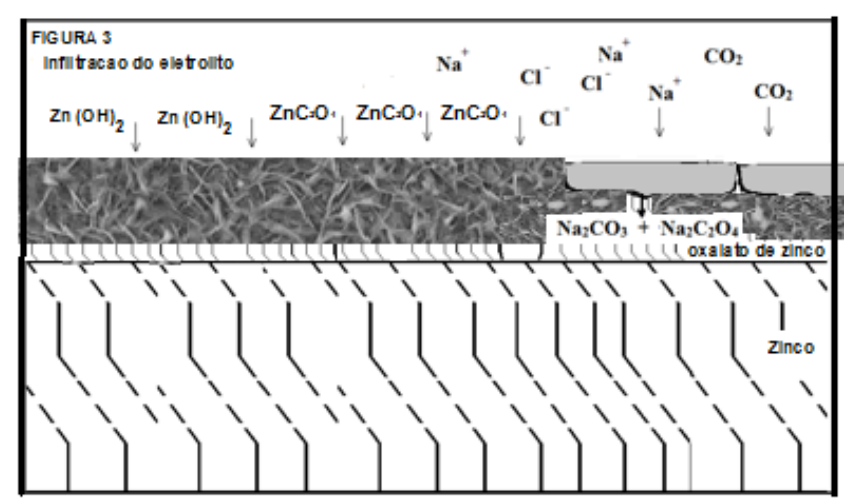

(c)

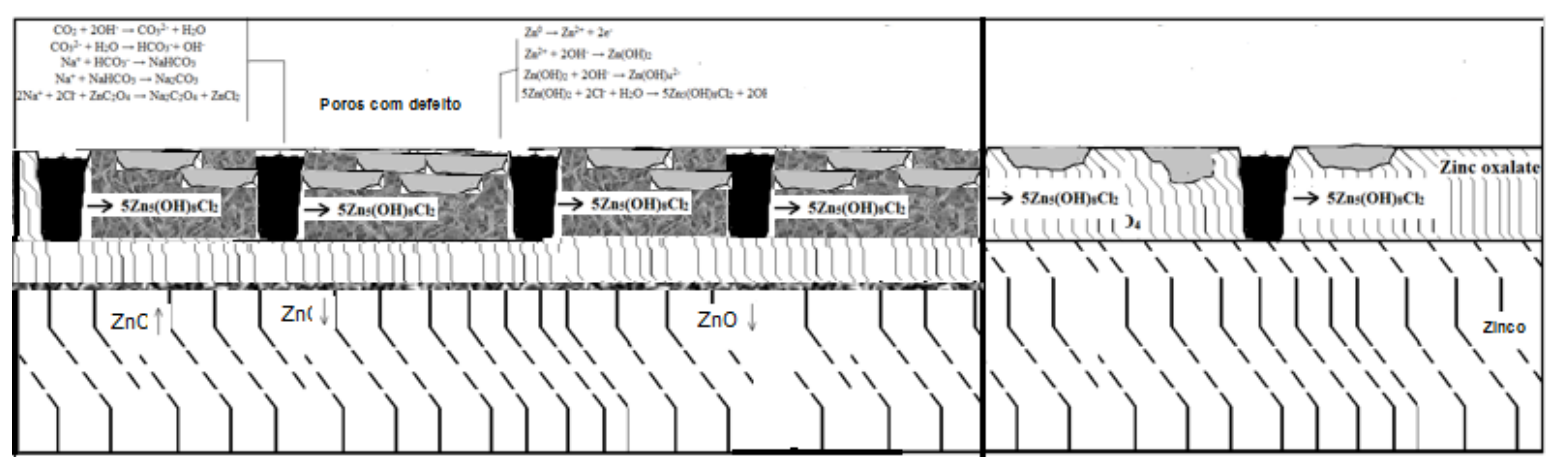

(d) 
Figura 49: Processo esquemático de corrosão para a camada de oxalato de zinco em diferentes tempos de exposição ao cloreto de sódio (a) primeiras horas (b) das primeiras horas até 1 dia, (c) de 3 a 5 dias e (d) entre 5 e 7 dias.

\section{CONCLUSÃO}

Neste trabalho, o efeito do ácido oxálico na formação de camadas de proteção contra a corrosão do zinco foi investigado. Camadas superficiais foram obtidas pela imersão de amostras de zinco em soluções de ácido oxálico com diferentes concentrações. Todas as soluções de tratamento mostraram elevada acidez (faixa entre 2,89 e 0,89) e resultaram em ataque da superfície 
de zinco. Os tratamentos de imersão resultaramna formação de camadas superficiais cuja composição, espessura, concentração de defeitos, comportamento eletroquímico, resistência à corrosão e interação com uma camada de verniz variou comconcentração do ácido oxálico.

Os resultados dos ensaios em câmarade névoa salina e ensaios de espectroscopia de impedância eletroquímica mostraram que tratamentos em soluções com composição superiores a $10^{-1} \mathrm{M}$ de ácido oxálico resultaram em camadas com muitos defeitos (porosidades e trincas) os quais favoreceram o ataque localizado o qual, no caso da solução com maior concentração resulta em superfícies com impedâncias menores que o zinco sem tratamento. Os resultados de ensaio em câmara de névoa salina e espectroscopia de impedância eletroquímica indicaram que a concentração de $10^{-1} \mathrm{M}$ de ácido oxálico foi a que produziu resultados mais promissores para a faixa de concentrações estudadas para a formação de um filme que confere proteção prolongada à superfície do zinco. A caracterização química desta camada foi realizada por várias técnicas como XPS, FIB, TEM.

Os ensaios em câmara de névoa salina para amostras sem tratamento ou tratadas na solução com $10^{-1} \mathrm{M}$ de ácido oxálico e camada de verniz, seja sem risco ou com risco para exposição do substrato metálico, mostraram boa interação entre a camada formada e o verniz, com boa aderência entre estas camadas, baixo descolamento catódico tendo sido notado na superfície das amostras tratadas e com verniz.

Os resultados de XPS mostraram a presença de um revestimento fino (película de óxido de zinco) para a amostra não tratada, composta principalmente de óxido de zinco e, também de hidróxido de zinco e carbonato de zinco. As camadas formadas em soluções de ácido oxálico na faixa de 10${ }^{3} \mathrm{M}$ a $10^{-1} \mathrm{M}$ são compostas de oxalato de zinco e produtos de corrosão do zinco, especificamente $\mathrm{ZnO}, \mathrm{Zn}(\mathrm{OH})_{2}$, e $\mathrm{ZnCO}_{3}$.No caso das amostras tratadas em solução com $1 \mathrm{M}$, apenas oxalato e óxido de zinco foram identificados.

Os resultados de XPS também mostraram a presença de carbonato de sódio, além de oxalato de sódio para períodos de (5 a 7) dias de exposição à solução $10^{-1} \mathrm{M}$ de $\mathrm{NaCl}$. Este produto provém da reação entre o dióxido de 
carbono e o oxalato de zinco com íons de sódio da solução e mostram a degradação da camada de oxalato de zinco com o tempo de ensaio. Os resultados de FIB mostraram que a camada de oxalato é consumida ao longo do processo de corrosão mas após 7 dias de ensaio resquícios desta ainda são observados na superfície.

As espessuras médias das camadas de conversão de oxalato de zinco preparadas em soluções com $10^{-1} \mathrm{M}$ e $1 \mathrm{M}$ de ácido oxálico estimadas por FIB foram respectivamente $600 \mathrm{~nm}$ e $300 \mathrm{~nm}$. Estes resultados mostraram que a concentração de $1 \mathrm{M}$ causou intenso ataque corrosivo da superfície e dissolução no meio de parte dos produtos de corrosão formados, enquanto a camada formada em meio com $10^{-1} \mathrm{M}$ permitiu a deposição de camada mais espessa e mais protetora contra a corrosão do substrato. A razão atribuída para este resultado foi a elevada acidez da solução com $1 \mathrm{M}$ de ácido oxálico.

Os resultados de difração de raios $X$ mostraram a presença de simonkolleite após 7 dias de exposição a solução corrosiva de cloreto de sódio. Este produto foi observado apenas nas amostras com camada de oxalato de zinco sugerindo que este atue como catalisador da formação deste produto de corrosão. Este produto atua por efeito barreira bloqueando os defeitos/porosidade da camada.

Foi observado também que a porosidade na camada de óxido/hidróxido de zinco diminuiu com o tempo em resultado da acumulação de produtos de corrosão que tornam a camada mais espessa e mais compacta. Estes resultados explicam o aumento de impedância da superfície com o tempo de exposição ao meio corrosivo.

\section{REFERÊNCIAS}

AKSU, S. Electrochemistry of copper in aqueous oxalic acid solutions. Journal Electrochemichal Society, 152(12), (2005) G938-G943.

ALEXANDER, M. R.; BEAMSON, G.; BLOMFIELD, C. J.; LEGGETT, G.; DUC, T. M. Interaction of carboxylic acids with the oxyhydroxide surface of aluminium: poly (acrylic acid), acetic acid and propionic acid on pseudoboehmite.Journal of Electron Spectroscopy and Related Phenomena,121(1-3), (2001) 19-32.

ALEXANDER, M. R.; LEWINGTON, T. A.; FOSTER, T. T.; THOMPSON, G. E.; LEGGETT, G. J.; MCALPINE, E. The surface chemistry of aluminium and its 
influence on chemisorption of organic molecules. ATB Métallurgie, 43(1-2), (2003) 60-65.

ALMEIDA, E.; MORCILLO, M.; ROSALES, B. Atmospheric corrosion of zinc Part 2: Marine atmospheres. British Corrosion Journal,35(4), (2000) 289-296.

AMADEH, B.; PAHLEVANI, B.; HESHMATI-MANESH, S.. Effects of rare earth metal addition on surface morphology and corrosion resistance of hot-dipped zinc coatings. Corrosion Science, 44(10), (2002) 2321-2331.

ARAMAKI, K. Preparation of chromate-free, self-healing polymer films containing sodium silicate on zinc pretreated in a cerium (III) nitrate solution for preventing zinc corrosion at scratches in $0.5 \mathrm{M} \mathrm{NaCl}$. Corrosion Science, 44(6), (2002) 1375-1389.

ARAMAKI, K. The inhibitions effects of cation inhibitors on corrosion of zinc in aerated 0.5 M NaCl. Corrosion Science, 43(8), (2001) 1573-1588.

ASTM B117 - Standard Practice for Operating Salt Spray (Fog) Apparatus 2016 Edition, ASTM American Society For Testing Materials (2016).

ATES, M.; ULUDAG, N. Synthesis and application of conducting polymers and their nanocomposites as a corrosion protection performances. Bulgarian Chemical Communications, 48, (2016), 27-32.

AZEVEDO, M. S.; ALLÉLY, C.; OGLE, K.; VOLOVITCH, P. Corrosion mechanisms of $\mathrm{Zn}(\mathrm{Mg}, \mathrm{Al})$ coated steel: 2 . The effect of $\mathrm{Mg}$ and $\mathrm{Al}$ alloying on the formation and properties of corrosion products in different electrolytes. Corrosion Science, 90, (2015) 482-490.

BACON, R. C.; SMITH, J. J.; RUGG, F. M. Electrolytic resistance in evaluating protective merit of coatings on metals. Industrial \& Engineering Chemistry, 40(1), (1948) 161-167.

BALA, T.; VPRASAD, B. L.; SASTRY, M.; KAHALY, M. U.; WAGHMARE, U. V. Interaction of different metal ions with carboxylic acid group: a quantitative study. The Journal of Physical Chemistry A, 111, (2007) 6183-6190.

BECK, F.; MICHAELIS, R.; SCHLOTEN, F.; ZINGER, B. Filmforming electropolymerization of pyrrole on iron in aqueous oxalic acid. Electrochimica Acta,39(2), (1994) 229-234.

BEERS, D.; GRAEDEL, T. E. Spatial characterisation of multi-level in-use copper and zinc stocks in Australia. Journal of Cleaner Production, 15(8-9), (2007) 849-861.

BIEZMA, M. V.; SAN CRISTOBAL, J. R. Methodology to study cost of corrosion. Corrosion Engineering, Science and Technology,40(4), (2005) 344.

BIRBILIS, T. S.; VENKATRAMAN, N.; COLE, M. S.I. S. Corrosion of zinc as a function of $\mathrm{pH}$. Corrosion, The Journal of Science and Engineering, 68(1), (2012) 015009-1.

BOISIER, G.; LAMURE, A.; PÉBÈRE, N.; PORTAIL, N.; VILLATTE, M. Corrosion protection of AA2024 sealed anodic layers using the hydrophobic properties of carboxylic acids. Surface and Coatings Technology, 203(22), 
(2009) 3420.

BOS, C.; SCHNITGER, H. C.; ZHANG, X.; HOVESTAD, A.; TERRYN, H.; WIT, J. H. W. Influence of alloying elements on the corrosion resistance of rolled zinc sheet. Corrosion Science, 48(6), (2006) 1483-1499.

BRAND, J.; BLAJIEV, O.; BEENTJES, P. C. J.; TERRYN, H.; WIT, J. H. W. Interaction of anhydride and carboxylic acid compounds with aluminum oxide surfaces studied using infrared reflection absorption spectroscopy. Langmuir, 20(15), (2004) 6308-6317.

BRASHER, D. M.; NURSE, T. J. Electrical measurements of immersed paint coatings on metal. II. Effect of osmotic pressure and ionic concentration of solution on paint breakdown. Journal of Chemical Technology and Biotechnology,9(2), (1959) 96.

BRESLIN, C. B.; FENELON, A. M.; CONROY, K. G. Surface engineering: corrosion protection using conducting polymers. Materials \& Design,26(3), (2005) 233-237.

BROWN, G. The Inaccessible Earth: An Integrated View to Its Structure and Composition. Springer Science \& Business Media (2012).

CALVENTE, J. J.; KOVOCOVA, Z.; SANCHEZ, M. D.; ANDREU, R.; FAWCETT, W.cVR. Langmuir 1996,

CASTLE, J. E.; WATTS, J. F.; LEIDHEISER, H. Corrosion Control by Organic Coatings, NACE, Houston, TX, 77-86 (1981)

CHAVAN, M. The corrosion behavior of cold sprayed zinc coatings on mild steel substrate. Journal of Thermal Spray Technology, (2013) 1.

CHEN, F.; LI, X.; HIHATH, J.; HUANG, Z.; TAO, N. J. Effect of anchoring groups on single-molecule conductance: comparative study of thiol-, amine-, and carboxylic-acid-terminated molecules,

CHEN, L.; DUDEK, A.; LEE, Y. L.; CHANG, C.H. Langmuir 2007, 23, 3123.

CHEN, L.; ZHU, H.; LI. W. LIU. $\mathrm{Zn}_{5}(\mathrm{OH})_{8} \mathrm{Cl}_{2} \cdot \mathrm{H}_{2} \mathrm{O}$-based quantum dotssensitized solar cells: A common corrosion product enhances the performance of photoelectrochemical cells. Electrochimica Acta, 105, (2013) 289.

CHEN, Z. Y.; PERSSON, D.; NAZAROV, A.; ZAKIPOUR, S.; THIERRY, D.; LEYGRAF, C. In situ studies of the effect of CO2 on the initial $\mathrm{NaCl}$-induced atmospheric corrosion of copper. Journal of the Electrochemical Society, 152(9), (2005) B342-B351.

COLE, H. G. Tests on the relative efficiency of chromate pigments in anticorrosive primers. Journal of Chemical Technology and Biotechnology,5(5), (1955) 197.

COLE, I. S.; AZMAT, N. S.; KANTA, A.; VENKATRAMAN, M. What really controls the atmospheric corrosion of zinc? Effect of marine aerosols on atmospheric corrosion of zinc. International Materials Reviews,54(3), (2009) 117.

COLE, I. S.; MARNEY, D. The science of pipe corrosion: A review of the 
literature on the corrosion of ferrous metals in soils.Corrosion Science, 56(5) (2012) 16.

CONSTANTINESCU, E.; HEITZ, E. On the influence of the water content on corrosion of metals in mono-carboxylic acids. Corrosion Science, 16(11), (1976) 857.

CORVO, F.; PEREZ, T.; DZIB, L. R.; MARTIN, Y.; CASTAÑEDA, A.; GONZALEZ, E.; PEREZ, J. Outdoor-indoor corrosion of metals in tropical coastal atmospheres. Corrosion Science, 50(1), (2008) 220.

CULLITY, B. D. Elements of X-Ray Diffraction, 2nd ed., Addison-Wesley, Massachusetts, 1978.

EGILMAN, D. Corporate corruption of science - The case of chromium (VI). International Journal of Occupational and Environmental Health, 12.2 (2006) 169-176

EL-KEMARY, M.; DIAB, A. S. M.; AYAD, M. I.; EL-DIN, N. S. Steel corrosion protection by polymer coatings. Global Journal for Research Analysis,4(9) (2015) 17-20.

EPPENSTEINER, F. W.; JENNKIND, M. R. Chromate conversion coatings. Metal Finishing, 105(10), (2007).413 424.

FAYYAD, E. M.; SANAD, S. H.; ISMAIL, A. A. Coatings of conducting polymers for corrosion protection of mild steel. Silicon, (2017) 1-15.

Ferreira Jr., 2017, Baker, M.A ${ }^{2}$, Watts J.F ${ }^{2}$, Costa, $I^{1}$ and Trindade, G.F

FERREIRA JR., J. M. ROSSI, J. L. BAKER, M. A. HINDER, S. J. COSTA, I. Deposition and characterization of a new mixed organic/inorganic cerium containing coating for the corrosion protection of eletrogalvanized steel. International Journal of Electrochemical Science, 9, (2014) 1827-1839.

FERREIRA JR., J. M.; SOUZA, K. P.; QUEIROZ, F. M.; COSTA, I.; TOMACHUK, C. R. Electrochemical and chemical characterization of electrodeposited zinc surface exposed to new surface treatments. Surface and Coatings Technology, 294, (2016) 36-46.

FERREIRA JR., J. M.; SOUZA, K. P.; ROSSI, J. L.; COSTA, I.; TRINDADE, G. F.; TOMACHUK, C. R. Corrosion protection of electrogalvanized steel by surface treatments containing cerium and niobium compounds. International Journal of Electrochemical Science, 11, (2016) 6655-6672.

FONTANA M. G.; GREENE, N. D. Corrosion Engineering, 3rd ed., McGraw Hill, New York (1986).

FREITAG, W.; STOYE, D. (Eds.). Paints, Coatings and Solvents. John Wiley \& Sons (2007).

GECE, G.; BILGIÇ, S. A theoretical study on the inhibition efficiencies of some amino acids as corrosion inhibitors of nickel. Corrosion Science,52(10), (2010) 3435-3443.

GENDEREN, E.; WILDNAUER, M.; SANTERO, N.; SIDI, N. A global life cycle assessment for primary zinc production. The International Journal of Life Cycle 
Assessment, 21(11), (2016) 1580-1593.

GORANTLA, V. R. K.; BABEL, A.; PANDIJA, S.; BABU, S. V. Oxalic acid as a complexing agent in CMP slurries for copper. Electrochemical and Solid State Letters, 8(5), (2005) G131-G134.

GRIVEAU, S.; PAVEZ, J.; ZAGAL, J.; BEDIOUI, F. Electro-oxidation of 2mercaptoethanol on adsorbed monomeric and electropolymerized cobalt tetraaminophthalocyanine films. Effect of film thickness. Journal of Electroanalytical Chemistry, 2001, 497, 75-83.

GRUNDMEIER, G.; SCHMIDT, W.; STRATMANN, M. Corrosion protection by organic coatings: electrochemical mechanism and novel methods of investigation. Electrochimica Acta,45(15-16), (2000) 2515-2533.

HAGANS, P. L., HAAS, C. M. Chromate conversion coatings.ASM Handbook Surface Engineering, Materials Park, OH: ASM International, 1987, 5 (1994) 405-411.

HUSSEIN, M. A.; AL-JUAID, S. S.; ABU-ZIED, B. M.; HERMAS, A.-E. A. Electrodeposition and corrosion protection performance of polypyrrole composites on aluminum. International Journal of Electrochemical Science,11(5), (2016) 3938-3951.

https://srdata.nist.gov/xps/WagnerPlot.aspx.

JACKOWSKA, K.; SKOMPSKA, M.; PRZYHSKA, E. Electra-oxidation of 1,5 and 1,8 diaminonaphthalene: an RDE study. Journal of Electroanalytical Chemistry, 418, (1996) 35-39.

JAGADISH, C.; PEARTON, S. (Eds.).Zinc Oxide Bulk, Thin Films and Nanostructures: Processing, Properties, and Applications. $1^{\text {st }}$ Edit., Elsevier (2011) 600 p.

JOLLY, J. H. Materials flow of zinc in the United States, 1850-1990. U.S. Bureau of Mines Open-File Report 72-92. Disponível em http://pubs.usgs.gov/usbmof/ofr-72-92/. Acessado em 16 abril 2011.

KALANTARY, M. R.; WILCOX, G. D.; GABE, D. R. Alternate layers of zinc and nickel electrodeposited to protect steel.British Corrosion Journal,33(3), (1998) 197-201.

KARAKASCH, N. Zinc coating review-2000 and beyond. Corrosion Manage,10(1), (2001) 3-9.

KATABY, G.; COJOCARU, M.; PROZOROV, R.; GEDANKEN, A. Coating carboxylic acids on amorphous iron nanoparticles, Langmuir, 15(5) (1999), 1703-1708.

KEDDAM, M.; HUGOT-LE-GOFF, A.; TAKENOUTI, H.; THIERRY, D.; AREVALO, M. C. The influence of a thin electrolyte layer on the corrosion process of zinc in chloride-containing solutions. Corrosion Science,33(8), (1992) 1243-1252.

KELLAR, J. J.; YOUNG, C. A.; KNUTSON, K.; MILLER, J. D. Thermotropic phase transition of adsorbed oleate species at a fluorite surface by in situ FT- 
IR/IRS spectroscopy. Journal of Colloid and Interface Science, 144(2), (1991) 381-389.

KENDIG, M. W.; LEIDHEISER Jr., H. The electrical properties of protective polymer coatings as related to corrosion of the substrate. Journal of the Electrochemical Society, 123 (7), (1976). 982-989.

KOMARNENI, S.; smith, D. M.; BECK, J. S. Advances in porous materials. In: Materials Research Society Symposium Proceedings, 1995. November 28December 1, Boston, Massachusetts, USA, vol. 371, (1995).

KORB, L. J. Corrosion. ASM Handbook, 9th ed., ASM International, Materials Park, Ohio, 13, (1987).

KRSTAJIĆ, N. V.; GRGUR, B. N.; JOVANOVIĆ, S. M.; VOJNOVIĆ, M. V. Corrosion protection of mild steel by polypyrrole coatings in acid sulfate solutions. Electrochimica Acta,42(11), (1997) 1685-1691.

KUZNETSOV, Y. I.; IBATULLIN, K. A. On the inhibition of the carbon dioxide corrosion of steel by carboxylic acids. Protection of Metals, 38(5), (2002) 439444.

LAHEM, D.; POELMAN, M.; ATMANI, F.; OLIVIER, M-G. Synergistic improvement of inhibitive activity of dicarboxylates in preventing mild steel corrosion in neutral aqueous solution. The International Journal of Corrosion Processes and Corrosion Control, 47(6), (2012) 463-471.

LAMBOURNE, R.; STRIVENS, T. A. (Eds.). Paint and Surface Coatings: Theory and Practice.Elsevier, (1999) $800 \mathrm{p}$.

LANDI, E.; TAMPIERI, A.; CELOTTI G.; SPRIO, S. Densification behavior and mechanisms of synthetic hydroxyapatite. Journal European Cerammic Society, 20(14-15), (2000) 2377-2387.

LEIDHEISER Jr., H. Electrical and electrochemical measurements as predictors of corrosion at the metal-organic coating interface. Progress in Organic Coatings,7(1), (1979) 79-104.

LEYGRAF, C.; WALLINDER, I. O.; TIDBLAD, J.; GRAEDEL, T. Atmospheric Corrosion. John Wiley \& Sons (2016).

LI, Y., ZOU, Y., HOU, Y. Synthesis and characterization of simonkolleite nanodisks and their conversion into ZnO nanostructures. Crystal Research and Technology, 46(3), (2011) 305-308.

LINDSTRÖM, R.; SVENSSON, J.; JOHANSSON, L. The atmospheric corrosion of zinc in the presence of $\mathrm{NaCl}$ the influence of carbon dioxide an temperature. Journal of The Electrochemical Society,147(5), (2000) 1751-1757.

LIU, X.; ZHANG, H.; WANG, J.; WANG, Z.; WANG, S. Preparation of epoxy microcapsule based self-healing coatings and their behavior.Surface and Coatings Technology, 206(23), (2012) 4976-4980.

MANSFELD, F. B. Corrosion Mechanisms, CRC Press (1986) 472 p.

MARDER, A. R. The metallurgy of zinc-coated steel. Progress in Materials Science, 45, (2000) 191-271. 
MEHROTRA, R. C.; BOHRA, R. Metal Carboxylates, Academic Press, New York, (1983) $396 \mathrm{p}$.

MERT, B. D. Corrosion protection of aluminum by electrochemically synthesized composite organic coating. Corrosion Science, 103, (2016) 88-94.

MOKADDEM, M.; VOLOVITCH, P.; OGLE. K. The anodic dissolution of zinc and zinc alloys in alkaline solution. I. Oxide formation on electrogalvanized steel. Electrochimica Acta, 55(27), (2010) 7867-7875.

MORGAN, S. W. K. Zinc and Its Alloys and Compounds. E. Horwood, Chi Chester, (1985) $245 \mathrm{p}$.

MORETTI, Stefano; LÖNNBLAD, Leif; SJÖSTRAND, Torbjörn. New and old jet clustering algorithms for electron-positron events. Journal of High Energy Physics, v. 1998, n. 08, p. 001, 1998.

MOUANGA, M.; PUIGGALI, M.; DEVOS, O. EIS and LEIS investigation of ageing low carbon steel with Zn-Ni coating. Electrochimica Acta, 106 (2013) 8290.

MUDD, G. M.; JOWITT, S. M.; WERNER, T. T. The world's lead-zinc mineral resources: Scarcity, data, issues and opportunities. Ore Geology Reviews, 80, (2017) 1160-1190.

MULDER, W. H.; CALVENTE, J. J.; ANDREU, R. A kinetic model for the reductive desorption of self-assembled Thiol monolayers. Langmuir, 17(11), (2001) 3273-3280.

NATORSKY, T. J. Zinc and zinc alloy plating in the 90's. Metal Finishing, 90(3), (1992) 15.

NEUFELD, K.; COLE, I. S.; BOND, A. M.; FURMAN, S. A. The initiation mechanism of corrosion of zinc by sodium chloride particle deposition. Corrosion Science, 44(3), (2002) 555-572.

NEWMAN, R. C., SIERADZKI, K. Metallic corrosion. Science, 263(5154), (1994) 1708-1709.

NISHIKATA, A.; OKAZAKI, T.; TADA, E. Electrochemical evaluation of degradation of $\mathrm{Zn}$-coated steel exposed to cyclic wet-dry condition. Meeting Abstract MA2016-02 1311, The Electrochemical Society, (2016) 1311.

NIST, X. ray Photoelectron Spectroscopy Database, version 3.4; NIST Standard Reference Database 20; National Institute of Standards and Technology: Gaithersburg, MD, 2003. Wagner plots available at http://srdata. nist. gov/xps/WagnerPlot. aspx (accessed April 2012).

NORMA BRASILEIRA ABNT NBR 11003 Primeira edição 29.09.2009 Válida a partir de 29.10.2009 Tintas. Determinação da aderência Paints and vernishes Determination of adhesion

NRIAGU, J. O.; NIEBOER, E. Eds.Chromium in the Natural and Human Environments. Wiley, New York, (1988) 571 p.

OBERG, K.; PERSSON, P.; SHCHUKAREV, A.; ELIASSON, B. Comparison of monolayer films of stearic acid and methyl stearate on an $\mathrm{Al}_{2} \mathrm{O}_{3}$ surface. Thin 
Solid Films, 397, (2001) 102-108.

ODNEVALL, I. Reaction sequences in atmospheric corrosion of zinc. ASTM Special Technical Publication, STP1239 (1995), 215 p.

ORTIZ, Z. I.; DÍAZ-ARISTA, P.; MEAS, Y.; ORTEGA-BORGES, R.; TREJO, G. Characterization of the corrosion products of electrodeposited $\mathrm{Zn}, \mathrm{Zn}-\mathrm{Co}$ and Zn-Mn alloys coatings. Corrosion Science,51(11), (2009) 2703-2715.

PANIAS, D.; TAXIARCHOU, M.; PASPALIARIS, I.; KONTOPOULOS, A. Mechanisms of dissolution of iron oxides in aqueous oxalic acid solutions. Hydrometallurgy,42(2), (1996) 257-265.

PEREIRA, M. S.; BARBOSA, L. L.; SOUZA, C. A. C.; MORAES, A. C. M.; CARLOS, I. A. The influence of sorbitol on zinc film deposition, zinc dissolution process and morphology of deposits obtained from alkaline bath. Journal of Applied Electrochemistry,36(6), (2006) 727-732.

PÉREZ, C.; COLLAZO, A.; IZQUIERDO, M.; MERINO, P.; NÓVOA, X. R. Electrochemical impedance spectroscopy study of the corrosion process on coated galvanized steel in a salt spray fog chamber. Corrosion,56(12), (2000) 1220-1232.

PEREZ-LOPEZ, O. W.; FARIAS, A. C.; MARCILIO, N. R.; BUENO, J. M. C The catalytic behavior of zinc oxide prepared from various precursors and by different methods. Materials Research Bulletin, 40(12), (2005) 2089-2099.

PERSINSKI, L. J.; WALKER, J. L.; BOFFARDI, B. P. Synergistic scale and corrosion inhibiting admixtures containing carboxylic acid/sulfonic acid polymers. U.S. Patent No. 4,640,793. Washington, DC: U.S. Patent and Trademark Office, (1987).

PERTAYS, K. M.; THOMPSON, G. E.; ALEXANDER, M. R. Self-assembly of stearic acid on aluminium: the importance of oxide surface chemistry. Surface and Interface Analysis, 36(10), (2004) 1361-1366.

PLANK, J.; BASSIONI, G. Adsorption of carboxylate anions on a $\mathrm{CaCO}_{3}$ surface. Verlag der Zeitschrift für Naturforschung, 62b, (2007) 1277-1284.

PLETINCX, S.; TROTOCHAUD, L.; FOCKAERT, I. L.; MOL, J. M.; HEAD, A. R.; KARSLIOĞLU, O.; HAUFFMAN, T. In situ characterization of the initial effect of water on molecular interactions at the interface of organic / inorganic hybrid systems. Scientific Reports, 7:45123, (2017) 1-8.

PORTER, F. C. Corrosion Resistance of Zinc and Zinc Alloys. CRC Press, (1994) $536 \mathrm{p}$.

PORTER, F. C. Painting of zinc surfaces British Corrosion Journal,4(4), (1969) 179-186.

QU, Q.; YAN, C.; WAN, Y.; CAO, C. Effects of $\mathrm{NaCl}$ and $\mathrm{SO}_{2}$ on the initial atmospheric corrosion of zinc. Corrosion Science, 44(12), (2002) 2789-2803.

REHMAN, N.; MEHMOOD, M.; RIZWAN, R.; RASHEED, M. A.; LING, F. C. C.; YOUNAS, M. Control of optical properties of ZnO nanostructures grown by a novel two-step synthesis approach. Chemical Physics Letters, 609, (2014) 26- 
32.

RENZ, M. Ketonization of carboxylic acids by decarboxylation: mechanism and scope. European Journal of Organic Chemistry, 2005(6), (2005) 979-988.

ROBEILS, A. G. Organic Coatings Properties Selection and Use. Building Research Division, Institute for Applied Technology, National Bureau of Standards, Washington, D.C. 20234, Building Science Series 7, Issued February 1968, 216 p.

ROEBUCK, A. H.; MORROW III, H.; NEVISON, D. C. H. Economics of zinc coating systems for corrosion protection.Journal of Protective Coatings Linings,1(2) (1984) 38-43.

ROSALBINO, F.; SCAVINO, G.; MACCIÒ, D.; SACCONE, A. Influence of the alloying component on the corrosion behaviour of zinc in neutral aerated sodium chloride solution. Corrosion Science, 89, (2014) 286-294.

ROSALBINO, F.; SCAVINO, G.; MORTARINO, G.; ANGELINI, E.; LUNAZZI, G. EIS study on the corrosion performance of a $\mathrm{Cr}$ (III)-based conversion coating on zinc-galvanized steel for the automotive industry. Journal of Solid State Electrochemistry, 15(4), (2011) 703-709.

ROSCHMANN, K.; BETTE, V.; AMTHOR, S.; BERGMANN, H.; SCHROEDER, M. Corrosion protection coatings. U.S. Patent n. 8,460,445, 11 jun. 2013.

SAGOE-CRENTSIL, K. K.; YILMAZ, V. T.; GLASSER, F. P. Corrosion inhibition of steel in concrete by carboxylic acids. Cement and Concrete Research,23(6), (1993) 1380-1388.

SALEM, F. Y.; PARKERTON, T. F.; LEWIS, R. V.; HUANG, J. H.; DICKSON, K. $\mathrm{L}$. Kinetics of chromium transformations in the environment. Science of the Total Environment,86(1-2), (1989) 25-41.

SASTRI, V. S. Challenges in Corrosion: Costs, Causes, Consequences, and Control. John Wiley Sons (2015), 432 p.

SAZOU, D. Electrodeposition of ring-substituted polyanilines on Fe surfaces from aqueous oxalic acid solutions and corrosion protection of Fe. Synthetic Metals,118(1-3), (2001).133-147.

SCHLESINGER, M.; PAUNOVIC, M. (Eds.). Modern Electroplating, $5^{\text {th }}$ Ed., John Wiley Sons (2014), 736 p.

SEIFZADEH, D.; MOHSENABADI, H. K.; RAJABALIZADEH, Z. Electroless Ni-P plating on magnesium alloy by innovative, simple and non-toxic oxalate pretreatment and its corrosion protection.RSC Advances,6(99), (2016) 9724197252.

SELVARAJ, V.; ALAGAR, M.; HAMERTON, I. Electrocatalytic properties of monometallic and bimetallic nanoparticles-incorporated polypyrrole films for electro-oxidation of methanol. Journal of Power Sources, 160(2), (2006) 940948.

SHAW, B. A.; KELLY, R. G. What is corrosion? Interface-Electrochemical Society,15(1), (2006) 24-26. 
SHORT, N. R.; ABIBSI, A.; DENNIS, J. K. Corrosion resistance of electroplated zinc alloy coatings. Transactions of the IMF,67(1), (1989) 73-77.

SHORT, N. R.; ZHOU, S.; DENNIS, J. K. Electrochemical studies on the corrosion of a range of zinc alloy coated steel in alkaline solutions. Surface and Coatings Technology, 79(1-3), (1996) 218-224.

SHREEPATHI, S.; BAJAJ, P.; MALLIK. B. P. Electrochemical impedance spectroscopy investigations of epoxy zinc rich coatings: Role of $\mathrm{Zn}$ content on corrosion protection mechanism. Electrochimica Acta, 55 (18), (2010) 51295134.

STANKIEWICZ, A.; SZCZYGIEŁ, I.; SZCZYGIEŁ, B. Self-healing coatings in anti-corrosion applications. Journal of Materials Science,48(23), (2013) 80418051.

TAHERI, P. Interfacial bonding mechanisms of carboxylic coatings on pretreated zinc surfaces, PhD Thesis, Delft University of Technology, (2012) 204 p.

TAHERI, P.; HAUFFMAN, T.; MOL, J. M. C.; FLORES, J. R.; HANNOUR, F.; WIT, J. H. W.; TERRYN, H. Molecular interactions of electroadsorbed carboxylic acid and succinic anhydride monomers on zinc surfaces. The Journal of Physical Chemistry C, 115(34), (2011) 17054-17067.

TAHERI, P.; HAUFFMAN, T.; MOL, J. M. C.; FLORES, J. R.; HANNOUR, F.; WIT, J. H. W.; TERRYN, H. Electrochemical analysis of the adsorption and desorption behaviors of carboxylic acid and anhydride monomers onto zinc surfaces. Electrochimica Acta, 56(25), (2011) 9317-9323.

TAHERI, P.; POHL, K.; GRUNDMEIER, G.; FLORES, J. R.; HANNOUR, F.; D WIT, J. H. W.; MOL, J. M. C.; TERRYN, H. Effects of surface treatment and carboxylic acid and anhydride molecular dipole moments on the Volta potential values of zinc surfaces. The Journal of Physical Chemistry C, 117(4), (2013) 1712-1721.

TAHERI, P.; WIELANT, J.; HAUFFMAN, T.; FLORES, J. R.; HANNOUR, F.; WIT, J. H. W.; MOL, J. M. C.; TERRYN, H. A comparison of the interfacial bonding properties of carboxylic acid functional groups on zinc and iron substrates. Electrochimica Acta, 56(4), (2011) 1904-1911.

TANAKA, H.; FUJIOKA, A.; FUTOYU, A.; KANDORI, K.; ISHIKAWA, T. Synthesis and characterization of layered zinc hydroxychlorides. Journal of Solid State Chemistry, 180(7), (2007) 2061-2066.

TAOUIL, E. T.; MAHMOUD, M. M.; LALLEMAND, F.; LALLEMAND, S.; GIGANDET, M.; HIHN, J. Corrosion protection by sonoelectrodeposited organic films on zinc coated steel. Ultrasonics Sonochemistry, 19(6), (2012) 1186-1193.

TERVAHATTU, Heikki; JUHANOJA, Jyrki; KUPIAINEN, Kaarle. Identification of an organic coating on marine aerosol particles by tof-sims. Journal of Geophysical Research: Atmospheres, v. 107, n. D16, 2002.

THISSEN, P.; WIELANT, J.; KÖYER, M.; TOEWS, S.; GRUNDMEIER, G. Formation and stability of organophosphonic acid monolayers on ZnAl alloy 
coatings. Surface and Coatings Technology, 204(21-22), (2010) 3578-3584.

TOMACHUK, C. R.; Elsner, C.I.; SARLI, A. R. D.; FERRAZ, O.B. Morphology and corrosion resistance of $\mathrm{Cr}(\mathrm{III})$-based conversion treatments for electrogalvanized steel. Journal of Coatings Technology and Research, 7(4), (2010) 493-502.

TOMACHUK, C. R.; SARLI, A. R. Black passivated pulsating plated ZnCo coatings: Electrodeposition and characterization. ChemXpress, 4(2) (2014) 237245.

TRINDADE, G. F. 3D ToF-SIMS depth profile of a polymer coating on a metal substrate. Disponível em https://www.youtube.com/watch?v=Ps0367AL8-4. Acessado em 18 maio 2017.

TSURU, T.; TAMIYA, K.; NISHIKATA, A. Formation and growth of microdroplets during the initial stage of atmospheric corrosion. Electrochimica Acta,49(17-18), (2004) 2709-2715.

U.S. Department of Energy. Top value added chemicals from biomass, Volume 1: Results of screening for potential candidates from sugars and synthesis gas. U.S. Department of Energy, 2004. Disponível em http://www.nrel.gov/docs/fy04osti/35523.pdf. Acessado em 12 novembro 2013.

U.S. Geological Survey. Mineral Yearbook (U.S. Department of the Interior, Geological Survey, Washington, DC). (2014) 188 p.

UHLIGS, H. H. Uhlig's Corrosion Handbook, 2nd ed., R. Winston Revie, Editor, John Wiley Sons, New York (2000), 1296 p.

VOLOVITCH, P.; VU, T. N.; ALLÉLY, C.; ABEL AAL, A.; OGLE, K. Understanding corrosion via corrosion product characterization: II. Role of alloying elements in improving the corrosion resistance of $\mathrm{Zn}-\mathrm{Al}-\mathrm{Mg}$ coatings on steel. Corrosion Science,53(8), (2011) 2437-2445.

Wan, 2012 AN, Y.; MACHA, E. N.; KELLY, R. G. Modification of ASTM B117 salt spray corrosion test and its correlation to field measurements of silver corrosion. Corrosion, The Journal of Science and Engineering, v. 68, n. 3, p. 036001-1-036001-10, 2012.

WIENSTRÖER, S.; FRANSEN, M.; MITTELSTÄDT, H.; NAZIKKOL, C.; VÖLKER, M. Zinc/iron phase transformation studies on galvannealed steel coatings by X-ray diffraction. In: ICDD International Centre for Diffraction Data, Advances in X-ray Analysis, 46, (2003), 291-296.

WILLIS, A.; TURRO, N.; O'BRIEN, S. Spectroscopic characterization of the surface of iron oxide nanocrystals, Chemestry of Materials, 17, (2005), 59705975.

WOLSTENHOLME, J. Electrochemical methods of assessing the corrosion of painted metals - a review. Corrosion Science,13(7), (1973) 521-530.

YADAV, A. P.; NISHIKATA, A.; TSURU, T. Degradation mechanism of galvanized steel in wet-dry cyclic environment containing chloride ions. Corrosion Science, 46(2), (2004) 361-376. 
YADAV, A. P.; NISHIKATA, A.; TSURU, T. Electrochemical impedance study on galvanized steel corrosion under cyclic wet-dry conditions - influence of time of wetness . Corrosion Science,46(1), (2004) 169-181.

Y. Wan, E.N. Macha, R.G. Kelly, Modification of ASTM B117 Salt Spray Corrosion Test and Its Correlation to Field Measurements of Silver Corrosion, CORROSION. 2012;68(3):036001-1-036001-10.

YAN, L.; GUO-ZHU L.; ZOU, Y.; WANG, Q.; ZHOU, Q.; LIAN, X. Preparation and sensing performance of petal-like $\mathrm{RuO}_{2}$ modified $\mathrm{ZnO}$ nano sheets via a facile solvothermal and calcination method. Transactions of Nonferrous Metals Society of China, 24(9), (2014) 2896-2903.

YASAKAU, K. A.; GINER, I.; VREE, C.; OZCAN, O.; GROTHE, R.; OLIVEIRA, A.; Grundmeier, G.; Ferreira, M.G.S.; ZHELUDKEVICH, M. L. Influence of stripping and cooling atmospheres on surface properties and corrosion of zinc galvanizing coatings. Applied Surface Science, 389, (2016) 144-156.

YÉPEZ, O. On the chemical reaction between carboxylic acids and iron, including the special case of naphthenic acid. Fuel,86(7-8), (2007) 1162-1168.

YOO, J. D.; VOLOVITCH, P.; ABEL AAL, A.; ALLELY, C.; OGLE, K. The effect of an artificially synthesized simonkolleite layer on the corrosion of electrogalvanized steel. Corrosion Science, 70, (2013) 1-10.

YUNOVICH, M.; THOMPSON, N. G. Corrosion of highway bridges: Economic impact and control methodologies. Concrete International,25(1), (2003), 52-57.

ZHANG, X. G. Corrosion and Electrochemistry of Zinc. Springer Science + Business Media New York, (1996), 474 p.

ZHANG, X.; SLOOF, W. G.; HOVESTAD, A.; WESTING, E. P. M.; TERRYN, $\mathrm{H}$.; WIT, J. H. W. Characterization of chromate conversion coatings on zinc using XPS and SKPFM.Surface and Coatings Technology,197(2-3), (2005) 168-176.

WILD, U.; PFÄNDER, N.; SCHLÖGL, R. Species analysis of automotive carbon particles: Application of XPS for integral analysis of filter samples. Fresenius' journal of analytical chemistry, v. 357, n. 4, p. 420-428, 1997.

ZHU, F.; PERSSON, D.; THIERRY, D.; TAXEN, C. Formation of corrosion products on open and confined zinc surfaces exposed to periodic wet/dry conditions. Corrosion, 56(12), (2000) 1256-1265. 
INSTITUTO DE PESQUISAS ENERGÉTICAS E NUCLEARES

Diretoria de Pesquisa, Desenvolvimento e Ensino

Av. Prof. Lineu Prestes, 2242 - Cidade Universitária CEP: 05508-000

Fone/Fax(0XX11) 3133-8908

SÃO PAULO - São Paulo - Brasil

http://www.ipen.br

O IPEN é uma Autaquia vinculada à Secretaria de Desenvolvimento, associada à Universiade de São Paulo e gerida técnica e administrativamente pela Comissão Nacional de Energia Nuclear, órgão do Ministério da Ciência, Tecnologia e Inovação. 